\title{
PATRONES MODELO DE MIGRACIÓN
}

\author{
ANDREI ROGERS \\ $Y$ \\ LUIS J. CASTRO
}

\section{PREFACIO}

DESDE EL INICIO de las actividades del Instituto Internacional para el Análisis de Sistemas Aplicados (IIASA), el interés por los sistemas y políticas sobre asentamientos humanos ha constituido un punto central en el trabajo relacionado con el urbanismo. De 1975 a 1978, este interés se manifestó en el trabajo Migration and Settlement Task, que se concluyó de manera formal en 1978. Desde entonces, la atención se ha dirigido hacia la diseminación de los resultados de este trabajo y hacia la conclusión del estudio comparativo que está llevando a cabo una evaluación cuantitativa y comparativa de los patrones sobre migración elaborados en forma más reciente, y la dinámica espacial de la población en los 17 países miembros del IIASA.

Este documento es parte del esfuerzo por difundir ese trabajo y se localiza en los patrones por edades de la población migrante; estos patrones surgieron del banco de datos que para los efectos de este estudio comparativo se implementó. Comienza con un análisis comparativo de más de 500 patrones observados sobre migración y posteriormente desarrolla, en base a este análisis, un patrón hipotético de familias con el fin de utilizarlo en los casos en que la información sobre migración no esté disponible o no sea correcta.

En la parte final de este documento se lista el resumen de los informes sobre los trabajos anteriores que sobre migración y asentamientos se efectuaron en el IIASA. Estos informes, basados en la información que sustenta este estudio deberán ser consultados para detalles adicionales.

\author{
ANDREI ROGERS \\ COORDINADOR \\ ASENTAMIENTOS HUMANOS \\ y ÁREA DE SERVICIOS
}




\section{AGRADECIMIENTOS}

Los autores quieren hacer público agradecimiento a los estudiosos que han participado en el Estudio Comparativo sobre Migración y Asentamientos llevado a cabo en el IIASA. Este documento no podría haberse realizado sin el esfuerzo colectivo que implica la recopilación de información para un banco de datos. También va nuestro agradecimiento a Richard Raquillet por sus contribuciones en la etapa inicial de este estudio y a Walter Kogler por sus grandes esfuerzos frente a la consola del centro de cómputo del IIASA. Kao Lee Liaw, Philip Rees, Warren Sanderson y un revisor anónimo, nos ofrecieron sus comentarios, siempre útiles, en la versión del primer borrador.

\section{RESUMEN}

Este documento trata sobre la regularidad fundamental mostrada por los perfiles de migración en todo el mundo, que posibilitan desarrollar un sistema de programas de un modelo de migración hipotético que puede ser utilizado en los análisis de población multirregional efectuados en países que no cuentan con la información adecuada sobre migración.

\section{CONTENIDO}

1. Introducción

2. Patrones de migración por edades

3. Análisis comparativo de los patrones modelo de migración observados

4. Patrones modelo de migración estimados

5. Conclusión

Apéndice A

Referencias

Publicaciones relacionadas con este estudio

\section{Introducción}

LA MAYORÍA de las tasas de fecundidad y mortalidad por edades, basadas en la experiencia humana, muestra, de manera notable, regularidades persistentes. En consecuencia, los demógrafos han tenido la posibilidad de resumir y codificar tales regularidades por medio de expresiones matemáticas llamadas patrones modelo. Aun cuando los estudios demográficos han concedido atención considerable al desarrollo de los patrones modelo de fecundidad y mortalidad, la construcción de patrones modelo de migración no ha corrido la misma suerte, a pesar de que las técnicas aplicadas a los primeros han tenido éxito.

Este informe comienza con un examen de las regularidades en el perfil de edades que muestran los patrones empíricos de tasas de migración, y adoptan la 
noción de "patrón modelo de migración" para expresar estas regularidades de manera matemática. Hemos utilizado otros modelos para examinar los patrones actuales de variación en un banco de datos considerable. Cuando diseñamos este análisis comparativo de patrones modelo de migración "observados", partimos de varios patrones de "familias" y concluimos con la indicación de la forma en que éstos podrían utilizarse para generar patrones modelo de migración hipotéti$\cos$ y "estimados". Éstos también pueden adaptarse a estudios sobre migración llevados a cabo en asentamientos poblacionales del Tercer Mundo, donde, con frecuencia, la información sobre migración es inadecuada o nada confiable.

\section{Patrones de migración por edades}

Las medidas de migración pueden aplicar conceptos, de manera útil, tomados de los análisis de mortalidad y fecundidad, modificándolos cuando sea necesario y tomando en cuenta los aspectos que son peculiares a la movilidad espacial. Los estudios sobre migración pueden tomar del análisis de mortalidad la noción "tabla de mortalidad", extendiéndola de modo que incluya aumentos y descensos que reflejen la interacción mutua de algunas cohortes regionales (Rogers, 1973 a, b y 1975; Rogers y Ledent, 1976). Los análisis de fecundidad pueden transferir técnicas ya comprobadas para así graduar los programas por edades (Rogers, Raquillet y Castro, 1978). La tasa de migración, a través de una definición aceptable, es fundamental para ambos "préstamos".

\subsection{Tasas y patrones de migración}

Durante el curso de un año, o durante un período de tiempo fijo, un número de personas que habitaba cierta comunidad cambió su lugar común de residencia. A esas personas las llamaremos movibles para distinguirlas de aquellas que no han cambiado su lugar de residencia, por ejemplo, las no movibles. Algunos individuos movibles habrán cambiado su residencia a una nueva comunidad; otros simplemente habrán transferido su casa a otra residencia dentro de la misma comunidad. A los primeros se les puede llamar móviles, a los últimos reubicados. En cada categoría, habrán muerto algunos antes de terminarse el intervalo de tiempo.

Si se valora la situación respecto del principio y del final del intervalo unitario de tiempo, podemos dividir a los móviles que sobrevivieron al final del intervalo en dos grupos: aquellos que vivían en la misma comunidad de residencia al inicio del intervalo y aquellos que vivian en otros lugares. Al primer grupo de móviles se le llamará sobrevivientes de retorno y, al segundo, migrantes sobrevivientes. Se puede hacer una división análoga de los móviles que mueren antes del final del intervalo para definir a los no sobrevivientes de retorno y a los migrantes no sobrevivientes.

Un movimiento, por tanto, es un evento: una separación de una comunidad. Un móvil es un individuo que ha efectuado un cambio por lo menos una vez durante un intervalo de tiempo dado. Por el otro lado, un migrante (por ejemplo, un migrante sobreviviente o no sobreviviente) es un individuo que al final de un 
intervalo de tiempo dado ya no habita la misma comunidad de residencia como lo hacía al principio del intervalo. (El acto de separación de un estado está ligado con el aumento en otro estado). Paradójicamente, un móvil múltiple puede ser un no migrante en nuestra definición, es decir, si un móvil en particular regresa a un lugar de residencia inicial antes del termino del intervalo de tiempo, se dice que no se llevó a cabo ninguna "migración". 1

La medida de migración más simple y común es la tasa bruta de migración, definida como el cociente del número de migrantes que deja una población en particular localizada en espacio y tiempo, y el número de personas promedio (con mayor exactitud, el número de personas-año) expuestas al riesgo de convertirse en migrantes. ${ }^{2}$

J Como la migración es altamente selectiva por edades, con una gran fracción de migrantes que son jóvenes, el cálculo de las tasas de migración por edades individuales representa una gran ayuda para comprender los patrones y la dinámica de la migración. Si se suman estas tasas en todas las edades, se obtiene la tasa de migraproducción bruta (TBM), la migración análoga de la tasa de reproducción bruta en la fecundidad.

2. La gráfica 2.1 indica que las tasas anuales por edades de la movilidad de residencia entre blancos y negros en los Estados Unidos de Norteamérica durante 1966-1971, mostraron un perfil común. Las tasas de movilidad entre los niños pequeños e hijos jóvenes reflejaron una tasa relativamente elevada de sus padres, adultos jóvenes al final de los veinte años. La movilidad de los adolescentes fue más baja pero excedió a la de los veinteañeros; estos últimos muestran un punto bajo local alrededor de los quince años de edad. A partir de ese punto, aumentaron las tasas de movilidad, "para alcanzar un máximo alrededor de los veintidós años y luego descendieron de manera monótona con la edad hasta las edades de retiro. Los niveles de movilidad en blancos y negros fueron muy similares; los blancos muestran una tasa bruta de migraproducción de cerca de 14 cambios; los negros, aproximadamente 15 durante el período de vida inalterada por la mortat lidad antes del final de las edades de movilización.

A pesar de que con frecuencia se ha asegurado que la migración es selectiva por sexo -donde los hombres se movilizan más que las mujeres--, investigaciones recientes indican que la selección por sexo es mucho menos pronunciada que la selección por edad y es la menos uniforme a través del tiempo y el espacio. Sin embargo, la mayoría de las medidas de migración también efectúa esta selección, en virtud de que la mayoría de los modelos y estudios sobre la dinámica de la población ejecuta la distinción entre los sexos.

La gráfica 2.2 ilustra el perfil por edad de patrones de migración masculina y femenina en cuatro países distintos, cercanos al mismo punto en el tiempo, entre áreas geográficas escasamente comparables: comunidades en los Países Bajos y Suecia, municipios en Polonia y condados en los Estados Unidos. Los niveles de migración son similares en todos esos lugares, con excepción de Polonia, y se obtienen variaciones entre 3.5 y 5.3 cambios por vida; los niveles para hombres y

1 La migración se define como la transición entre estados, experimentada por el migrante.

2 En virtud de que la información sobre los migrantes no sobrevivientes por lo general no está disponible, el numerador en este cociente por lo general los excluye. 
Gráfica 2.1 .

TASAS DE MOVILIDAD OBSERVADAS POR AÑO, POR COLOR Y POR EDADES INDIVIDUALES. E.U.A., 1966-1971.

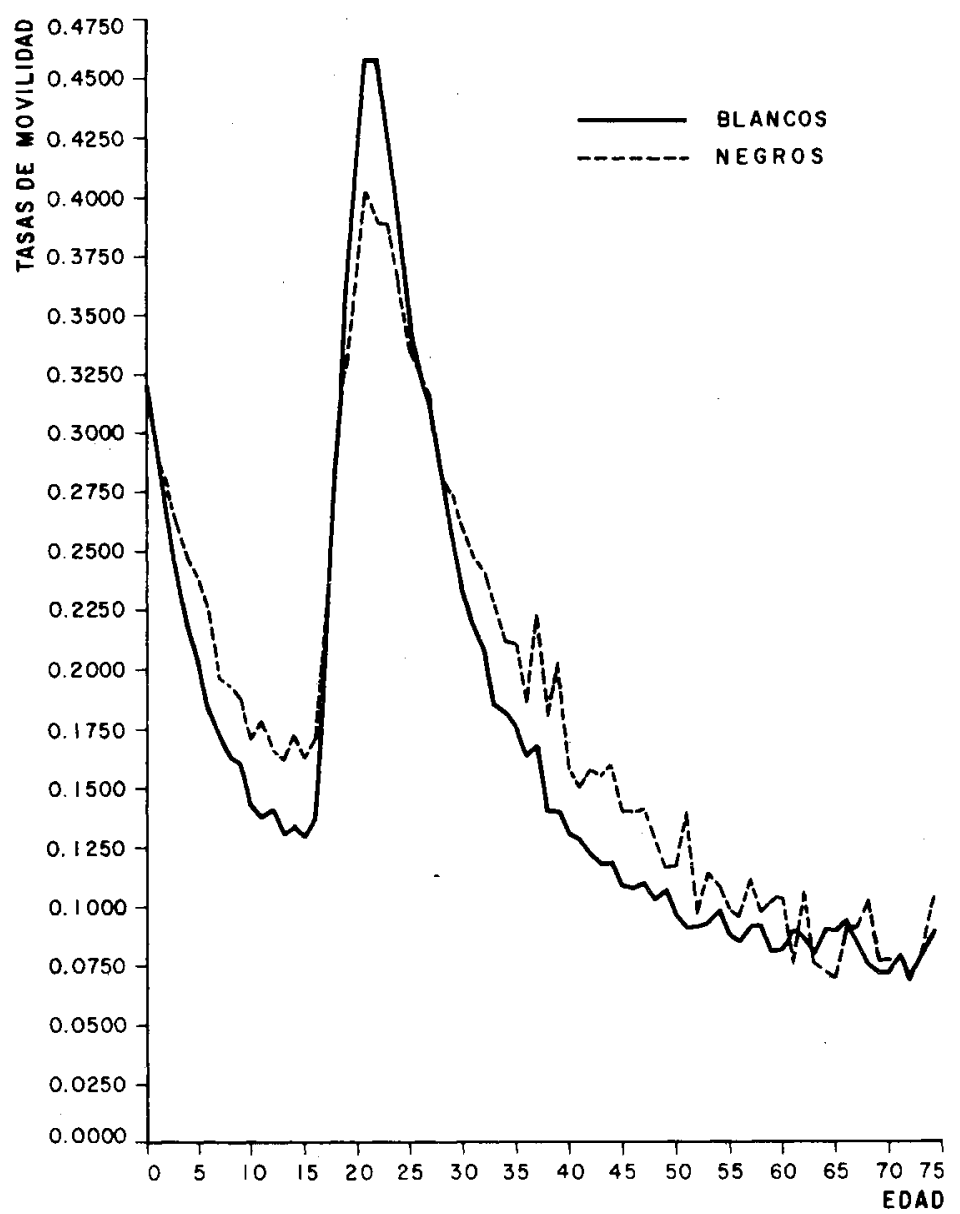

mujeres son aproximadamente los mismos. Sin embargo, los perfiles por edad muestran una diferencia distinta y consistente. El nivel máximo del patrón femenino precede siempre al de hombres por una cantidad que parece aproximarse a la diferencia entre el promedio por edades en el casamiento de ambos sexos.

Bajo condiciones estadísticas normales, los movimientos de punto a punto están agregados en flujos entre una división civil y otra. En consecuencia, el nivel de la migración interregional depende del tamaño de las unidades geográficas seleccionadas. Asi, si esta unidad geográfica seleccionada representa una división civil menor - como la de un condado o una comuna-, se incluirá la migración 
Gráfica 2.2.

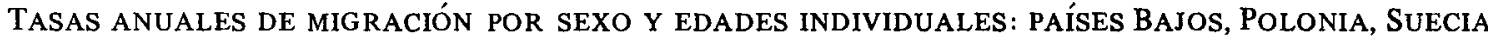

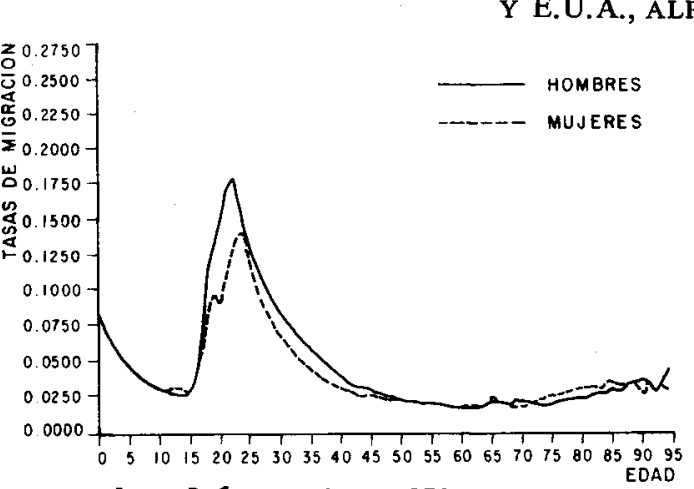

A. Palses Bajos, 1972

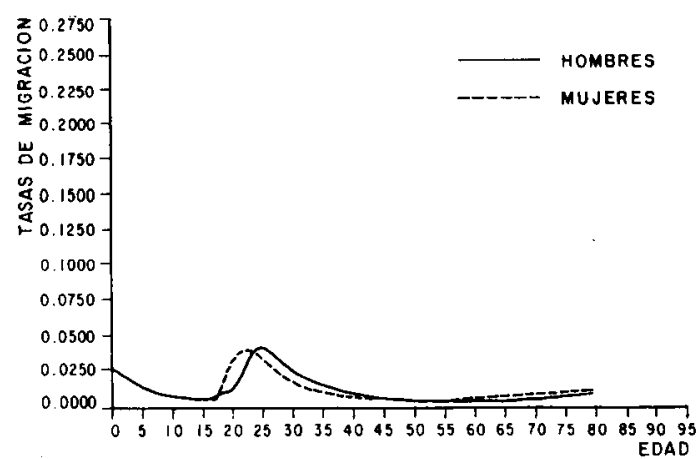

B. Polonia, 1973
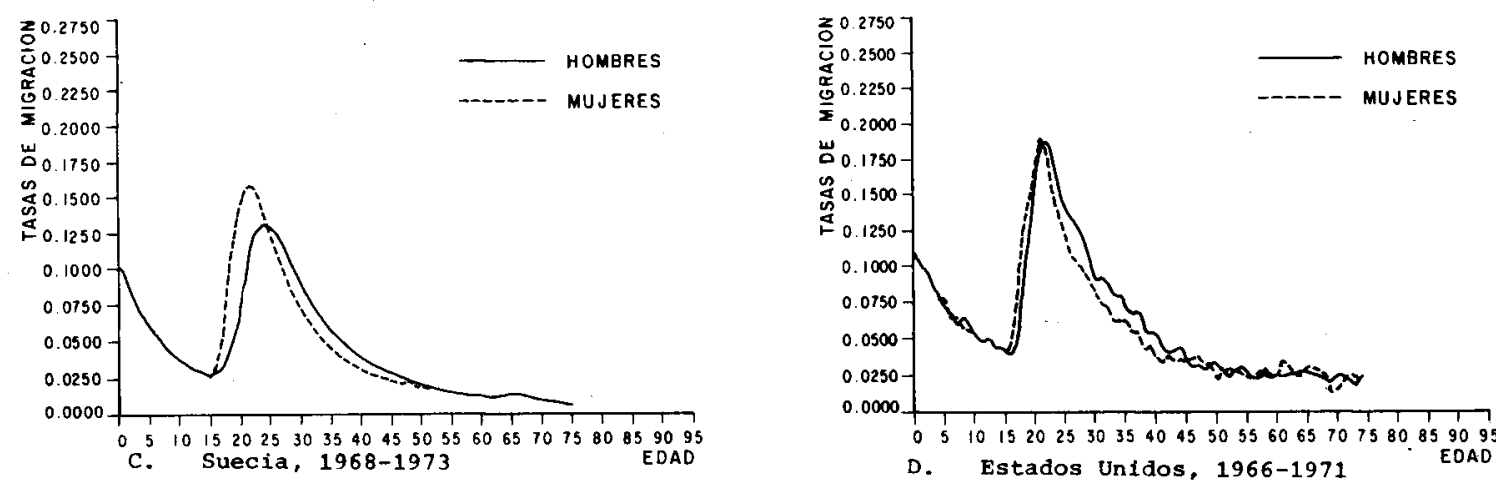

*En los Países Bajos, migración intercomunal; en Polonia, migración intermunicipios; en E.U.A., migración intercondados. 
como una proporción más amplia que la ubicación residencial, como si la unidad geográfica seleccionada fuera una división civil más grande -como puede ser el caso de un estado o provincia.

La gráfica 2.3 presenta los perfiles por edades de la movilidad femenina y los patrones de migración medidos en unidades geográficas de distintos tamaños: 1) todos los movimientos de una residencia a otra, 2) cambios de residencia dentro de los límites del condado, 3) migración entre condados y 4) migración entre estados. Las cuatro tasas brutas de migraproducción (TBM) son: 14.3, 9.3, 5.0 y 2.5 , respectivamente. Los cuatro perfiles de edad son muy similares, lo que indi-

Gráfica 2.3.

TASAS DE MIGRACIÓN ANUALES OBSERVADAS EN EL SEXO FEMENINO POR NIVELES DE ÁREA GEOGRÁFICA Y EDADES INDIVIDUALES: E.U.A., 1966-1971.

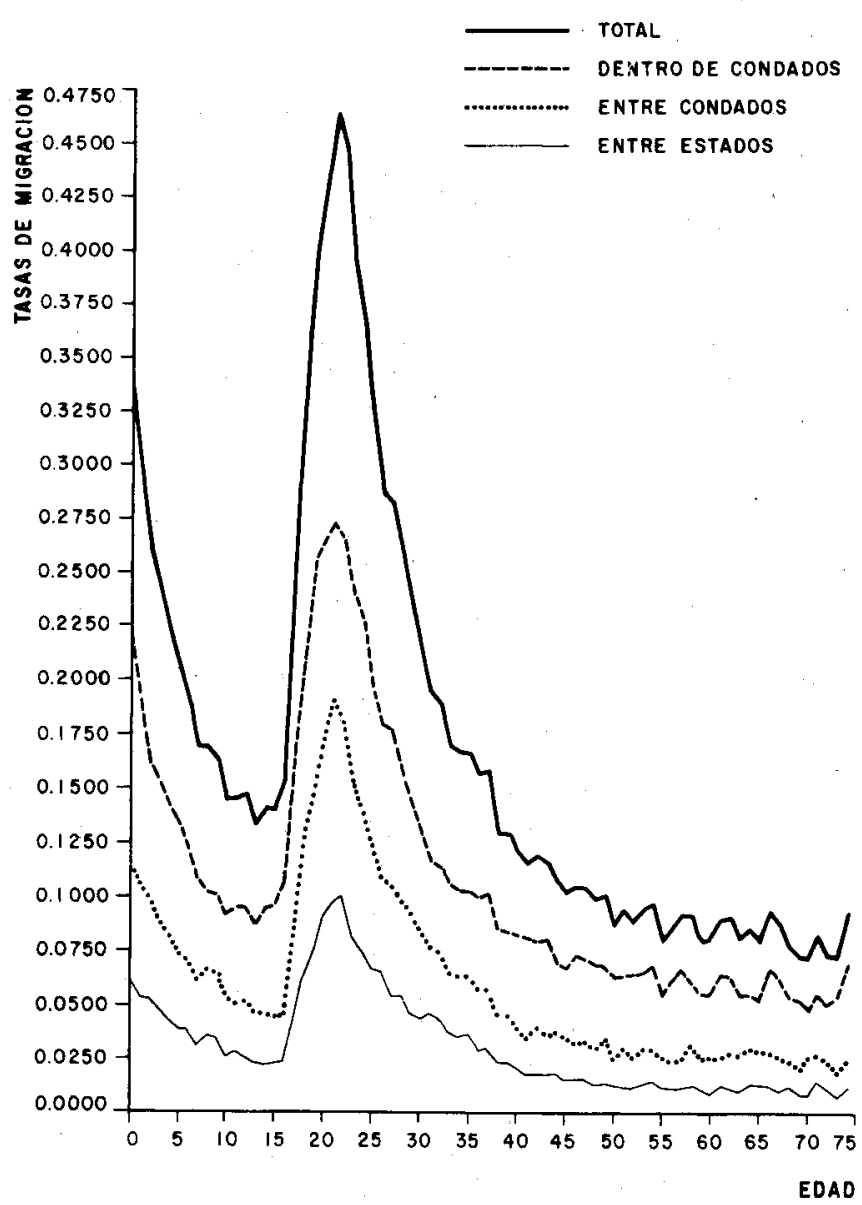


ca que la regularidad en el patrón de edad persiste a lo largo de las delimitaciones de áreas geográficas de distintos tamaños.

Finalmente, la migración ocurre en el tiempo y en el espacio; por lo tanto, los estudios de este patrón deben delinear su ocurrencia tanto respecto a los intervalos de tiempo, como en el sistema de áreas geográficas. En general, cuanto más grande sea el intervalo de tiempo, mayor será el número de los móviles de retorno y de los migrantes no sobrevivientes; esto da origen a que cuanto más elevado sea el número total de migrantes mayor será la subestimación del número de móviles del interárea (y desde luego, también la de los movimientos). Philip Rees, por ejemplo, después de examinar los cocientes de uno a cinco años de los migrantes entre las regionales normales de la Gran Bretaña, encontró que:

el número de migrantes registrados en cinco años en un flujo interregional tiene una variación registrada, en un año, de cuatro a dos veces el número de migrantes. (Rees, 1977, p. 247).

\subsection{Patrones modelo de migración}

La selectividad de la migración respecto de la edad fue la regularidad más sobresaliente que se encontró en las tasas de migración por edades específicas en los patrones empíricos. Los adultos jóvenes, veinteañeros, por lo general muestran las tasas de migración más elevadas y los adolescentes, las más bajas. Las tasas de migración de los niños reflejan las mismas que las de sus padres, de ahí que las tasas de migración de los niños pequeños excedan a las de los adolescentes. Finalmente, los flujos de migración que se dirigen hacia las regiones de climas más cálidos, y hacia o fuera de las grandes ciudades con niveles relativamente elevados de servicios sociales y actividades culturales, con frecuencia muestran un "máximo de retiro" en edades que parten de los sesenta y cinco años.

La gráfica 2.4 ilustra un programa típico observado de migración por edades (la línea dentada) y su graduación por un patrón modelo (la línea suave sobrepuesta) que se define como la suma de cuatro componentes:

1) una curva exponencial negativa y sencilla de las edades previas a la actividad económica (prelaborales), con su tasa de descenso, $\alpha_{1}$;

2) una curva unimodal sesgada a la izquierda de las edades económicamente activas colocada en $\mu_{2}$ en el eje por edades que muestran tasas de ascenso, $\lambda_{2}$ y descenso, $\alpha_{2}$

3) una curva en forma de campana de las edades posteriores a la actividad económica (poslaborales) colocadas en $\mu_{3}$ en el eje por edades y que muestra tasas de ascenso, $\lambda_{3}$ y desscenso, $\alpha_{3}$

4) una curva constante, $c$, que incluye el aumento de la calidad de adecuación proporcionada por la expresión matemática del programa.

La descomposición descrita sugiere la suma simple de cuatro curvas (Rogers, Raquillet y Castro, 1978): ${ }^{3}$

3 Los componentes de la población económicamente activa y los poslaborales que se incluyen en la ecuación (1) están descritos por la curva "doble exponencial" formulada por Coale y McNeil (1972) en sus estudios sobre nupcialidad y fecundidad. 


$$
\begin{aligned}
M(x) & =a_{1} e^{-\alpha_{1} x} \\
& +a_{2} e^{-\alpha_{2}\left(x-\mu_{2}\right)-e^{-\lambda_{2}\left(x-\mu_{2}\right)}} \\
& +a_{3} e^{-\alpha_{3}\left(x-\mu_{3}\right)-e^{-\lambda_{3}\left(x-\mu_{3}\right)}} \\
& +c \quad, x=0,1,2, \ldots, z
\end{aligned}
$$

$\alpha_{1}=$ tasa de descenso de la curva de las edades prelaborales

$\lambda_{2}=$ tasa de ascenso de la curva de la actividad económica

$\alpha_{2}=$ tasa de descenso de la curva de la fuerza de trabajo

$\lambda_{3}=$ tasa de ascenso de la curva de las edades poslaborales

$\alpha_{3}=$ tasa de descenso de la curva de las edades poslaborales edad de trabajar

$c=$ constante

$\mathrm{x}_{2}=$ punto mínimo

$\mathrm{x}_{\mathrm{h}}=$ máximo

$\mathrm{x}_{\mathrm{r}}=$ máximo de retiro

$\mathrm{X}=$ curva de la actividad económica

$A=$ curva de parentesco

$\mathbf{B}=$ el salto

El programa del modelo "completo" en la ecuación (1) cuenta con once parámetros: $\mathrm{a}_{1}, \alpha_{1}, \mathrm{a}_{2}, \mu_{2}, \alpha_{2}, \lambda_{2}, \mathrm{a}_{3}, \mu_{3}, \alpha_{3}, \lambda_{3}$ y c. El perfil del patrón modelo completo está definido por siete de los once parámetros: $\alpha_{1}, \mu_{2}, \alpha_{2}, \lambda_{2}, \mu_{3}, \alpha_{3}$ y $\lambda_{3}$. El nivel lo determinan los cuatro parámetros restantes: $a_{1}, a_{2}, a_{3}$ y c. Cualquier cambio en el valor de la tasa bruta de migraproducción de un patrón modelo en particular altera de manera proporcional, los valores del último sin alterar al primero. Sin embargo, como veremos en la sección siguiente, algunos aspectos del perfil dependen también de la distribución del nivel del patrón entre los componentes de edades previas y posteriores a la participación económica (fuerza de trabajo), asi como de la participación del total del nivel que responde por el término constante, c. Finalmente, los patrones de migración sin un máximo de retiro pueden representarse por medio de un modelo "reducido" con siete parámetros, porque en tales instancias se omite el tercer componente de la ecuación (1). 
Gráfica 2.4 .

PATRÓN MODELO DE MIGRACIÓN

Tasa de migracion, $M(x)$

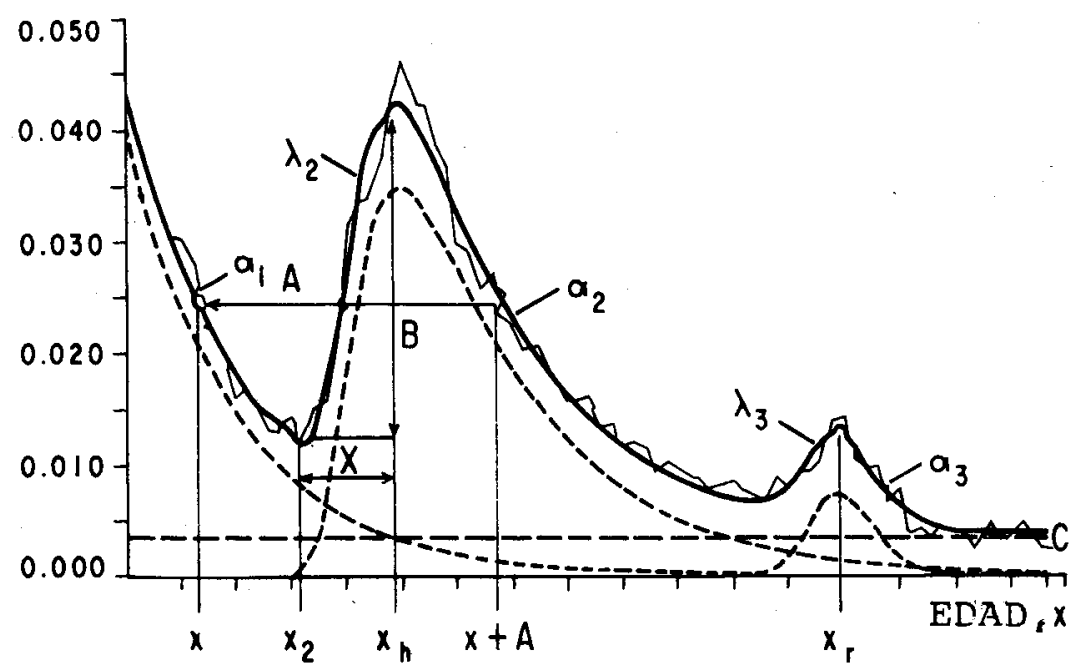


El cuadro 2.1 muestra, de manera ilustrativa, los valores de las medidas básicas y derivadas que se presentan en la gráfica 2.4. La información se refiere a los patrones de migración de 1974, para una desagregación de ocho regiones en Suecia (Andersson y Holmberg, 1980). El método que se escogió para adecuar el patrón modelo a la información fue el procedimiento de minimización funcional, mejor conocido como el algoritmo modificado de Levenberg-Marquardt. ${ }^{4}$ Los estimadores chicuadrados mínimos se utilizan para dar más peso a los grupos de edades con tasas más bajas de migración.

Con el objeto de valorar la calidad de ajuste que proporciona el patrón modelo -cuando se aplique con la información observada-, se ha calculado el "error medio absoluto como por ciento del recurso observado":

$$
\mathrm{E}=\frac{\frac{1}{\mathrm{n}} \mathrm{x}_{\mathrm{M}} \hat{\mathrm{M}}(\mathrm{x})-\mathrm{M}(\mathrm{x})}{\frac{1}{\mathrm{n}} \sum \mathrm{M}(\mathrm{x})} \cdot 100
$$

Esta medida indica que el ajuste del modelo a la información de Suecia es razonablemente aceptable, porque los ocho índices de adecuación, son: 6.87, $6.41,12.15,11.01,9.31,10.77,11.75$ y 14.82 para hombres y $7.30,7.23$, $10.71,8.78,9.31,11.61,11.38$ y 13.28 para mujeres. La gráfica 2.5 ilustra de manera expresa la adecuación del programa modelo a la información observada sobre migración regional para las mujeres en Suecia.

Los patrones modelo de migración, de la forma especificada en la ecuación (1), pueden clasificarse en familias según el rango de valores empleados por sus parámetros más importantes. Por ejemplo, podemos ordenar patrones de acuerdo con sus niveles de migración, según la definición de valores de los parámetros de cuatro niveles de la ecuación (1), i. e., $a_{1}, a_{2}, a_{3}$ y c (o por sus tasas brutas asociadas de migraproducción). De manera alterna, podemos distinguir patrones con un máximo de retiro de aquellos que no lo tienen, o nos podemos dirigir a los patrones con valores relativamente bajos o elevados para una tasa de descenso $\lambda_{2}$, o la edad media $\bar{n}$. En varias aplicaciones, también resulta significativo caracterizar los patrones de migración en términos de varias de las medidas fundamentales ilustradas en la gráfica 2.4, tales como el punto bajo, $\mathrm{x}_{\ell}$, el máximo, $\mathrm{x}_{\mathrm{h}}, \mathrm{y}$ el máximo de retiro, $\mathrm{x}_{\mathrm{r}}$. La curva de la fuerza de trabajo $\mathrm{x}$ está asociada con la primera pareja de puntos, $\mathrm{X}$, que se define como la diferencia en años entre las edades máximas y el punto bajo, i. e., $X=x_{h}-x_{\ell}$. Al incremento en la tasa de migración de individuos en edades $\mathrm{x}_{\mathrm{h}}$ sobre los $\mathrm{x}_{\ell}$, se la nombrará salto, $\mathrm{B}$.

La correspondencia tan cercana entre las tasas de migración de los niños con las de sus padres, sugiere otro cambio importante en los patrones de migración observados. Si por cada punto $x$ en el máximo posterior de la curva de migración, se obtiene por interpolación (donde existe) la edad, $\mathrm{x}-\mathrm{A}_{\mathrm{x}}$, digamos, con una tasa idéntica de migración en parte del punto bajo anterior a la curva de migración, entonces el promedio de los valores $A_{x}$, calculados en aumento para el

4 Véase cl Apéndice y Brown y Dennis (1972), Levenberg (1944) y Marquardt (1963). 
Cuadro 2.1.

PARÁMETROS Y VARIABLES QUE DEFINEN LOS PATRONES MODELO DE MIGRACIÓN OBSERVADOS. REGIONES DE SUECIA, 1974

\begin{tabular}{|c|c|c|c|c|c|c|c|c|c|c|c|c|c|c|c|c|}
\hline \multirow{3}{*}{$\begin{array}{l}\begin{array}{c}\text { Parámetros } \\
y \\
\text { variables }\end{array} \\
\text { CMR * }\end{array}$} & \multicolumn{2}{|c|}{ Estocolmo } & \multicolumn{2}{|c|}{$\begin{array}{c}\text { Suecia } \\
\text { meridionaI }\end{array}$} & \multicolumn{2}{|c|}{$\begin{array}{c}\text { Sureste } \\
\text { de Suecia }\end{array}$} & \multirow{2}{*}{\multicolumn{2}{|c|}{ Sur }} & \multirow{2}{*}{\multicolumn{2}{|c|}{ oriente }} & \multirow{2}{*}{\multicolumn{2}{|c|}{$\begin{array}{c}\text { Suecia } \\
\text { Nororiental }\end{array}$}} & \multirow{2}{*}{\multicolumn{2}{|c|}{ 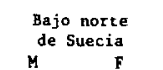 }} & \multirow{2}{*}{\multicolumn{2}{|c|}{$\begin{array}{l}\text { AIto norte } \\
\text { de Suecia }\end{array}$}} \\
\hline & M & $\mathbf{F}$ & 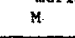 & & $M$ & & & & M & & & & & & & \\
\hline & 1.45 & 1.43 & 1.44 & 1.48 & 1.33 & 1.41 & 0.87 & 0.84 & 0.80 & 0.82 & 1.22 & 1.33 & 1.33 & 1.46 & 1.03 & 1.24 \\
\hline$a_{1}$ & .033 & .041 & .035 & .039 & .032 & .033 & .025 & .021 & .021 & .022 & .031 & .027 & .034 & .031 & .024 & .023 \\
\hline $\mathbf{a}_{1}$ & .097 & .091 & .088 & .108 & .096 & .106 & .117 & .104 & .090 & .106 & .104 & .102 & .123 & .119 & .135 & .128 \\
\hline$a_{2}$ & .059 & .067 & .079 & .096 & .091 & .112 & .066 & .067 & .046 & .055 & .084 & .116 & .109 & .141 & .079 & .116 \\
\hline$\mu_{2}$ & 20.80 & 19.32 & 20.27 & 18.52 & 19.92 & 18.49 & 21.17 & 19.88 & 20.36 & 19.36 & 19.75 & 18.18 & 19.62 & 17.93 & 19.47 & 17.62 \\
\hline$a_{2}$ & .077 & .094 & .090 & .109 & .104 & .127 & .115 & .129 & .091 & .114 & .103 & .139 & .118 & .148 & .114 & .143 \\
\hline$\lambda_{2}$ & .374 & .369 & .406 & .491 & .404 & .560 & .269 & .442 & .416 & .442 & .437 & .561 & .427 & .701 & .449 & .711 \\
\hline $\mathrm{a}_{3}$ & .000 & .000 & & & & & & & & & & & & & & \\
\hline$\mu_{3}$ & 76.55 & 85.01 & & & & & & & & & & & & & & \\
\hline$a_{3}$ & .776 & .369 & & & & & & & & & & & & & & \\
\hline$\lambda_{3}$ & .145 & .072 & & & & & & & & & & & & & & \\
\hline c & .003 & .003 & .003 & .004 & .003 & .004 & $:^{002}$ & .002 & .001 & .002 & .002 & .004 & .003 & .004 & .003 & .004 \\
\hline$\overline{\mathbf{n}}$ & 31.02 & 29.54 & 29.17 & 28.38 & 28.29 & 27.96 & 28.26 & 28.14 & 28.49 & 28.39 & 28.09 & 28.17 & 28.24 & 27.93 & 29.91 & 28.99 \\
\hline$z(0-14)$ & 25.61 & 25.95 & 22.81 & 22.59 & 21.40 & 20.67 & 22.76 & 21.93 & 23.54 & 23.18 & 21.52 & 10.40 & 19.84 & 18.26 & 18.29 & 16.40 \\
\hline$z(15-64)$ & 64.49 & 65.10 & 70.38 & 69.48 & 72.47 & 71.73 & 70.73 & 70.76 & 70.34 & 69.03 & 72.51 & 72.45 & 73.61 & 73.65 & 73.46 & 74.56 \\
\hline$z(65+)$ & 9.90 & 8.94 & 6.81 & 7.94 & 6.13 & 7.60 & 6.51 & 7.31 & 6.12 & 7.79 & 5.97 & 8.15 & 6.55 & 8.09 & 8.25 & 9.04 \\
\hline$\delta_{1}$ & 13.56 & 13.06 & 12.14 & 9.79 & 12.26 & 8.90 & 13.27 & 9.93 & 14.42 & 10.11 & 13.34 & 7.27 & 11.38 & 7.41 & 8.29 & 5.84 \\
\hline$\delta_{12}$ & .716 & .604 & .446 & .403 & .350 & .293 & .377 & .312 & .457 & .395 & .369 & .237 & .310 & .219 & .305 & .198 \\
\hline$s_{32}$ & .003 & .003 & & & & & & & & & & & & & & \\
\hline$B_{12}$ & 1.26 & .977 & .981 & .993 & .921 & .883 & 1.02 & .809 & .979 & .926 & 1.00 & .730 & 1.04 & .801 & 1.19 & .890 \\
\hline $\mathrm{a}_{2}$ & 4.86 & 3.94 & 4.52 & 4.49 & 3.88 & 4.40 & 2.34 & 3.43 & 4.55 & 3.87 & 4.23 & 4.03 & 3.63 & 4.74 & 3.95 & 4.95 \\
\hline$o_{3}$ & .187 & .196 & & & & & & & & & & & & & & \\
\hline x & 16.39 & 14.81 & 15.92 & 14.80 & 15.41 & 15.07 & 14.52 & 15.61 & 16.11 & 15.23 & 15.56 & 14.71 & 15.19 & 15.07 & 15.21 & 14.77 \\
\hline$x_{h}$ & 24.68 & 22.70 & 23.78 & 21.46 & 23.12 & 21.06 & 24.16 & 22.58 & 23.80 & 22.30 & 22.93 & 20.60 & 22.56 & 20.12 & 22.47 & 19.85 \\
\hline$x_{r}$ & 64.80 & 61.47 & & & & & & & & & & & & & & \\
\hline $\mathrm{x}$ & 8.29 & 7.89 & 7.86 & 6.66 & 7.71 & 5.99 & 9.64 & 6.97 & 7.69 & 7.07 & 7.37 & 5.89 & 7.37 & 5.05 & 7.26 & 5.08 \\
\hline$A$ & 27.87 & 25.49 & 29.99 & 27.32 & 29.93 & 27.27 & 29.90 & 27.87 & 29.57 & 27.42 & 29.92 & 27.01 & 30.15 & 26.94 & 31.61 & 28.30 \\
\hline 8 & .029 & .030 & .040 & .022 & .044 & .059 & .026 & .032 & .023 & .027 & .042 & .059 & .053 & .077 & .040 & .063 \\
\hline
\end{tabular}

calculadas con un patrón modelo que comprende un rango de edad de 95 años. 
número de años entre cero y el punto bajo $\mathrm{x}_{\ell}$, se definirá como la curva de parentesco, $\mathrm{A}$, observada.

Puede describirse, dentro de un cierto número de modos úciles, un patrón de migración por edades específicas observadas (o graduadas). Por ejemplo, pueden efectuarse referencias a la altura de una edad en particular, a la ubicación de los máximos importantes o líneas máximas, a las curvas del patrón que van junto al perfil por edad, a los cocientes entre una altura en particular o curvas, a áreas bajo partes de la curva, y a las distancias horizontales y verticales entre alturas y ubicaciones importantes. Las medidas varias que describen la caracterización de un patrón modelo de migración por edades, pueden agruparse, de manera conveniente, en las siguientes categorías y subcategorías:

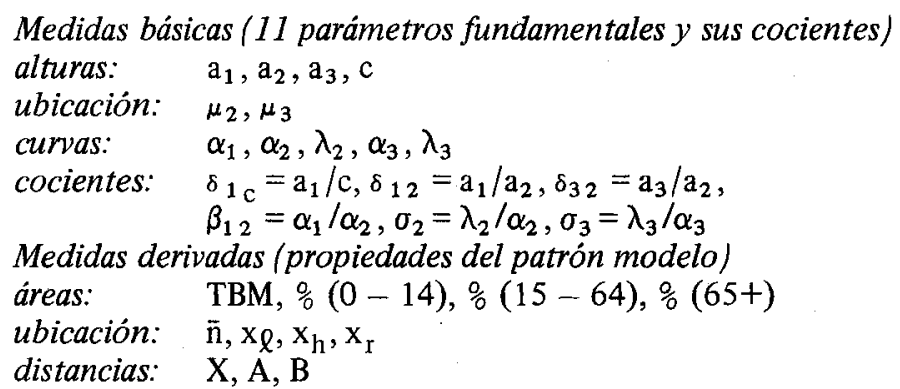

El enfoque más conveniente para caracterizar un patrón modelo de migración observado -i. e., un programa empírico graduado por la ecuación (1) - consiste en comenzar con la curva central de la actividad económica y "añadir" los componentes de edades prelaborales y poslaborales, y el componente constante. Este enfoque se presenta en la gráfica 2.6 .

Se puede imaginar la descripción de la descomposición del patrón modelo de migración junto con las dimensiones verticales y horizontales; e. g., la distribución de la fracción de su nivel al componente constante y después dividir el remanente entre los otros tres (o dos) componentes. El cociente $\delta_{1} \mathrm{c}=\mathrm{a}_{1} / \mathrm{c}$ mide la distribución anterior, $\delta_{12}=a_{1} / a_{2}$ y $\delta_{32}=a_{3} / a_{2}$ reflejan la división anterior.

La altura de los componentes de la actividad económica y la prelaboral y poslaboral, se reflejan en los parámetros $\mathrm{a}_{2}$ y $\mathrm{a}_{1}$ de manera respectiva, con lo que el cociente $\mathrm{a}_{2} / \mathrm{a}_{1}$ indica el grado de "dominación laboral", y su recíproco, $\delta_{12}=$ $\mathrm{a}_{1} / \mathrm{a}_{2}$, indice de la dependencia infantil, mide el nivel en el cual los niños efectúan la migración junto con sus padres. Así, cuanto más bajo es el valor de $\delta_{12}$, más bajo será el grado de la dependencia infantil que muestra un patrón de migración $\mathrm{y}$, en correspondencia, será mayor su dominancia laboral. Esto sugiere una clasificación dicotómica de los patrones de migración en las categorías dependientes infantiles y dominancia de edades activas.

Se puede aplicar un argumento análogo a la curva de edades poslaborales y $\delta_{32}=a_{3} / a_{2}$ muestra ser el índice adecuado. Sin embargo, para nuestros propósitos, será suficiente con confiar en el valor tomado de paráme tro $\lambda_{3}$, con los valores positivos que señalen la presencia del máximo de retiro y un valor de cero que indique su ausencia. Los valores elevados de $\lambda_{3}$ se interpretarán para identificar la dominancia de retiro. 
Gráfica 2.5 .

PATRONES MODElo DE MIGRACIÓN OBSERVADOS: MuJeres. REgIONES DE SUECIA, 1974.
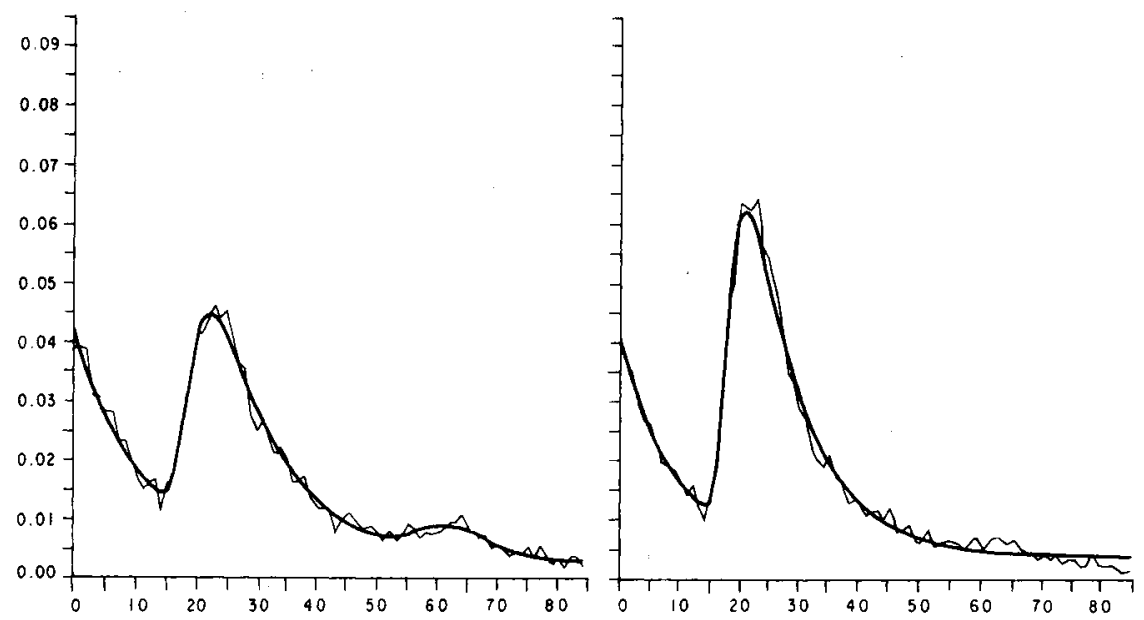

A. Región 1: Estocolmo

B. Región 2: Suecia meridional
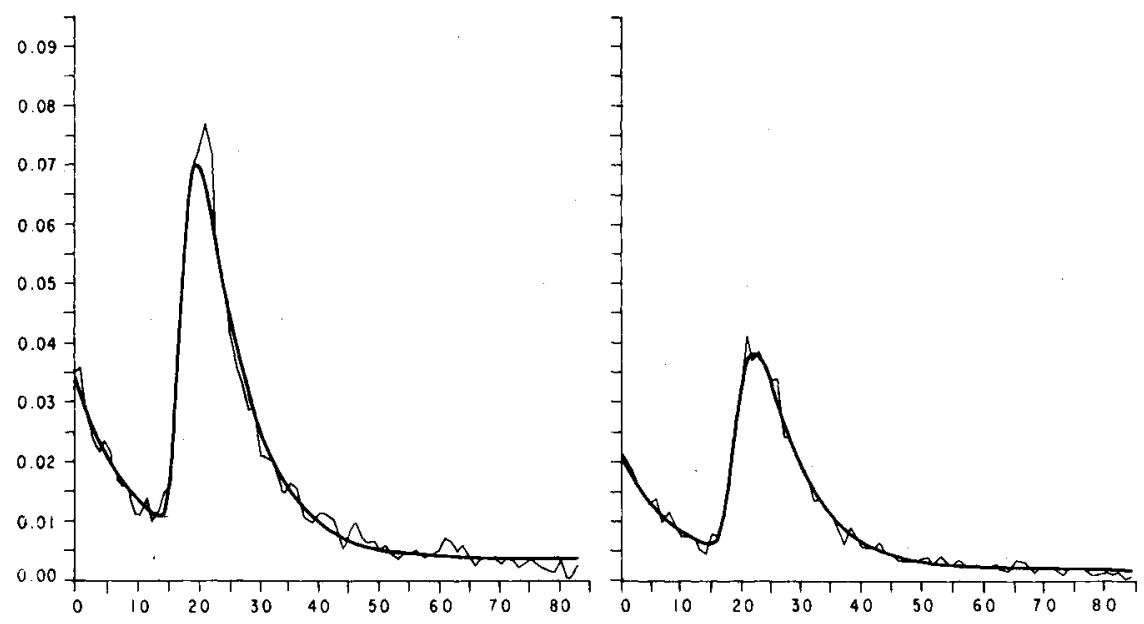

C. Región 3: Sureste de Suecia

D. Región 4: Sur

La dominancia de edades activas refleja los niveles de migración relativa de los que se encuentran en las edades relativas de trabajar con aquellas de los niños y los pensionados. La asimetria laboral se refiere a la curva de la asimetría de la curva en forma de campana que describe el perfil de la migración de la actividad 
Gráfica 2.5 .

Patrones modelo de migración observados: Mujeres, Regiones de SUECIA, 1974. (CONTINUACIÓN)
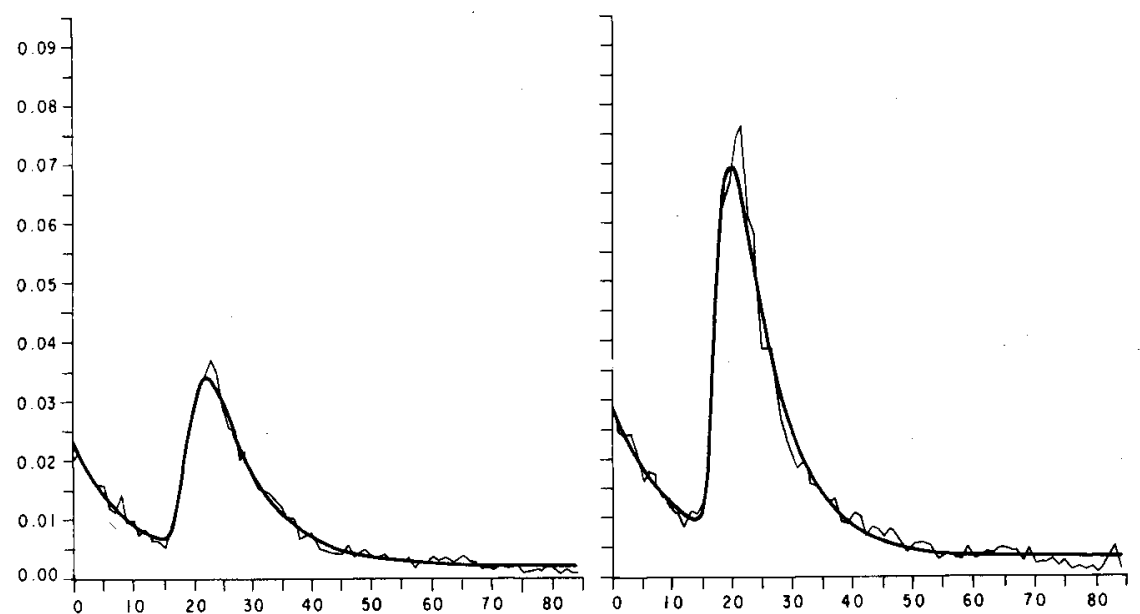

E. Región 5: Oriente

F. Región 6: Suecia nororiental
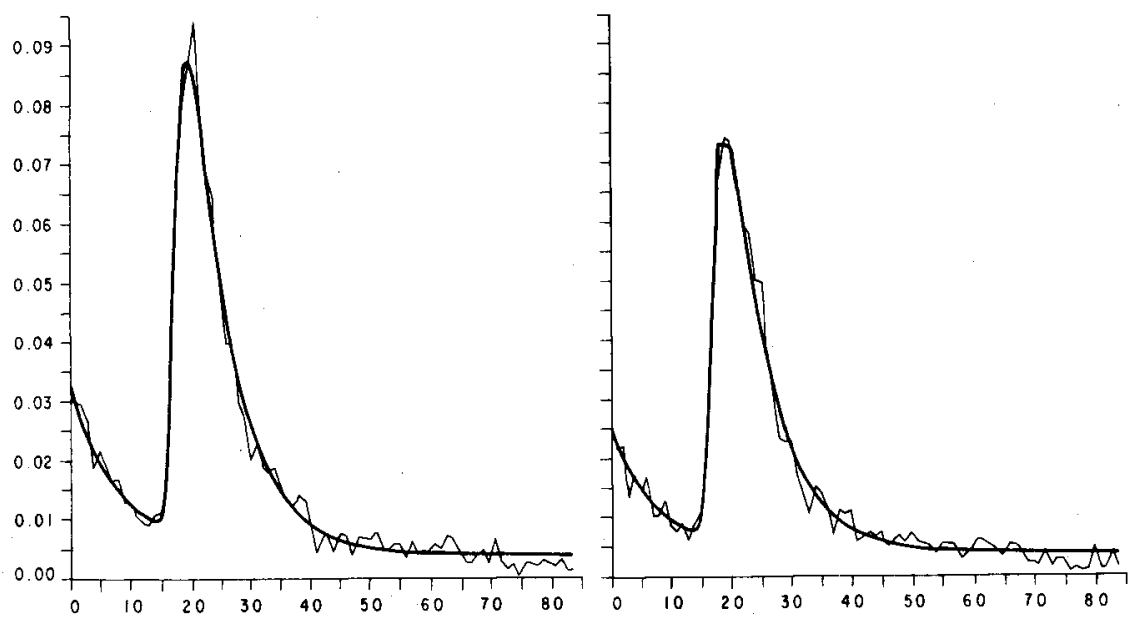

G. Región 7: Bajo norte de

H. Región 8: Alto norte de Suecia Suecia

económica. Imaginemos que si la línea perpendicular conecta el máximo con la base de la curva en forma de campana (i. e., el salto, B), divide la base en dos segmentos g y h, según se ilustra de manera esquemática en el diagrama: 


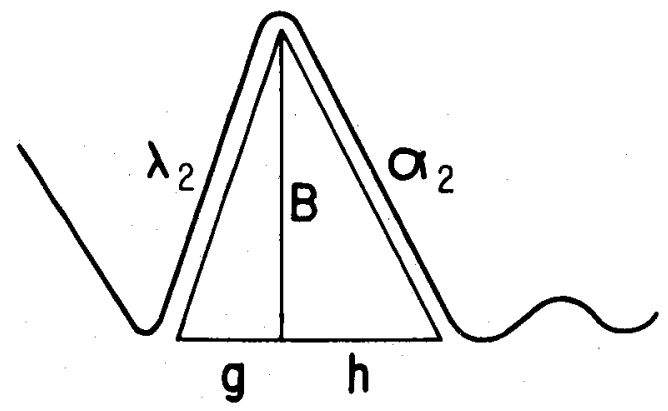

Resulta evidente que el cociente $\mathrm{h} / \mathrm{g}$ es un indicador del grado de asimetría de la curva. El cociente $\sigma_{2}=\lambda_{2} / \alpha_{2}$, resulta un índice más conveniente porque se utilizan exclusivamente dos parámetros del patrón modelo, el índice de la asimetría laboral. Su movimiento se relaciona grandemente con el de $\mathrm{h} / \mathrm{g}$ debido a la relación aproximada:

$$
\sigma_{2}=\frac{\lambda_{2}}{\alpha_{2}} \sim \frac{B}{g} \div \frac{B}{h}=\frac{h}{g}
$$

donde $\sim$ denota proporcionalidad. Así, $\sigma_{2}$ puede utilizarse para clasificar los patrones de migración de acuerdo con su grado de asimetría laboral.

De nuevo, se aplica un argumento análogo a la curva de las edades poslaborales $y, \sigma_{3}=\lambda_{3} / \alpha_{3}$ puede definirse como el indice de la asimetria de retiro.

Cuando se "suma" una curva de las edades prelaborales de un nivel dado al componente de la fuerza de trabajo, también resulta importante hacer alguna indicación de su contorno. Por ejemplo, si las tasas de migración de los niños reflejan las de sus padres, entonces $\alpha_{1}$ debe ser casi igual a $\alpha_{2}$, y $\beta_{12}=\alpha_{1} / \alpha_{2}$, y el indice de regularidad de la curva patema debe estar cercana a la unidad.

Los patrones de migración regional en Suecia, y que se describen en la gráfica 2.5 y cuadro 2.1 , pueden caracterizarse en términos de algunas medidas básicas y que se han derivado de lo que hemos descrito con anterioridad. Comencemos con la observación de que los niveles de emigración son similares en todas las demás regiones, de un rango bajo de 0.80 para hombres en la región 5 , a uno elevado de 1.48 para mujeres en la región 2 . Esta similitud permite una valoración

Gráfica 2.6 .

DIAGRAMA ESQUEMÁTICO DE LOS COMPONENTES FUNDAMENTALES DEL PATRÓN MODELO DE MIGRACIÓN.
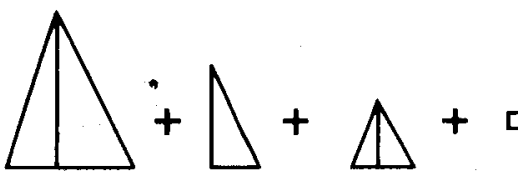

Componente

de la antividad Componente Componente económica prelaboral poslaboral

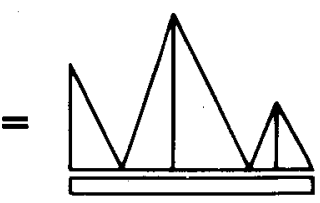


visual razonablemente exacta en la gráfica 2.5 , así como la caracterización de sus perfiles.

Las diferencias tan diversas en las tasas brutas de migraproducción otorgan una elevación a las curvas y a las relaciones verticales entre los patrones que no son comparables cuando se examinan visualmente. Entonces, debe recurrirse a la normalización de las áreas bajo las curvas de migración, por ejemplo, efectuar una revisión general de la escala a la unidad de la TBM. Es conveniente hacer notar, que esta dificultad no aparece en la información numérica del cuadro 2.1 porque, como se señaló con anterioridad, la curva principal y los parámetros de ubicación, así como los cocientes utilizados para caracterizar los patrones, no se ven afectados por los cambios en los niveles. Solamente la altura, áreas y distancias verticales, así como el salto, son medidas dependientes del nivel.

De las ocho regiones examinadas, sólo las primeras dos muestran un máximo de retiro definitivo, en donde el máximo masculino es el de mayor dominio en cada caso. El índice de la dependencia infantil en la región 1 resultó ser el más elevado, y el de la región 8 , el más bajo. Este último se distinguió del perfil dominante laboral del patrón de emigración de dependencia infantil de Estocolmo. El índice de la asimetría de edades activas tiene una variación baja de 2.34 en el caso de hombres en la región 4, a una elevada de 4.95 para el perfil de emigración femenina de la región 8 . Para terminar, pero con una posible excepción en los hombres de la región 1 y las mujeres de la región 6 , resulta evidente que las tasas de migración infantil parecen reflejar las mismas de sus padres. El índice de la regularidad del contorno de los padres es de 1.26 en el primer caso, y de .730 en el segundo; para la mayoría de los demás patrones, está cercano a la unidad.

\section{Análisis comparativo de los patrones modelo de migración observados}

La sección anterior demostró que las tasas de migración por edades muestran un perfil fundamental por edades que puede expresarse de manera matemática y que se llama "patrón modelo de migración", mismo que define un total de 11 parámetros. En esta sección se intenta establecer los rangos de valores que adoptan cada uno de estos parámetros y sus variables derivadas asociadas. Este ejercicio puede realizarse gracias a la disponibilidad de la información base, relativamente extensa, cuya tarea de recolección llevó a cabo el estudio sobre migración comparada y asentamientos. Este estudio se terminó recientemente en el Instituto Internacional para Análisis de Sistemas Aplicados (IIASA), en Laxenburg, Austria (Rogers, 1976a, 1976b, 1978; Rogers y Willekens, 1978, y Willekens y Rogers, 1978). La información sobre migración que se incluyó en este trabajo se presenta en los informes por naciones.

\subsection{Preparación de la información, cálculos de los parámetros $y$ resumen de estadisticas}

Las tasas de migración por edades utilizadas para demostrar la conveniencia del patrón modelo de migración que se presenta en la última sección, representaron 
tasas por edades individuales. Tal información es muy lacónica a nivel regional y se encuentra disponible, en nuestro análisis comparativo, exclusivamente para Suecia. La demás información sobre migración por regiones se ha presentado por grupos de edades de cinco años y, en consecuencia, debe interpolarse para proporcionar el proceso de alimentación de información necesaria por edades individuales. En todos los ejemplos, los patrones de migración por región se clasificaron, primero, a una tasa bruta de migraproducción de unidad ( $\mathrm{TBM}=1$ ), antes de sujetarla a una interpolación spline cúbica (McNeil, Trussell y Turner, 1977).

Si el patrón de migración comienza con una TBM unitaria y tasas por edades individuales, el cálculo del algoritmo del parámetro no lineal produce, en última instancia, un conjunto de estimados para el modelo de los parámetros de los patrones. ${ }^{5}$ El cuadro 2.1, de la sección 2, prestó los resultados que se obtuvieron al utilizar la información para Suecia. La influencia del procedimiento de interpolación pudo valorarse en virtud de que esta información se encontraba disponible. El cuadro 3.1 muestra las diferencias de los cálculos de los patrones femeninos del cuadro 2.1 con los que se obtuvieron cuando la misma información se agregó a los grupos de cinco años, desagregándola después de los grupos por edades individuales, a través de una interpolación spline cúbica. La comparación de los cálculos de los parámetros indica que el procedimiento de interpolación arroja, por lo general, resultados satisfactorios.

El cuadro 3.1 se refiere a los resultados de las tasas de migración de cada una de las ocho regiones al resto de Suecia. Si se desagregan estas tasas por región de destino, entonces los patrones interregionales $8^{2}=64$, requieren un examen por sexos, lo que complica la comparación con varias naciones. A fin de resolver esta dificultad, asociaremos un patrón "típico" con cada una de las recopilaciones de las tasas nacionales, calculando el promedio de cada parámetro y la variable derivada. El cuadro 3.2 ilustra los resultados para la información sobre Suecia.

Para evitar la influencia de observaciones no representativas en el cálculo de los promedios que define el patrón nacional típico, se decidió suprimir aproximadamente el 10 por ciento de los patrones "extremos". De manera específica, los parámetros y variables derivadas se ordenaron de un valor bajo a uno elevado; el 5 por ciento más bajo y el 5 por ciento más elevado fueron definidos como los valores extremos. Se desecharon los patrones con el número más grande de valores extremos, elevado y bajo, en un orden de sucesión cercana al 90 por ciento del número original de los patrones restantes. Entonces, este conjunto reducido sirvió a modo de población de los patrones para calcular el resumen de las distintas estadísticas. El cuadro 3.3 ilustra los valores medios de los parámetros que se obtuvieron con la información de Suecia. En virtud de que la media, la moda, el error medio estándar, y los límites más bajos y más elevados resultan de interés, también se incluyen como una parte más detallada de los resultados de los cálculos, mismos que se reproducen en Rogers y Castro (1981).

La comparación de las cifras obtenidas, que muestra el cuadro 3.1, al utilizar intervalos de edades de uno y cinco años para la misma información en Suecia, indica que el procedimiento de interpolación arrojó resultados satisfactorios. Sin embargo, también se sugirió que el parámetro $\lambda_{2}$ se subestimó de manera consis-

5 Véase el Apéndice para mayores detalles. 
unasio 2.1 .

PARÁMETROS QUE DEFINEN PATRONES MODELO DE MIGRACIÓN OBSERVADOS Y LOS OBTENIDOS CON INTER POLACIÓN SPLINE CÚBICA. REgIONES DE SUECIA, 1974, PARA MUJERES.*

\begin{tabular}{|c|c|c|c|c|c|c|c|c|c|c|c|c|c|c|c|c|}
\hline \multirow[t]{2}{*}{ Farámetros } & \multicolumn{2}{|c|}{ Estoco1mo } & \multicolumn{2}{|c|}{$\begin{array}{c}\text { Suecia } \\
\text { meridional }\end{array}$} & \multicolumn{2}{|c|}{$\begin{array}{l}\text { Sureste de } \\
\text { Suecia }\end{array}$} & \multicolumn{2}{|c|}{ Sur } & \multicolumn{2}{|c|}{ Oriente } & \multicolumn{2}{|c|}{$\begin{array}{c}\text { Suecia } \\
\text { nororiental }\end{array}$} & \multicolumn{2}{|c|}{ Bajo norte } & \multicolumn{2}{|c|}{ Norte alto } \\
\hline & 1 año & 5 años & 1 año & 5 años & 1 aก̃o & 5 años & 1 año & 5 años & 1 año & 5 años & 1 año & 5 años & 1 año & 5 años & 1 año & 5 años \\
\hline$a_{1}$ & .029 & .028 & .026 & .026 & .023 & .023 & .025 & .025 & .027 & .025 & .021 & .022 & .021 & .021 & .019 & .021 \\
\hline$\alpha_{1}$ & .091 & .089 & .108 & .106 & .106 & .105 & .104 & .106 & .106 & .095 & .102 & .115 & .119 & .130 & .128 & .160 \\
\hline$a_{2}$ & .047 & .049 & .065 & .070 & .080 & .087 & .080 & .085 & .067 & .069 & .087 & .097 & .096 & .118 & .094 & .106 \\
\hline$\omega_{2}$ & 19.32 & 19.69 & 18.52 & 18.99 & 18.49 & 18.93 & 19.88 & 20.23 & 19.36 & 19.72 & 18.18 & 18.57 & 17.93 & 19.11 & 17.62 & 18.00 \\
\hline$\alpha_{2}$ & .094 & .098 & .109 & .117 & .127 & .136 & .129 & .135 & .114 & .121 & .139 & .145 & .148 & .172 & .143 & .150 \\
\hline$\lambda_{2}$ & .369 & .313 & .491 & .351 & .560 & .375 & .442 & .367 & .442 & .367 & .442 & .395 & .561 & .345 & .711 & .330 \\
\hline c & .002 & .002 & .003 & .003 & .003 & .003 & .003 & .003 & .003 & .003 & .003 & .003 & .003 & .003 & .003 & .003 \\
\hline$a_{3}$ & .000 & .000 & & & & & & & & & & & & & & \\
\hline$\mu_{3}$ & 85.01 & 81.20 & & & & & & & & & & & & & & \\
\hline$a_{3}$ & .369 & .364 & & & & & & & & & & & & & & \\
\hline$\lambda_{3}$ & .072 & .080 & & & & & & & & & & & & & & \\
\hline
\end{tabular}

* La información que se estudió se refiere a edades individuales ( 1 año); los procesos de alimentación de interpolación spline cúbica se obtuvieron después de observar información por grupos de 5 años ( 5 años). 
Cuadro 3.2 .

VALORES PROMEDIO DE LOS PARÁMETROS QUE DEFINEN EL CONJUNTO TOTAL DE LOS PATRONES MODELO DE MIGRACIÓN OBSERVADOS: SUECIA, 8 REGIONES.* INFORMACION OBSERVADA EN 1974 POR EDADES INDIVIDUALES, HASTA

84 AÑOS Y MÁS.

\begin{tabular}{|c|c|c|c|c|c|c|}
\hline \multirow{2}{*}{ Parámetros } & \multicolumn{3}{|c|}{ Hombres } & \multicolumn{3}{|c|}{ Mujeres } \\
\hline & $\begin{array}{l}\text { sin máximo de retiro } \\
\text { (52 patrones) }\end{array}$ & con & $\begin{array}{l}\text { maximo de retiro } \\
\text { (11 patrones) }\end{array}$ & $\sin \frac{I}{l}$ & $\begin{array}{l}\text { maximo de retiro } \\
\text { (58 patrones) }\end{array}$ & $\begin{array}{c}\text { con máximo de retiro } \\
\text { ( } 5 \text { patrones) }\end{array}$ \\
\hline$a_{1}$ & 0.029 & & 0.025 & & 0.027 & 0.023 \\
\hline$\alpha_{I}$ & 0.126 & & 0.080 & & 0.114 & 0.087 \\
\hline$a_{2}$ & 0.066 & & 0.050 & & 0.078 & 0.051 \\
\hline$\mu_{2}$ & 21.09 & & 21.52 & & 19.13 & 19.20 \\
\hline$\alpha_{2}$ & 0.113 & & 0.096 & & 0.133 & 0.101 \\
\hline$\lambda_{2}$ & 0.459 & & 0.439 & & 0.525 & 0.377 \\
\hline c & 0.003 & & 0.002 & & 0.003 & 0.003 \\
\hline$a_{3}$ & & & 0.0012 & & & 0.0017 \\
\hline$\mu_{3}$ & & & 75.75 & & & 72.07 \\
\hline$\alpha_{3}$ & & & 0.797 & & & 0.688 \\
\hline$\lambda_{3}$ & & & 0.294 & & & 0.192 \\
\hline
\end{tabular}

* La región 1 (Estocolmo), es una región comunal y, por tanto, no existe ningún patrón "interregional", lo que arroja $(8)^{2}-1=63$ patrones. 
tente en la información de cinco años. Para confirmar esta sugerencia, se tomaron de nuevo los resultados del cuadro 3.3, además de la información base de Suecia, utilizando una agregación con intervalos de cinco años. Los resultados que se presentan en el cuadro 3.4, muestran una vez más que $\lambda_{2}$ se ha subestimado consistentemente en el procedimiento de interpolación. Debe hacerse notar y tener en mente esta tendencia.

También es importante hacer notar, que el comportamiento erróneo del máximo de retiro, se debe en apariencia a su extrema sensibilidad para perder información que se origina en la agregación. Así, a pesar de que continuaremos presentando los resultados relacionados con las edades poslaborales, éstas no formarán parte de nuestra pesquisa sobre patrones de familias.

\subsection{Contrastes nacionales}

Los cuadros 3.3 y 3.4 de la subsección anterior, resumieron los valores medios de los parámetros para 57 patrones modelo de migración en hombre y mujeres. En esta subsección extenderemos nuestro análisis con el objeto de incluir una información base mucho más amplia. Se sumarán a los 114 patrones modelo de Suecia, otros 164 patrones del Reino Unido (cuadro 3.5); 114 de Japón y 20 de los Países Bajos (cuadro 3.6); 58 de la Unión Soviética, 8 de los Estados Unidos y 32 de Hungría (cuadro 3.7). El resumen de las estadísticas para estos 510 patrones se presenta en Rogers y Castro (1980), de los cuales 206 son patrones masculinos, 206 femeninos y 98 una combinación de ambos sexos (hombres más mujeres). ${ }^{6}$

Un número importante de patrones mostró un patrón de migración en las edades poslaborales que difieren del patrón modelo de migración de 11 parámetros, el cual se definió en la ecuación (1). En vez de obtener un máximo de retiro, el perfil de la edad tomó la forma de "curva ascendente". Con tales instancias, se introdujo una modificación de 9 parámetros de un modelo de migración básico, a saber:

$$
\begin{aligned}
M(x)= & a_{1} e^{-\alpha_{1} x} \\
& +a_{2} e^{-\alpha_{2}\left(x-\mu_{2}\right)-e^{-\lambda_{2}\left(x-\mu_{2}\right)}} \\
& +a_{3} e^{\alpha_{3} x} \\
& +c \quad, x=0,1,2, \ldots, z
\end{aligned}
$$

Por ejemplo, la mitad derecha del cuadro 3.6, muestra los cálculos promedio de los parámetros de esta forma modificada del patrón modelo de migración para los Países Bajos.

6 Este total no incluye los 56 patrones que se excluyeron como patrones "extremos". Durante el proceso de adecuación del patrón modelo a estos patrones de migración interregional, de más de 500, se encontró con frecuencia el problema de la ocurrencia de un valor negativo para la constante c. En todos estos ejemplos, el valor inicial de c fue similar a la tasa de migración observada más baja y se empezó de nuevo el procedimiento de cálculo no lineal. 
Cuadro 3.3 .

VALORES PROMEDIO DE LOS PARÁMETROS QUE DEFINEN EL CONJUNTO REDUCIDO DE LOS PATRONES MODELO DE MIGRACIÓN OBSERVADOS: SUECIA, 8 REGIONES.* INFORMACIÓN OBSERVADA EN 1974 POR EDADES INDIVIDUALES, HASTA 84 AÑOS Y MÁS.

\begin{tabular}{|c|c|c|c|c|}
\hline \multirow[b]{2}{*}{ Parámetros } & \multicolumn{2}{|c|}{ Hombres } & \multicolumn{2}{|c|}{ Mujeres } \\
\hline & $\begin{array}{l}\text { sin maximo de retiro } \\
\text { (48 patrones) }\end{array}$ & $\begin{array}{c}\text { con maximo de retiro } \\
\text { ( } 9 \text { patrones) }\end{array}$ & $\begin{array}{l}\text { sin máximo de retiro } \\
\text { (54 patrones) }\end{array}$ & $\begin{array}{c}\text { con maximo de retiro } \\
\text { ( } 3 \text { patrones) }\end{array}$ \\
\hline$a_{1}$ & 0.029 & 0.026 & 0.026 & 0.024 \\
\hline$\alpha_{1}$ & 0.124 & 0.085 & 0.1 .08 & 0.093 \\
\hline$a_{2}$ & 0.067 & $0.05 \dot{1}$ & 0.076 & 0.055 \\
\hline$\mu_{2}$ & 20.50 & 21.25 & 19.09 & 18.87 \\
\hline$\alpha_{2}$ & 0.104 & 0.093 & 0.127 & 0.106 \\
\hline$\lambda_{2}$ & 0.448 & 0.416 & 0.537 & 0.424 \\
\hline c & 0.003 & 0.002 & 0.003 & 0.003 \\
\hline$a_{3}$ & & 0.0006 & & 0.0001 \\
\hline$\mu_{3}$ & & 76.71 & & 74.78 \\
\hline$\alpha_{3}$ & & 0.0847 & & 0.938 \\
\hline$\lambda_{3}$ & & 0.158 & & 0.170 \\
\hline
\end{tabular}

* La región 1 (Estocolmo), es una región comunal y, por tanto, no existe ningún patrón "interregional", lo que arroja $(8)^{2}-1=63$ patrones, de los cuales se desecharon 6 . 


\begin{tabular}{|c|c|c|c|c|}
\hline \multirow{2}{*}{ Parámetros } & \multicolumn{2}{|c|}{ Hombres } & \multicolumn{2}{|c|}{ Mujeres } \\
\hline & $\begin{array}{l}\text { sin maximo de retiro } \\
\text { (49 patrones) }\end{array}$ & $\begin{array}{c}\text { con maximo de retiro } \\
\text { (8 patrones) }\end{array}$ & $\begin{array}{l}\text { sin maximo de retiro } \\
\text { (54 patrones) }\end{array}$ & $\begin{array}{c}\text { con máximo de retiro } \\
\text { ( } 3 \text { patrones) }\end{array}$ \\
\hline$a_{1}$ & 0.028 & 0.026 & 0.026 & 0.026 \\
\hline$\alpha_{1}$ & 0.115 & 0.088 & 0.108 & 0.077 \\
\hline$a_{2}$ & 0.068 & 0.052 & 0.080 & 0.044 \\
\hline$\mu_{2}$ & 20.61 & 20.26 & 19.52 & 19.18 \\
\hline$\alpha_{2}$ & 0.105 & 0.084 & 0.133 & 0.089 \\
\hline$\lambda_{2}$ & 0.396 & 0.390 & 0.374 & 0.341 \\
\hline c & 0.002 & 0.001 & 0.002 & 0.002 \\
\hline$a_{3}$ & & 0.0017 & & 0.0036 \\
\hline$\mu_{3}$ & & 77.47 & & 77.72 \\
\hline$\alpha_{3}$ & & 0.603 & & 0.375 \\
\hline$\lambda_{3}$ & & 0.148 & & 0.134 \\
\hline
\end{tabular}

* La región 1 (Estocolmo) es una región comunal y, por tanto, no existe ningún patrón “interregional", lo que arroja $(8)^{2}-1=63$ patrones, de los cuales se desecharon 6. 
(uadro s.s.

VALORES PROMEDIO DE LOS PARÁMETROS QUE DEFINEN UN CONJUNTO REDUCIDO DE PATRONES MODELO DE MIGRACIÓN OBSERVADOS: REINO UNIDO, 10 REGIONES, $1970^{*}$

\begin{tabular}{|c|c|c|c|c|}
\hline \multirow{2}{*}{ Parámetros } & \multicolumn{2}{|c|}{ Hombres } & \multicolumn{2}{|c|}{ Mujeres } \\
\hline & $\begin{array}{c}\text { sin maximo de retiro } \\
\text { (59 patrones) }\end{array}$ & $\begin{array}{c}\text { con maximo de retiro } \\
\text { (23 patrones) }\end{array}$ & $\begin{array}{c}\text { sin máximo de retiro } \\
\text { (61 patrones) }\end{array}$ & $\begin{array}{c}\text { con maximo de retiro } \\
\text { (21 patrones) }\end{array}$ \\
\hline$a_{1}$ & 0.021 & 0.016 & 0.021 & 0.018 \\
\hline$\alpha_{1}$ & 0.099 & 0.080 & 0.097 & 0.089 \\
\hline$a_{2}$ & 0.059 & 0.053 & 0.063 & 0.048 \\
\hline $\mathrm{H}_{2}$ & 22.00 & 20.42 & 21.35 & 21.56 \\
\hline$\alpha_{2}$ & 0.127 & 0.120 & 0.151 & 0.153 \\
\hline$\lambda_{2}$ & 0.259 & 0.301 & 0.327 & 0.333 \\
\hline c & 0.033 & 0.004 & 0.003 & 0.004 \\
\hline$a_{3}$ & & 0.007 & & 0.002 \\
\hline$\mu_{3}$ & & 71.11 & & 71.84 \\
\hline$\alpha_{3}$ & & 0.692 & & 0.583 \\
\hline$\lambda_{3}$ & & 0.309 & & 0.403 \\
\hline
\end{tabular}

* No había información interregional disponible; de ahí que se analizaron $(10)^{2}-10=90$ patrones, de los que se desecharon 8. 
Cuadro 3.6.

VALORES PROMEDIO DE LOS PARÁMETROS QUE DEFINEN UN CONJUNTO REDUCIDO DE PATRONES MODELO DE MIGRACIÓN OBSERVADOS: JAPÓN, 8 REGIONES, 1970; PAÍSES BAJOS, 12 REGIONES, 1974*

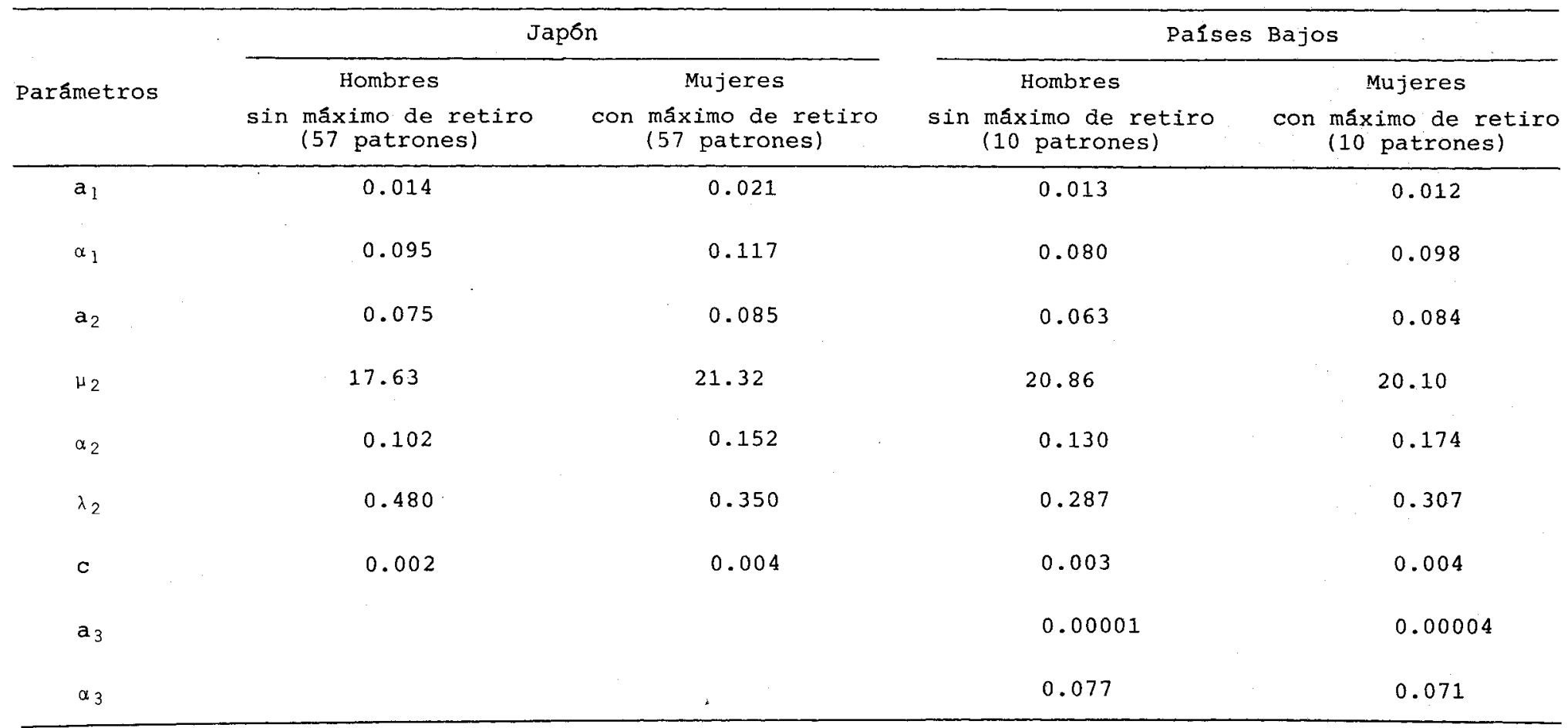

* La región 1 de Japón (Hokkaido) es una región de prefectura, por lo que no existe ningún patrón interregional; se dejaron $(8)^{2}-1=63$ patrones, de los cuales se desecharon 6. El único patrón de migración disponible para los Países Bajos se refería a las tasas de migración de cada región, sin hacer mención al destino, de ahí que se utilizaran solamente 12 patrones, de los cuales se desecharon 2. 
Cuadro 3.7 .

VALORES PROMEdio DE LOS PARÁMETROS QUE DEFINEN EL CONJUNTO REDUCIDO DE PATRONES MODELO DE MIGRACIÓN OBSERVADOS: URS S, 8 REGIONES, 1974; E.U.A., 4 REGIONES, 1970-1971; H UNGRÍA, 6 REGIONES, 1974*

\begin{tabular}{|c|c|c|c|c|c|}
\hline & \multicolumn{2}{|r|}{ URSS } & EUA & \multicolumn{2}{|c|}{ Hungría } \\
\hline & $\begin{array}{l}\text { Total } \\
\text { Sin }\end{array}$ & $\begin{array}{l}\text { (hombres + mujeres) } \\
\text { maximo de retiro } \\
\text { ( } 58 \text { patrones) }\end{array}$ & $\begin{array}{l}\text { Total (hombres + mujeres) } \\
\text { Con máximo de retiro } \\
\text { ( } 8 \text { patrones) }\end{array}$ & $\begin{array}{l}\text { Total (hombr } \\
\text { Sin curva de retiro } \\
\text { ( } 7 \text { patrones) }\end{array}$ & $\begin{array}{l}\text { + mujeres) } \\
\text { Con curva de retiro } \\
\text { ( } 25 \text { patrones) }\end{array}$ \\
\hline$a_{1}$ & & 0.005 & 0.021 & 0.010 & 0.015 \\
\hline$\alpha_{1}$ & & 0.302 & 0.075 & 0.245 & 0.193 \\
\hline$a_{2}$ & & 0.126 & 0.060 & 0.090 & 0.099 \\
\hline$\mu_{2}$ & & 19.14 & 20.14 & 17.22 & 18.74 \\
\hline$\alpha_{2}$ & & 0.176 & 0.118 & 0.130 & 0.159 \\
\hline$\lambda_{2}$ & & 0.130 & 0.569 & 0.415 & 0.274 \\
\hline c & & 0.004 & 0.002 & 0.004 & 0.003 \\
\hline$a_{3}$ & & & 0.002 & & 0.00032 \\
\hline$\mu_{3}$ & & & 81.80 & & \\
\hline$\alpha_{3}$ & & & 0.430 & & 0.033 \\
\hline$\lambda_{3}$ & & & 0.119 & & \\
\hline
\end{tabular}

* Se incluyó la migración interregional en la formación de la URSS y Hungría pero no asi en la de los E.U.A. Por lo tanto, se dio $(8)^{2}=64$ patrones para la URSS, de los cuales se desecharon $6 ;(6)^{2}=36$ patrones para Hungría, de los cuales se desecharon $4 ;$ y $(4)^{2}-4=12$ patrones para E.U.A., de los cuales se desecharon 2 por falta del máximo de retiro; se desecharon otros 2 por sus valores extremos. 
De los cuadros 3.3 al 3.7 se presenta información abundante sobre los patrones nacionales de migración por edades. Los parámetros, que se presentan en columnas, definen un amplio rango de los patrones de migración. Unicamente cuatro de ellos se refieren al nivel de migración: $\mathrm{a}_{1}, \mathrm{a}_{2}, \mathrm{a}_{3}$ y $\mathrm{c}$. Sus valores son para la tasa bruta de migración por unidad; si se desean obtener valores correspondientes para otros niveles de migración, deben multiplicarse estos cuatro números por el nivel deseado de la TBM. Por ejemplo, la твM observada para la migración femenina que sale de la región de Estocolmo fue de 1.43 en 1974. Si se multiplica $\mathrm{a}_{1}=0.029$ por 1.43 , arroja 0.041 , valor apropiado de $\mathrm{a}_{1}$ con el que se genera el patrón de migración, para así obtener una TBM de 1.43.

Los patrones restantes del patrón modelo se refieren al perfil de migración por edades: $\alpha_{1}, \mu_{2}, \alpha_{2}, \lambda_{2}, \mu_{3}, \alpha_{3}$ y $\lambda_{3}$. Sus valores permanecen constantes para todos los niveles de la TBM. Si se toman juntos, definen el perfil por edad de migración de una región hacia otra. Los patrones sin un máximo de retiro conducen sólo a cuatro perfiles de parámetros: $\alpha_{1}, \mu_{2}, \alpha_{2}$. y $\lambda_{2}$, y los patrones con curva de retiro obtienen un perfil de parámetro adicional, $\alpha_{3}$.

No está dentro de los alcances de este trabajo obtener un análisis detallado de los parámetros que definen las varias clases de informes; sin embargo, pueden señalarse algunos contrastes básicos entre los perfiles nacionales del promedio por edad y que pueden resultar de utilidad.

Comencemos con un examen del componente de la actividad económica definida por cuatro parámetros, $\mathrm{a}_{2}, \mu_{2}, \alpha_{2}$ y $\lambda_{2}$. Los valores promedio de la nación para estos parámetros, por lo general caen dentro de los siguientes rangos:

$$
\begin{gathered}
0.05<\mathrm{a}_{2}<0.10 \\
17<\mu_{2}<22 \\
0.10<\alpha_{2}<0.20 \\
0.25<\lambda_{2}<0.60
\end{gathered}
$$

Con excepción de dos ejemplos, los valores femeninos para $\mathrm{a}_{2}, \alpha_{2}$ y $\lambda_{2}$ son más grandes que para los de los hombres. El caso contrario es para $\mu_{2}$, con dos excepciones; la más importante la mostró el patrón femenino de Japón en el que surgió un máximo con más edad que el de los hombres.

Los dos parámetros que definen el componente de la edad prelaboral $a_{1}$ y $\alpha_{1}$, por lo general caen dentro del rango de 0.01 a 0.03 y 0.08 a 0.12 , de manera respectiva. Las excepciones las conforman la Unión Soviética y Hungría, que muestran valores excepcionalmente elevados para $\alpha_{1}$. El componente de la fuerza de trabajo representa el caso contrario, donde es difícil identificar diferenciales consistentes por sexos.

Los perfiles por edades de la migración promedio nacional, como en la mayoría de las agregaciones, esconden más de lo que revelan. Puede encontrarse cierta agudeza dentro de los rangos de variaciones que se promediaron, si se consultan los límites bajos y elevados y los errores medios estándares que se listaron en Rogers y Castro (1981) para cada conjunto de patrones nacionales. Para termi- 
nar, y a modo de ejemplo, el cuadro 3.8 ilustra la forma en que los parámetros efectúan sus variaciones en distintos patrones nacionales no promediados. Los patrones modelo presentados describen las corrientes migratorias hacia y fuera de las capitales de la región de cada uno de los seis países: Finlandia, Hungría, Japón, los Países Bajos, Suecia y el Reino Unido. Los primeros patrones describen los perfiles de la migración fuera de la capital; los últimos, los perfiles de migración hacia la capital. Todo esto se ilustra en la gráfica 3.1

En el segundo, la diferencia más aparente entre el perfil por edades de la corriente que sale de la capital y el patrón de migración que va hacia la capital, es el predominio de los migrantes jóvenes en edad de trabajar; esto quiere decir que aparece un número más elevado, de manera proporcional, en las edades jóvenes en los patrones que muestran un flujo hacia la capital. Esto indica que la dominancia de edades activas equivale a los valores más amplios del producto $a_{2} \lambda_{2}$ en los patrones de inmigración y el del cociente $\delta_{12}=a_{1} / a_{2}$ en los patrones de emigración.

Una segunda atribución del perfil es el grado de asimetria en el componente de la actividad económica del patrón de migración, i. e., el cociente de la tasa de ascenso $\lambda_{2}$, a la tasa de descenso $\alpha_{2}$, definida como $\sigma_{2}$ en la sección 2 . Con excepción del caso de Japón, la curva de la actividad económica del perfil de migración que sale de la capital es más asimétrica que la que corresponde al perfil de inmigración. A esta característica se la refiere como "asimetría en las edades de trabajo".

Si se examinan las tasas observadas de descenso de las curvas de la actividad económica y la de las edades prelaborales, $\alpha_{2}$ y $\alpha_{1}$, de manera respectiva, encontramos que, por ejemplo, están más cercanas a la igualdad con los patrones de emigración de Helsinki y Estocolmo, y resultan sumamente desiguales con los casos de Budapest, Tokio y Amsterdam. En cuatro de los seis perfiles de inmigración a la capital $\alpha_{2}>\alpha_{1}$. Los perfiles que tienen distintos valores, que pueden ser importantes para $\alpha_{2}$ y $\alpha_{1}$, se dice que son irregulares.

En conclusión, la información empírica sobre migración de seis naciones industrializadas sugiere la siguiente hipótesis. El perfil por edad de un patrón típico de migración hacia la capital tiene, en general, mayor dominancia de edades activas y mayor asimetria de edades activas que el perfil por edades del patrón de migración correspondiente que sale de la capital. No puede efectuarse ninguna comparación en esta hipótesis en cuanto a su grado anticipado de irregularidad.

\subsection{Familias de patrones}

En este documento se han definido tres conjuntos de patrones modelo de migración, a saber: el patrón de 11 parámetros con máximo de retiro, el patrón alterno de 9 parámetros con curva de retiro y el patrón simple de 7 parámetros sin máximo ni curva. De esta forma, contamos por lo menos con tres familias de patrones.

En la sección 2 se definen los análisis comparativos de los perfiles de migración por edades de la nación, así como las medidas básicas y variables definidas que sugieren dimensiones adicionales que clasifiquen los patrones en familias. 
Perfiles de MIGRACIÓN POR EDAdES DE EMIGRACióN E INMIGRACIÓN DE LA CAPITAL DE LA REGIÓN
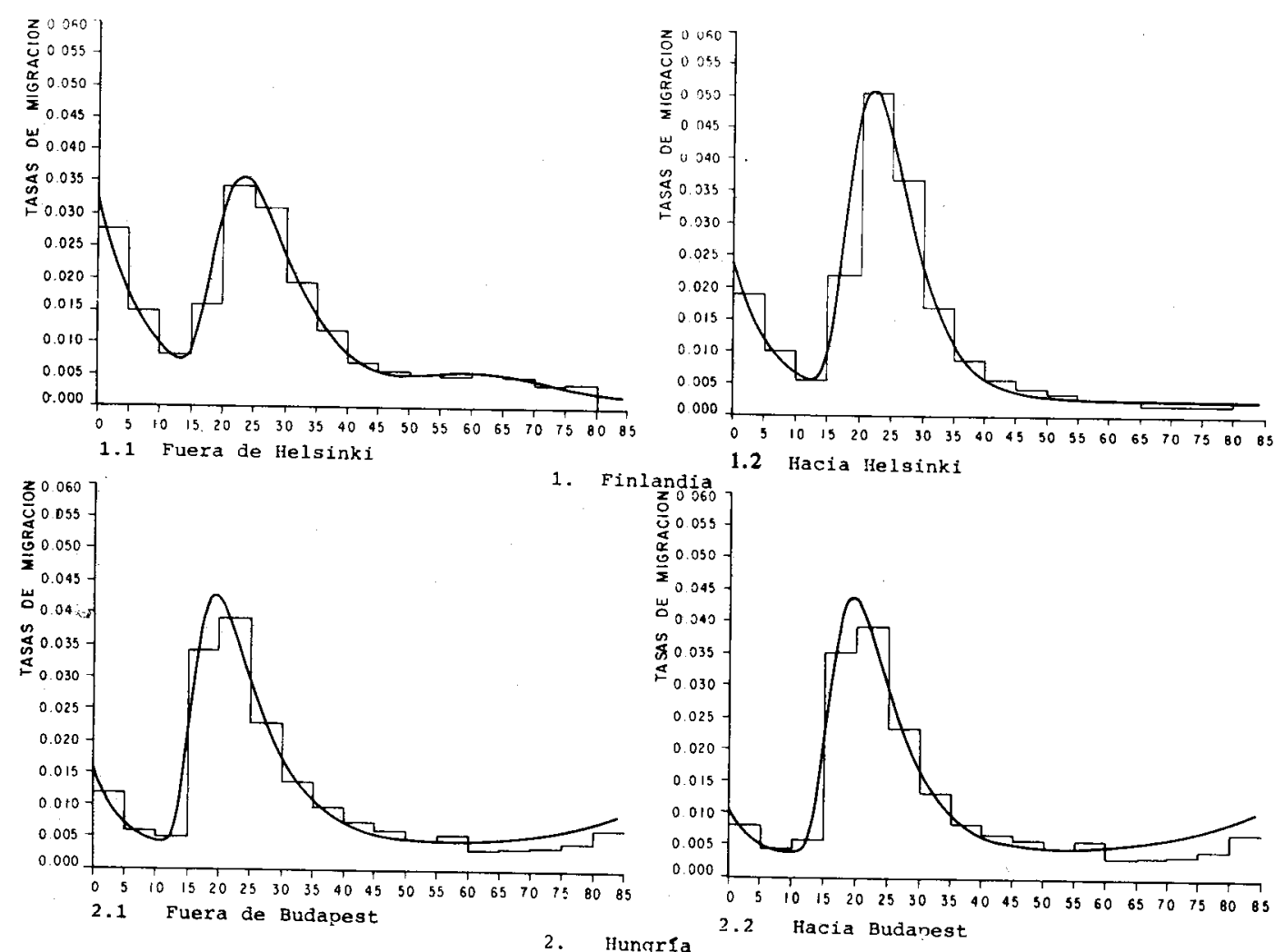

Hungria 
Gráfica 3.1.

PERFILES DE MIGRACIÓN POR EDADES DE EMIGRACIÓN E INMIGRACIÓN DE LA CAPITAL DE LA REGIÓN (CONT.)
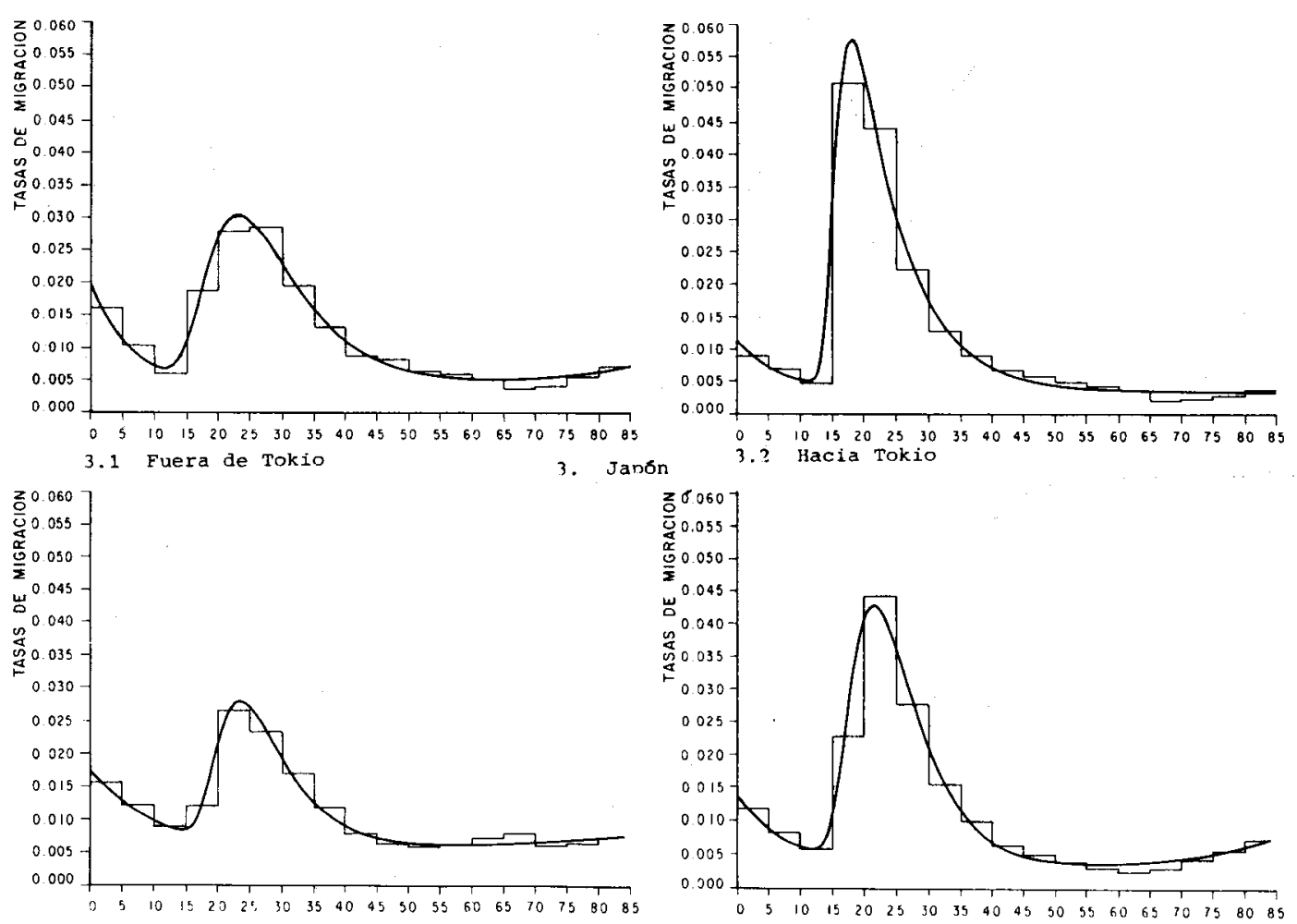

4.1 Fuera de Amsterdam

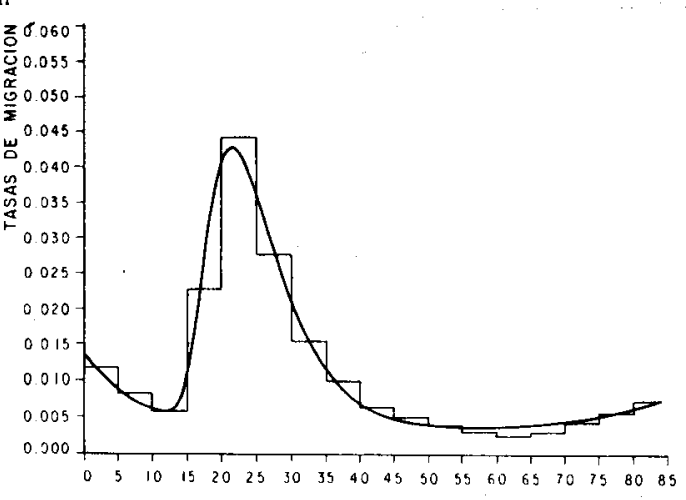

4. Parses Bajos 
Gráfica 3.1.

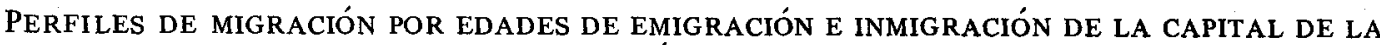
REGIÓN (CONT.)
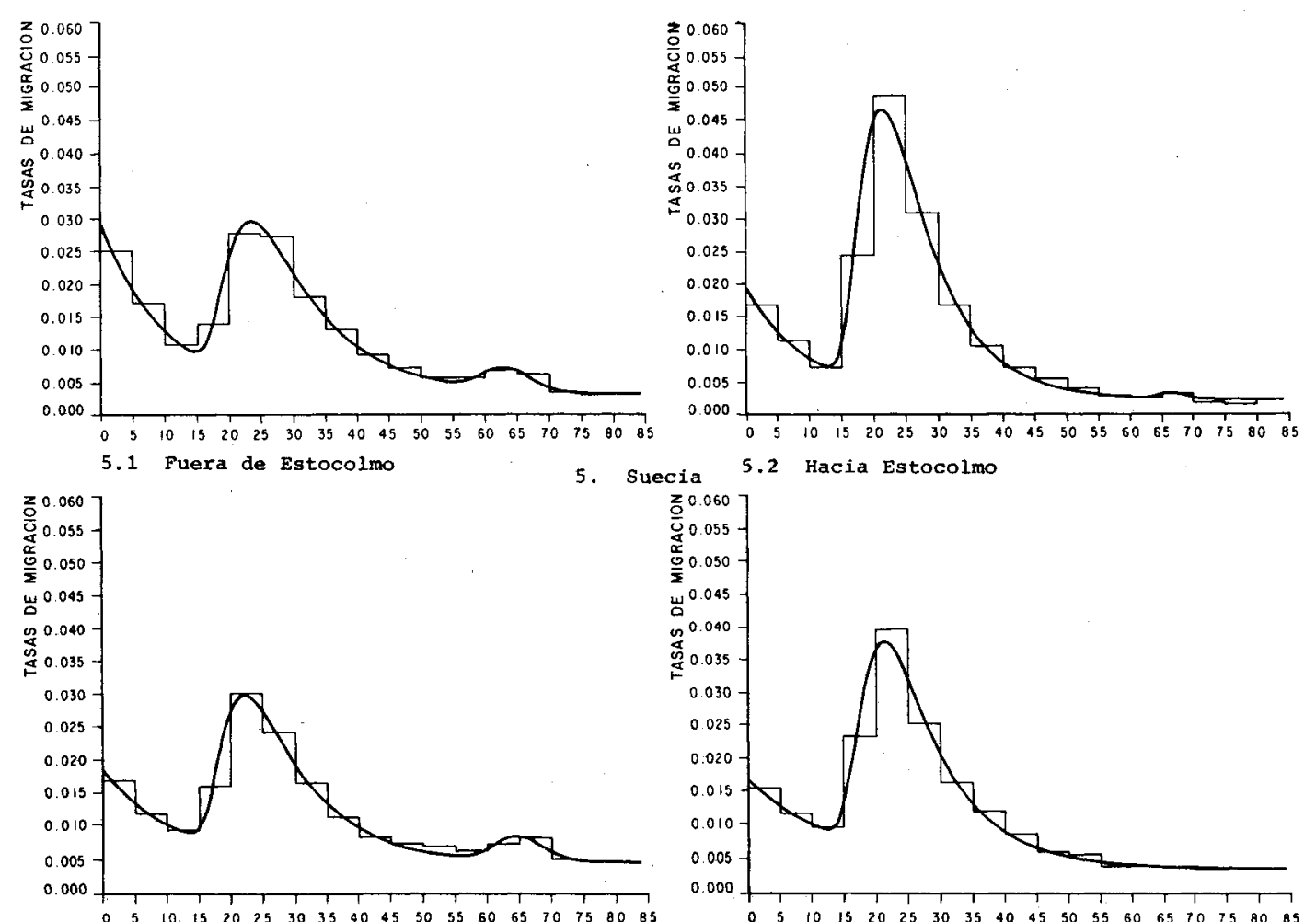

Suecia 5.2 Hacia Estocolmo

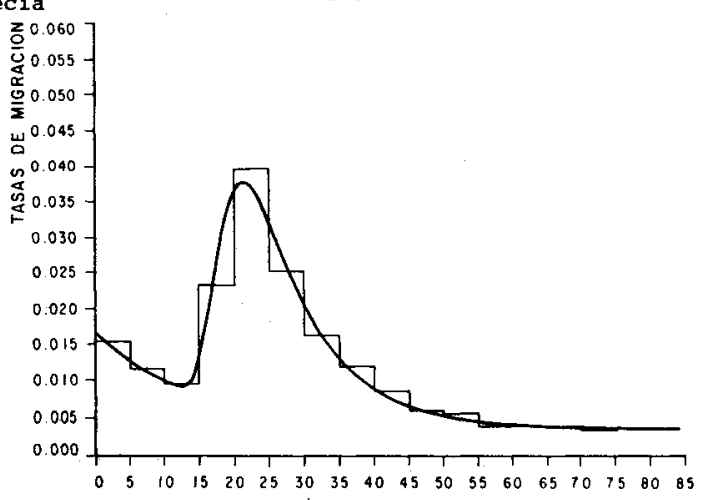

6. Re1no Unido 6.2 Hacia Londres 
Cuadro 3.8 .

PARÁMETROS QUE DEFINEN LOS TOTALES DE LOS PATRONES MODELO DE MIGRACIÓN OBSERVADOS (HOMBRES MÁS MUJERES) POR CORRIENTES DE LA CAPITAL DE LA REGION: FINLANDIA, 1974; HUNGRIA, 1974; JAPÓN, 1970; PAISES BAJOS, 1974; SUECIA, 1974; REINO UNIDO, 1970.

\begin{tabular}{|c|c|c|c|c|c|c|c|c|c|c|c|c|}
\hline \multirow{2}{*}{ Parâmetros } & \multicolumn{2}{|c|}{ Finlandia } & \multicolumn{2}{|c|}{ Hungría } & \multicolumn{2}{|c|}{ Japón } & \multirow{2}{*}{$\frac{\text { Países }}{\begin{array}{c}\text { de } \\
\text { Amsterdam }\end{array}}$} & \multirow{2}{*}{$\frac{\text { Bajos }}{\substack{a \\
\text { Ansterdam }}}$} & \multicolumn{2}{|c|}{ Suecia } & \multicolumn{2}{|c|}{ Reino Unido } \\
\hline & $\begin{array}{c}\mathrm{de} \\
\text { Helsinki }\end{array}$ & $\underset{\text { Helsink } i}{a}$ & $\begin{array}{c}\text { de } \\
\text { Budapest }\end{array}$ & $\begin{array}{c}a \\
\text { Budapest }\end{array}$ & de Tokio & a Tokio & & & $\begin{array}{l}\text { de } \\
\text { Estocolmo }\end{array}$ & $\underset{\text { Estocolmo }}{a}$ & de Londres & a Londres: \\
\hline$a_{1}$ & 0.037 & 0.024 & 0.015 & 0.008 & 0.019 & 0.008 & 0.015 & 0.012 & 0.028 & 0.018 & 0.015 & 0.014 \\
\hline$\alpha_{1}$ & 0.127 & 0.170 & 0.239 & 0.262 & 0.157 & 0.149 & 0.085 & 0.108 & 0.098 & 0.102 & 0.090 & 0.072 \\
\hline$a_{2}$ & 0.081 & 0.130 & 0.082 & 0.094 & 0.064 & 0.096 & 0.050 & 0.093 & 0.046 & 0.093 & 0.048 & 0.067 \\
\hline$\mu_{2}$ & 21.42 & 22.13 & 17.10 & 17.69 & 20.70 & 15.74 & 21.62 & 19.66 & 20.48 & 19.20 & 19.65 & 18.81 \\
\hline$a_{2}$ & 0.124 & 0.198 & 0.130 & 0.152 & 0.111 & 0.134 & 0.141 & 0.150 & 0.095 & 0.134 & 0.111 & 0.123 \\
\hline$\lambda_{2}$ & 0.231 & 0.231 & 0.355 & 0.305 & 0.204 & 0.577 & 0.284 & 0.288 & 0.322 & 0.323 & 0.327 & 0.320 \\
\hline c & 0.000 & 0.003 & 0.003 & 0.003 & 0.003 & 0.002 & 0.002 & 0.003 & 0.003 & 0.002 & 0.005 & 0.004 \\
\hline$a_{3}$ & 0.00027 & & 0.00001 & 0.00005 & 0.00002 & 0.00131 & 0.00229 & 0.00002 & 0.00004 & 0.00003 & 0.00003 & \\
\hline$u_{3}$ & 99.32 & & & & & & & & 80.32 & 73.19 & 81.13 & \\
\hline & & & & & & & & & & & & \\
\hline$\alpha_{3}$ & 0.204 & & 0.072 & 0.059 & 0.061 & 0.000 & 0.012 & 0.066 & 0.616 & 1.359 & 0.676 & \\
\hline$\lambda_{3}$ & 0.042 & & & & & & & & 0.105 & 0.255 & 0.112 & \\
\hline
\end{tabular}


Estas dimensiones reflejan distintas ubicaciones en los ejes horizontales y verticales del patrón, además de distintos cocientes de curvas y alturas.

De los 528 patrones modelo de migración que se estudiaron en esta sección, 416 se refieren a edades específicas $y$, de los mismos, 336 no mostraron ningún máximo ni curva de retiro. En virtud de que las cifras de los parámetros que describen el perfil por edades de la migración en edades poslaborales no son confiables, nuestra investigación se restringirá a familias de patrones de los 164 patrones modelos masculinos y a los 172 femeninos, además del resumen de estadísticas que se muestra en los cuadros 3.9 y 3.10 .

El examen de los valores paramétricos que mostraron los 336 patrones de migración, resumidos en los cuadros 3.9 y 3.10, sugiere que la variación que muestran estos patrones -en una fracción considerable--., es una consecuencia de los cambios en los valores de los siguientes cuatro parámetros y de las variables derivadas: $\mu_{2}, \delta_{12}, \sigma_{2}$ y $\beta_{12}$.

Los patrones de migración pueden tener un máximo temprano o tardío, según la ubicación de $\mu_{2}$ en el eje (por edad) horizontal. A pesar de que este parámetro por lo general acepta un valor cercano a 20,3 de 4 observaciones caen, sin embargo, dentro del rango de 17 a 25 . A los que tienen menos de 19 años, se los nombrará patrones de máximo temprano y los de más de 22 años, natrones de máximo tardio.

El cociente de los dos parámetros verticales básicos, $\mathrm{a}_{1}$ y $\mathrm{a}_{2}$, es la medida de la importancia relativa de la migración de niños en un patrón modelo de migración. El índice de dependencia infantil, $\delta_{12}=a_{1} / a_{2}$, tiende a mostrar un valor medio de aproximadamente un tercio, con el 80 por ciento de los valores que caen dentro de uno y cuatro quintos. Los patrones con un índice de un quinto o menos, se denominarán dominancia de edades activas; los que tienen más de dos quintos, se llamarán dependencia infantil.

Los patrones de migración con componentes de actividad económica que toman la forma de curva en forma de campana relativamente simétrica, se denominarán patrones de asimetria de edades activas. Estos patrones tenderán a mostrar un índice de asimetría de edades activas, $\sigma_{2}=\lambda_{2} / \alpha_{2}$, que es menor de 2 . Los patrones de asimetría de edades activas, por otro lado, en general adoptarán valor para $\sigma_{2}$ de 5 , o más. El patrón promedio de migración tenderá a mostrar un valor $\sigma_{2}$ de cerca de 4 , de los cuales aproximadamente 5 de 6 patrones muestran $\sigma_{2}$ dentro del rango de 1 a 8 .

Para terminar, el índice de regularidad del cambio de parentesco en varios patrones es cercano a la unidad, en el que cerca del 70 por ciento de los valores van de uno a cuatro tercios. Los valores de $\beta_{12}=\alpha_{1} / \alpha_{2}$ que son menores a cuatro quintos, o más elevados de seis quintos, se denominarán irregulares.

Podemos imaginar, así, una clasificación cruzada de patrones de migración de 3 por 4 que definen una docena de "familias promedio". 
Cuadro 3.9

CÁLCULO DE ESTADÍSTICAS RESUMIDAS DE PARÁMETROS Y VARIABLES ASOCIADOS CON CONJUNTOS REDUCIDOS DE PATRONES MODELO DE MIGRACION OBSERVADOS PARA SUECIA, REINO UNIDO Y JAPON: 164 PATRONES MASCULINOS.

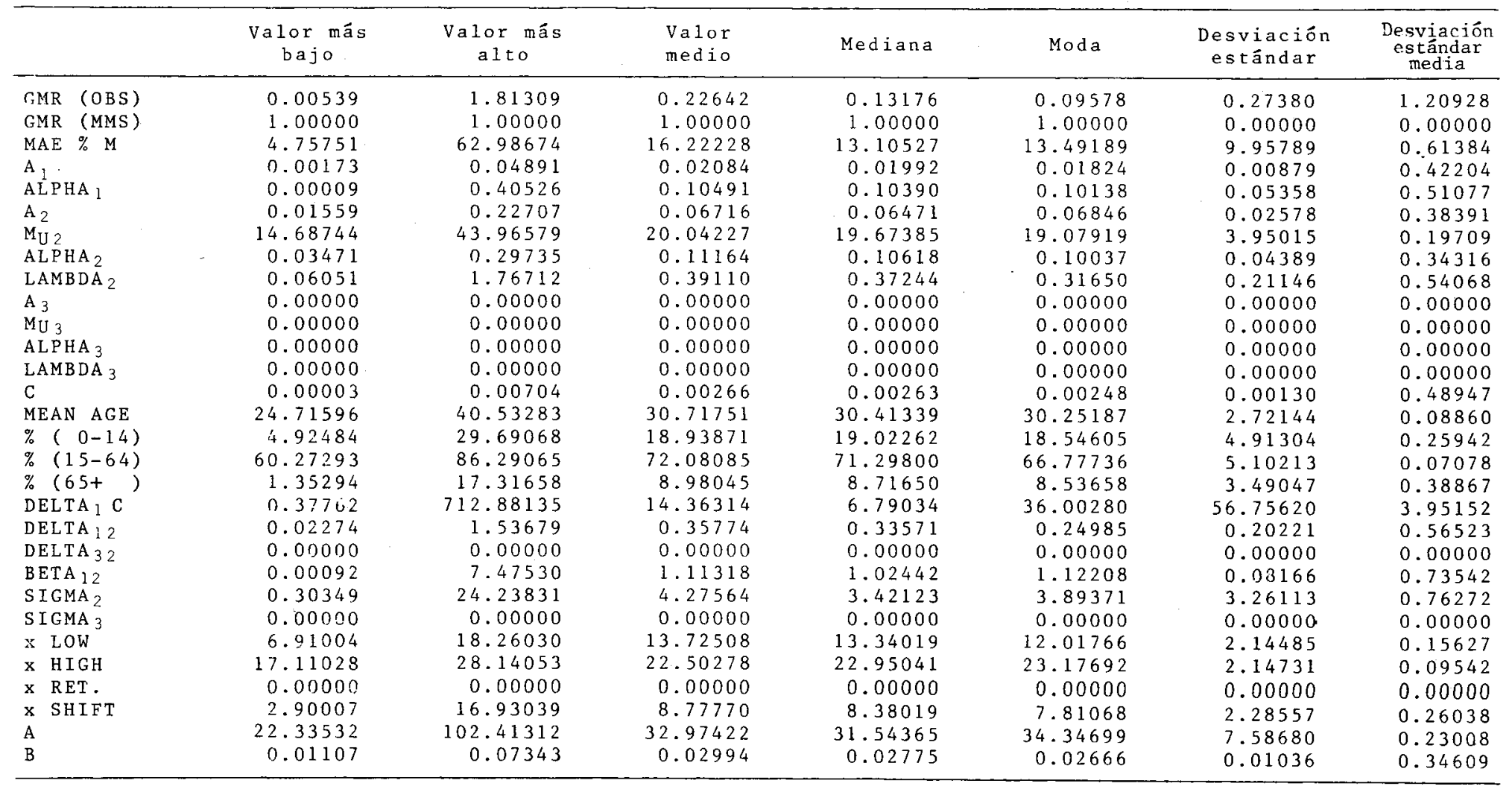


Cuadro 3.10

CÁlCUlo de ESTAdístiCAS RESUMIDAS DE PARÁMETROS Y VARIABLES ASOCIADOS CON CONJUNTOS REDUCIDOS DE PATRONES MODELO DE MIGRACION OBSERVADOS PARA SUECIA, REINO UNIDO Y JAPON: 172 PATRONES FEMENINOS.

\begin{tabular}{|c|c|c|c|c|c|c|c|}
\hline & $\begin{array}{l}\text { Valor más } \\
\text { bajo }\end{array}$ & $\begin{array}{c}\text { Valor más } \\
\text { al to }\end{array}$ & $\begin{array}{l}\text { Valor } \\
\text { medio }\end{array}$ & Mediana & Moda & $\begin{array}{c}\text { Desviación } \\
\text { estândar }\end{array}$ & $\begin{array}{c}\text { Desviación } \\
\text { eständar } \\
\text { media }\end{array}$ \\
\hline GMR (OBS) & 0.00388 & 1.59564 & 0.19909 & 0.11590 & 0.08347 & 0.24085 & 1.20973 \\
\hline GMR (MMS) & 1.00000 & 1.00000 & 1.00000 & 1.00000 & 1.00000 & 0.00000 & 0.00000 \\
\hline $\mathrm{MAE} \% \mathrm{M}$ & 4.17964 & 60.83579 & 15.42092 & 12.26192 & 7.01245 & 9.85544 & 0.63910 \\
\hline & 0.00526 & 0.04496 & 0.02259 & 0.02209 & 0.01916 & 0.00851 & 0.37664 \\
\hline ALPHA & 0.01585 & 0.41038 & 0.10698 & 0.10883 & 0.11448 & 0.05091 & 0.47587 \\
\hline $\mathrm{A}_{2}$ & 0.02207 & 0.18944 & 0.07426 & 0.06935 & 0.06391 & 0.02693 & 0.36263 \\
\hline $\mathrm{MU}_{2}^{2}$ & 15.06610 & 37.76019 & 20.63237 & 19.88280 & 18.47021 & 3.50346 & 0.16980 \\
\hline $\mathrm{ALPHA}_{2}$ & 0.05467 & 0.33556 & 0.14355 & 0.13434 & 0.12489 & 0.04993 & 0.34784 \\
\hline $\mathrm{LAMBDA}_{2}$ & 0.08367 & 1.49869 & 0.40032 & 0.37870 & 0.29592 & 0.19248 & 0.48081 \\
\hline $\mathrm{A}_{3}$ & 0.00000 & 0.00000 & 0.00000 & 0.00000 & 0.00000 & 0.00000 & 0.00000 \\
\hline $\mathrm{MU}_{3}$ & 0.00000 & 0.00000 & 0.00000 & 0.00000 & 0.00000 & 0.00000 & 0.00000 \\
\hline $\mathrm{ALPHA}_{3}$ & 0.00000 & 0.00000 & 0.00000 & 0.00000 & 0.00000 & 0.00000 & 0.00000 \\
\hline $\mathrm{LAMBDA}_{3}$ & 0.00000 & 0.00000 & 0.00000 & 0.00000 & 0.00000 & 0.00000 & 0.00000 \\
\hline $\mathrm{C}$ & 0.00012 & 0.00085 & 0.00347 & 0.00350 & 0.00315 & 0.00139 & 0.39940 \\
\hline MEAN AGE & 24.51402 & 37.86541 & 30.65265 & 30.53835 & 29.18701 & 2.69720 & 0.08799 \\
\hline$\%(0-14)$ & 9.37675 & 31.87480 & 20.93872 & 20.68939 & 19.50087 & 4.26504 & 0.20369 \\
\hline$\%(15-64)$ & 60.55278 & 81.17286 & 68.65491 & 68.07751 & 67.76981 & 4.34828 & 0.06334 \\
\hline$\%(65+)$ & 1.46164 & 19.56255 & 10.40638 & 10.32867 & 9.60705 & 3.40400 & 0.32711 \\
\hline $\mathrm{DELTA}_{3} \mathrm{C}$ & 0.89359 & 192.60318 & 9.39987 & 5.95881 & 10.47907 & 16.22441 & 1.72602 \\
\hline DELTA 12 & 0.02828 & 0.90435 & 0.34847 & 0.32367 & 0.33490 & 0.17420 & 0.49989 \\
\hline $\operatorname{DELTA}_{32}$ & 0.00000 & 0.00000 & 0.00000 & 0.00000 & 0.00000 & 0.00000 & 0.00000 \\
\hline $\mathrm{BETA}_{12}$ & 0.09121 & 2.48385 & 0.81472 & 0.84944 & 0.92863 & 0.37720 & 0.46298 \\
\hline $\mathrm{SIGMA}_{2}$ & 0.38917 & 12.23371 & 3.26434 & 2.89784 & 2.16585 & 2.12718 & 0.65164 \\
\hline $\operatorname{SIGMA}_{3}$ & 0.00000 & 0.00000 & 0.00000 & 0.00000 & 0.00000 & 0.00000 & 0.00000 \\
\hline$x$ LOW & 10.32012 & 21.79038 & 14.51330 & 14.75022 & 14.33471 & 1.95309 & 0.13457 \\
\hline $\mathrm{XHIG}$ & 17.03028 & 30.92059 & 22.49959 & 22.46040 & 21.89189 & 2. 14262 & 0.09523 \\
\hline & 0.00000 & 0.00000 & 0.00000 & 0.00000 & 0.00000 & 0.00000 & 0.00000 \\
\hline $\mathrm{X}$ SHIFT & 2.89007 & 15.09035 & 7.98629 & 7.61017 & 7.16017 & 2.11207 & 0.26446 \\
\hline A & 23.73040 & 37.24700 & 28.50972 & 28.17807 & 27.10955 & 2.47098 & 0.08667 \\
\hline B & 0.00831 & 0.09111 & 0.03118 & 0.02970 & 0.02901 & 0.01149 & 0.36845 \\
\hline
\end{tabular}




\begin{tabular}{l|c|c|c|c}
\hline \multicolumn{1}{l|}{ Medida } & Máximo & Dominancia & Simetría & Regularidad \\
\cline { 2 - 5 } Patrón & $\mu_{2}=20$ & $\delta_{12}=1 / 3$ & $\sigma_{2}=4$ & $\beta_{12}=1$ \\
\hline $\begin{array}{l}\text { Máximo de } \\
\text { retiro }\end{array}$ & + & + & + & + \\
$\begin{array}{l}\text { Curva de } \\
\text { retiro }\end{array}$ & + & + & + & + \\
Forma reducida & + & + & + & + \\
\hline
\end{tabular}

Si se introduce un valor bajo y uno elevado para cada uno de los parámetros, se origina un aumento a 16 familias adicionales por cada una de las tres clases de patrones. Por lo tanto, puede concebirse un conjunto mínimo de 60 familias, divididas de igual manera entre los patrones con máximo de retiro, con los que tienen curva de retiro y con los que no tienen máximo ni curva de retiro.

En la gráfica $3.2 \mathrm{~A}$ se presentan seis perfiles de dominancia de edades activas con el objeto de complementar la discusión anterior con algunas ilustraciones, con $\delta_{1 \mathrm{c}}$ fijo en 22. Los tres más altos muestran una tasa decreciente de descenso $\alpha_{2}=.3$; los tres más cortos muestran una curva mucho más moderada de $\alpha_{2}=.06$. Dentro de cada familia de tres curvas, se encuentran variaciones en $\mu_{2}$ y en la tasa de ascenso $\lambda_{2}$. Si se aumenta el último, la curva cambia hacia la derecha junto con el eje horizontal; si se aumenta el último parámetro entonces crece la altura relativa del máximo.

Los seis parámetros de la gráfica 3.2B describen las dos familias correspondientes de perfiles de dependencia infantil. Por lo general, los resultados son similares a los de la gráfica $3.2 \mathrm{~A}$, con excepción de que la importancia relativa de la migración en grupos de edad poslaboral aumenta de manera considerable. Los efectos más importantes del cambio en $\delta_{12}$, son: (1) un aumento de la intersección $a_{1}+c$ junto con los ejes verticales y (2) una reducción simultánea en la altura del componente de la actividad económica para así mantener un área de unidad constante bajo cada curva.

Para terminar, la docena de patrones en las gráficas 3.2C y 3.2D describen familias de curvas de migración similares; sin embargo, la contribución del componente constante a la unidad твм en estos perfiles, aumenta de manera significativa (i. e., $\delta_{1 \mathrm{c}}=2.6$ ). Es importante hacer notar que tales medidas "puras" del perfil como $\mathrm{x}_{\ell}, \mathrm{x}_{\mathrm{h}}, \mathrm{x}$ y A no se afectan con este cambio, mientras que las medidas "impuras" del perfil, como la edad media de migración, $\bar{n}$, muestran un conjunto diferente de valores.

\subsection{Análisis de sensitividad}

Las subsecciones anteriores se han focalizado en la comparación de los parámetros fundamentales que definen el modelo de migración por perfil de edades en un cierto número de naciones. Tal comparación produjo rangos de valores dentro de 
Gráfica 3.2.

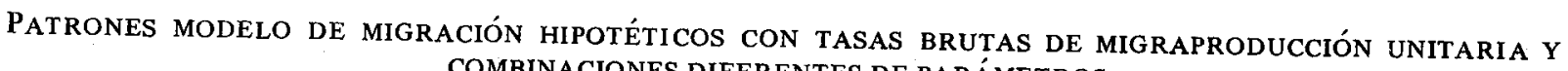

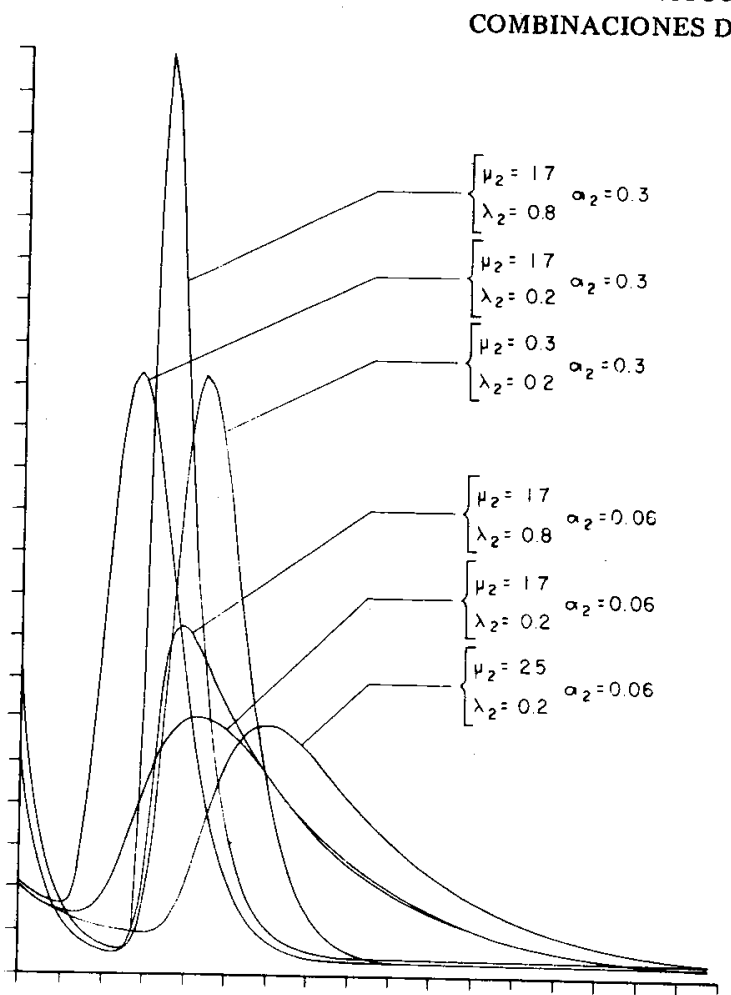

A. Patrón de dominancia de edades activas con $\delta_{16}=22.0$ y $\delta_{12}=0.2$

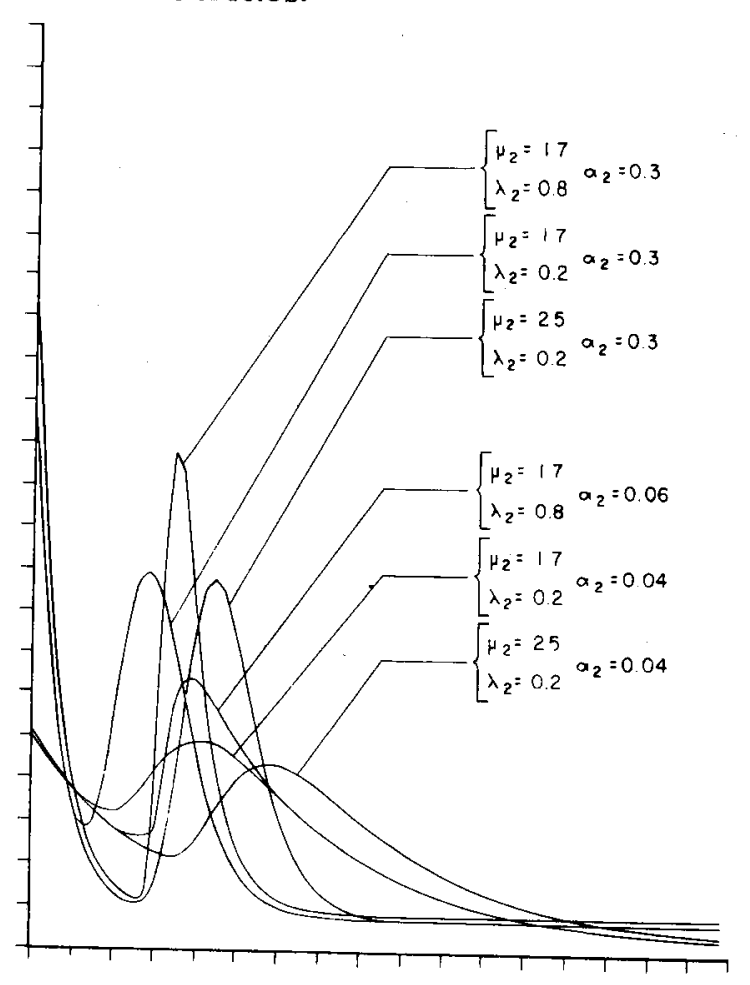

B. Patrones de dependencia infant1l con $\delta_{10}=22.0$ y $\delta_{12}=0.8$ 
PATRONES MODELO DE MIGRACIÓN HIPOTÉTICOS CON TASAS BRUTAS DE MIGRAPRODUCCIÓN UNITARIA Y COMBINACIONES DIFERENTES DE PARÁMETROS (CONT.)

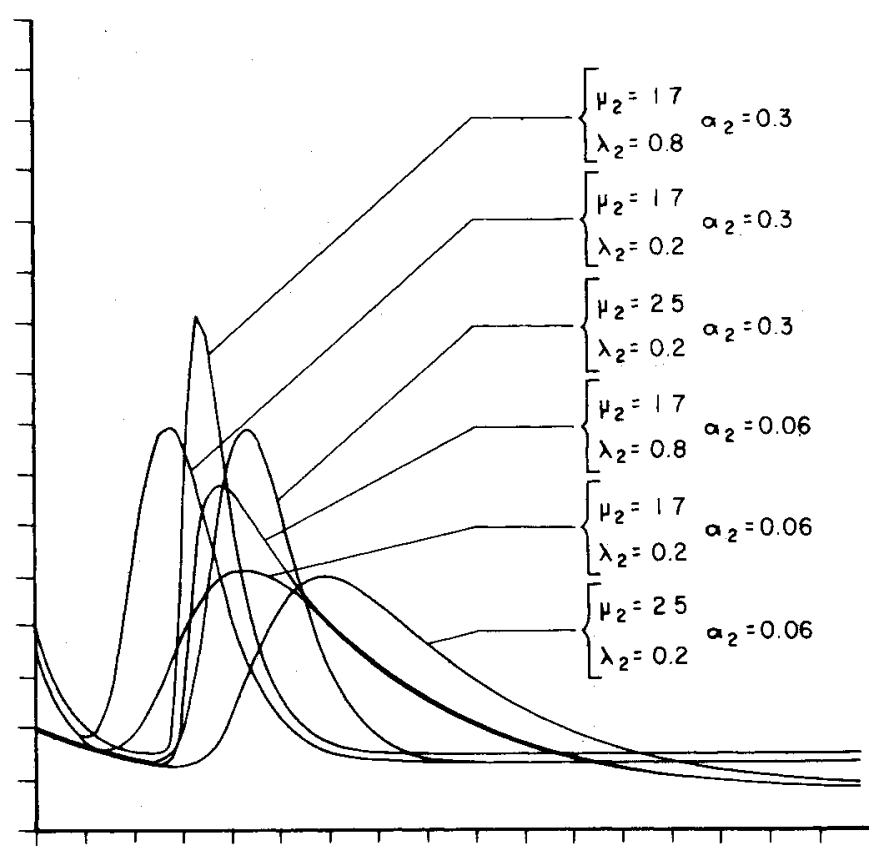

C. Patrón de dominancia de edades activas con $\delta_{1 \mathrm{c}}=2.6$ y $\delta_{12}=0.2$

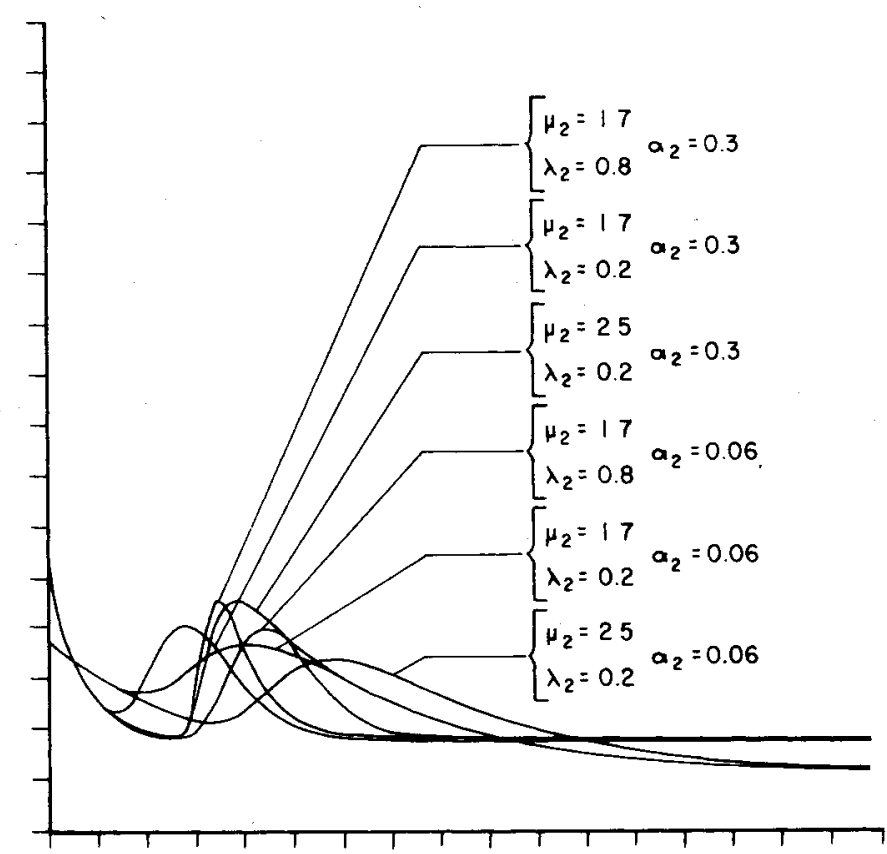

D. Patrones de dependencia infantil con $\delta_{1 \mathrm{c}}=2.6$ y $\delta_{12}=0.8$ 
los cuales puede esperarse que cada parámetro caiga, y sugiera una clasificación de patrones en familias. Ahora nos dirigiremos al examen analítico de la forma en que se manifiestan los cambios en algunos de los parámetros más importantes en los perfiles por edades del patrón modelo. Por razones de conveniencia analítica, empezaremos por enfocar las propiedades de la doble curva exponencial que describe el componente de la actividad económica:

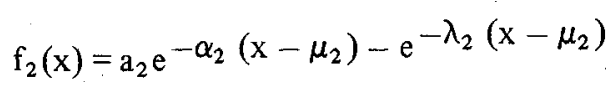

Se observa de principio que si $\alpha_{2}$ es un conjunto igual a $\lambda_{2}$ en la expresión anterior, entonces el componente de la actividad económica adopta la forma de una bien conocida distribución que se ha utilizado en el estudio de los flujos sanguíneos (Gumbel, 1941; Kimball, 1946). En tal caso, $\mathrm{x}_{\mathrm{h}}=\mu_{2}$ y la función $\mathrm{f}_{2}(\mathrm{x})$ alcanza su máximo, $y_{h}$, en tal punto. Si se analiza el caso más general donde $\alpha_{2} \neq \lambda_{2}$, se pueden derivar expresiones analíticas para ambas variables al diferenciar la ecuación (4) de $x$, colocando el resultado igual a cero, $y$ después efectuando la solución para así llegar a

$$
x_{h}=\mu_{2}-\frac{1}{\lambda_{2}} \ln \left(\frac{\alpha_{2}}{\lambda_{2}}\right)
$$

una expresión que no incluye $a_{2}, y$

$$
y_{h}=a_{2}\left(\frac{\alpha_{2}}{\lambda_{2}}\right)^{\frac{\alpha_{2}}{\lambda_{2}}} e^{-\frac{\alpha_{2}}{\lambda_{2}}}
$$

una expresión que no incluye $\mu_{2}$.

Nótese que si $\lambda_{2}>\alpha_{2}$, casi siempre el caso, entonces se llega a $x_{h}>\mu_{2}$. También, obsérvese que si $\alpha_{2}=\lambda_{2}$, entonces las dos ecuaciones anteriores se simplifican en

$$
\begin{aligned}
& \mathrm{x}_{\mathrm{h}}=\mu_{2} \\
& \mathrm{y}_{\mathrm{h}}=\frac{\mathrm{a}_{2}}{\mathrm{e}}
\end{aligned}
$$

En virtud de que $\mu_{2}$ exclusivamente afecta $x_{h}$ como una sustitución, nos podemos concentrar en la variación de $x_{h}$ como una función de $\alpha_{2}$ y $\lambda_{2}$. Si se elabora una gráfica de $x_{h}$ contra $\alpha_{2}$, para $\lambda_{2}$ fija, muestra que incrementos en $\alpha_{2}$ llevan a decrementos en $x_{\mathrm{h}}$. De manera análoga, el aumento en $\lambda_{2}$, para $\alpha_{2}$, fija, producen incremento en $x_{h}$, pero con una tasa que desciende rápidamente en la medida en que la última variable se aproxima a su asíntota.

El comportamiento de $y_{h}$ es independiente de $\mu_{2}$ y varía de manera proporcional con $a_{2}$. De ahí que su variación también depende fundamentalmente de las dos variables $\alpha_{2}$ y $\lambda_{2}$. Si se elabora una gráfica de $y_{h}$ contra $\alpha_{2}$, para un $\lambda_{2}$ 
fijo, se observa un aumento en una curva con forma de $U$ que alcanza su mínimo en $\alpha_{2}=\lambda_{2}$. Si se aumenta $\lambda_{2}$ se amplía la forma de la $U$.

Si se examina la tasa de cambio proporcional de la función $f_{2}(x)$, se puede valorar la influencia de $\alpha_{2}$ y $\lambda_{2}$ en el componente de la actividad económica.

$$
\frac{f_{2}^{\prime}(x)}{f_{2}(x)}=-\alpha_{2}+\lambda_{2} e^{-\lambda_{2}\left(x-\mu_{2}\right)}
$$

La ecuación (7) define esta tasa de cambio como la suma de dos componentes: $-\alpha_{2}$ y la exponencial $\lambda_{2} e^{-} \lambda_{2}\left(x-\mu_{2}\right)$. Para demostrar la forma en que están relacionadas las tasas reales de ascenso y descenso a $\lambda_{2}$ y $\alpha_{2}$, podemos tomar, por ejemplo, un conjunto típico de valores de parámetros tales como $\alpha_{2}=0.1$, $\lambda_{2}=0.4$, y $\mu_{2}=20$, para entonces proceder a efectuar el cálculo de las cantidades presentadas en el cuadro 3.11. Estos cálculos indican que en edades menores a 16, la tasa real de descenso es casi idéntica a menos $\alpha_{2}$. La tasa real de ascenso es muy distinta del valor de $\lambda_{2}$, excepto para edades cercanas a $\mathrm{x}=\mu_{2}$.

$\mathrm{La}$ introducción del componente de la actividad económica al perfil, por lo general moviliza $x_{h}$ a una edad ligeramente más joven y aumenta $y_{h}$ en cerca de $\mathrm{a}_{1} \mathrm{e}^{-} \alpha_{1} \mathrm{x}_{\mathrm{h}}$, por lo general una cifra insignificante. Desde luego que el aumento de término constante $c$, afecta exclusivamente $y_{h}$, aumentándolo por la cifra de la constante. Así la tasa de migración en la edad $\mathrm{x}_{\mathrm{h}}$ puede expresarse como

$$
M\left(x_{h}\right) \doteqdot a_{1} e^{-\alpha_{1} x_{h}+Y_{h}+c .}
$$

El contorno del parentesco, A, es la variable que interrelaciona los componentes de la edad prelaboral y de la actividad económica. Con el objeto de simplificar nuestro análisis de su posible dependencia de los parámetros fundamentales, es conveniente suponer que $\alpha_{1}$ y $\alpha_{2}$, son aproximadamente iguales. En tales circunstancias, para edades inmediatas posteriores al máximo $\mathrm{x}_{\mathrm{h}}$, la componente de la actividad económica del patrón modelo de migración, se puede aproximar bastante por la función

$$
\mathrm{a}_{2} \mathrm{e}^{-\alpha_{2}\left(\mathrm{x}_{2}-\mu_{2}\right)}
$$

Recordemos que la curva de las edades prelaborales está dada por

$$
\mathrm{a}_{1} \mathrm{e}^{-\alpha_{2} \mathrm{x}_{1}}
$$

cuando $\alpha_{1}=\alpha_{2}$, por lo que podemos igualar las dos funciones para resolver la diferencia en edades que se ha denominado cambio de parentesco:

$$
\mathrm{A}=\mathrm{X}_{2}-\mathrm{X}_{1}=\mu_{2}+\frac{1}{\alpha_{2}} \ln \frac{1}{\delta_{12}}
$$

7 Estamos agradecidos de la sugerencia efectuada por Kao Lee Liaw en el sentido de examinar la ecuación (7), y por señalar que los parámetros $\lambda_{2}$ y $\alpha_{2}$ en realidad no son tasas de ascenso y descenso, respectivamente. 
Cuadro 3.11

IMPACTU DE $\lambda_{2} \quad \mathrm{Y} \mathrm{a}_{2}$. EN LAS TASAS REALES DE ASCENSO Y DESCENSO DEL COMPONENTE DE LA ACTIVIDAD ECONÓMICA: $\lambda_{2}=0.4, \alpha_{2}=0.1, \mathrm{Y} \mu_{2}=20$

\begin{tabular}{|c|c|c|c|c|}
\hline & Edad & rasas $r$ & reales de ascenso & $y$ descenso \\
\hline & $x$ & $g(x)=\lambda_{2}$ & $e^{-\lambda_{2}\left(x-\mu_{2}\right)}$ & $-\alpha_{2}+g(x)$ \\
\hline \multirow{4}{*}{$\begin{array}{l}\text { En este rango puede } \\
\text { ignorarse el impacto } \\
\text { de } \mathbf{a}_{2} \text {. }\end{array}$} & 0 & & 1192 & 1192 \\
\hline & 5 & & 161 & 161 \\
\hline & 10 & & 22 & 22 \\
\hline & 15 & & 3 & 3 \\
\hline \multirow{8}{*}{$x=u_{2}$} & 16 & & 1.98 & 1.88 \\
\hline & 17 & & 1.33 & 1.23 \\
\hline & 18 & & 0.89 & 0.79 \\
\hline & 19 & & 0.60 & 0.50 \\
\hline & 20 & & 0.40 & 0.30 \\
\hline & 21 & & 0.27 & 0.17 \\
\hline & 22 & & 0.18 & 0.08 \\
\hline & 23 & & 0.12 & 0.02 \\
\hline \multirow[t]{3}{*}{$x_{\max }$} & 24 & & 0.08 & -0.02 \\
\hline & 25 & & 0.05 & -0.05 \\
\hline & 30 & & 0.007 & -0.093 \\
\hline $\begin{array}{l}\text { En este rango puede } \\
\text { ignorarse ell impacto } \\
\text { de } \lambda_{2} \text {. }\end{array}$ & 35 & & 0.001 & $\begin{array}{l}-0.100 \\
\ldots \ldots\end{array}$ \\
\hline
\end{tabular}

Esta ecuación muestra que el cambio de parentesco aumentará con los valores en ascenso de $\mu_{2}, y$ descenderá con los valores en ascenso de $\alpha_{2}$ y $\delta_{12}$. El cuadro 3.12 muestra la comparación de este cambio de los valores del parentesco definido como "teórico", de manera analítica, con los cambios de parentesco observados - presentados en el cuadro 2.1 - para hombres y mujeres de Suecia. Las dos definiciones parecen producir valores numéricos similares; sin embargo, la definición analítica tiene la ventaja de ser más simple en su cálculo y análisis.

Considérese el perfil por edades de la migración rural-urbana definida por los parámetros del cuadro 3.13. En este perfil, los valores de $\alpha_{2}$ y $\lambda_{2}$ son casi iguales, derivándose una ilustración conveniente de algunos puntos surgidos en nuestra discusión.

Primero, si se calcula $x_{h}$ con la ecuación (5), resulta

$$
x_{h}=21.10-\frac{1}{.270} \ln \left(\frac{.237}{.270}\right)=21.58
$$

contra $x_{h}=21.59$ presentado en el cuadro 3.13. Si se deriva $y_{h}$ con la ecuación (6), resulta

$$
Y_{h}=0.187(0.878)^{0.878} e^{-0.878}=0.069
$$


Cuadro 3.12

VALORES OBSERVADOS Y TEORICOS DEL CAMBIO DE PARENTESCO: REGIONES DE SUECIA, 1974

\begin{tabular}{|c|c|c|c|c|c|c|c|c|}
\hline \multirow[b]{2}{*}{$\begin{array}{l}\text { Cambio de } \\
\text { parentesco }\end{array}$} & \multicolumn{8}{|c|}{ Regiones de Suecia } \\
\hline & $\begin{array}{c}1 \\
\text { Estocolmo }\end{array}$ & $\begin{array}{c}2 \\
\text { Suecia } \\
\text { meridional }\end{array}$ & $\begin{array}{c}3 \\
\text { Sureste }\end{array}$ & $\begin{array}{c}4 \\
\text { Sur }\end{array}$ & $\begin{array}{c}5 \\
\text { Oriente }\end{array}$ & $\begin{array}{c}6 \\
\text { Suecia } \\
\text { nororiental }\end{array}$ & $\begin{array}{c}7 \\
\text { Bajo } \\
\text { norte }\end{array}$ & $\begin{array}{c}8 \\
\text { Alto } \\
\text { norte }\end{array}$ \\
\hline Observado, ${ }^{a}$ hombres & 27.87 & 29.86 & 29.91 & 29.89 & 29.57 & 29.92 & 30.15 & 31.61 \\
\hline Teórico, ${ }^{b}$ hombres & 25.14 & 29.24 & 30.01 & 29.65 & 28.97 & 29.43 & 26.61 & 29.89 \\
\hline Observado, ${ }^{a}$ mujeres & 25.47 & 27.21 & 27.26 & 27.87 & 27.42 & 27.09 & 26.94 & 28.36 \\
\hline Teбrico, $b$ mujeres & 24.68 & 26.85 & 28.16 & 28.91 & 27.51 & 28.54 & 28.19 & 28.95 \\
\hline
\end{tabular}

a) Fuente: Cuadro 2.1

b) Fuente: Rogers, Raquillet y Castro (1978, p. 497). 
donde $\alpha_{2} / \lambda_{2}=0.237 / 0.270=0.878$. Asi, $\mathrm{M}(21.59)$ es casi igual a $\mathrm{y}_{\mathrm{b}}+\mathrm{c}=$ $0.069+0.004=0.073$. El valor dado de la ecuación del patrón modelo de migración, también es 0.073 .

Dado que $\alpha_{1} \neq \alpha_{2}$, no se puede comprobar de manera adecuada la veracidad de la ecuación (8) como un estimador de A. Sin embargo, puede utilizarse para explicar el valor tan enorme del cambio de parentesco. Si se sustituyen los valores para $\mu_{2}, \alpha_{2}$ y $\delta_{12}$ en la ecuación (8), encontramos:

$$
\begin{aligned}
A & =21.10+\frac{1}{.237} \ln \left(\frac{1}{.011}\right) \\
& =21.10+\frac{4.51}{.237}=40.13
\end{aligned}
$$

Aun cuando éste es una subestimación de 45.13 , sugiere que la causa principal del elevado valor de A es el valor excesivamente bajo de $\delta_{12}$. Si este último parámetro encuentra el valor para los hombres en Estocolmo, por ejemplo, el cambio de parentesco puede mostrar el valor extremadamente bajo de 22.52 .

\section{Patrones modelo de migración estimados}

Un patrón modelo estimado es la colección de tasas específicas por edad que se deriva de patrones observados en varias poblaciones, diferentes al estudio, $y$ algunos datos incompletos de este último. La justificación de tal aproximación es que los perfiles por edad de fecundidad, mortalidad y movilidad geográfica varían dentro de límites predeterminados para la mayoría de las poblaciones humanas. Las tasas de natalidad, mortalidad y migración para un grupo de edad, están altamente correlacionadas con las tasas correspondientes para otros grupos de edades. Las expresiones de tales interrelaciones conforman las bases de la construcción del patrón modelo. Un área que ha recibido gran atención por parte de la investigación demográfica contemporánea es el uso de estas regularidades con el fin de estructurar patrones hipotéticos que se consideren aproximaciones cercanas a los patrones no observados de poblaciones que no cuentan con registros estadísticos veraces sobre su movilidad.

\subsection{Introducción: perspectivas alternas}

Los esfuerzos más recientes en el desarrollo de los patrones modelo se basaron exclusivamente en un parámetro, de ahí que tengan muy poca flexibilidad (Naciones Unidas, 1955). Los demógrafos no tardaron mucho en descubrir que las variaciones en los regimenes de mortalidad y fecundidad de distintas poblaciones necesitan formulaciones un poco más complejas. En los estudios sobre mortalidad se introdujo una mayor flexibilidad cuando se proporcionaron familias de patrones (Coale y Demeny, 1966), o se aumentó el número de parámetros utilizados para describir el patrón por edades (Brass, 1975). Esta última estrategia también se adoptó en la formulación de patrones modelo mejorados de fecundi- 
Cuadro 3.13

PARÁMETROS Y VARIABLES QUE DE FINEN LOS PATRONES MODELO OBSERVADOS DE MIGRACIÓN URBANO-RURAL PARA FLUJOS URBANO-RURALES: URSS, 1974

\begin{tabular}{|c|c|c|}
\hline \multirow{2}{*}{$\begin{array}{l}\text { Variables Y } \\
\text { parámetros }\end{array}$} & \multicolumn{2}{|c|}{ Total (hombres mas mujeres) } \\
\hline & Urbano-mural & Rural-urbana \\
\hline GMR & 0.74 & 3.41 \\
\hline$a_{1}$ & 0.005 & 0.002 \\
\hline$\alpha_{1}$ & 0.313 & 0.431 \\
\hline$a_{2}$ & 0.127 & 0.187 \\
\hline$\mu_{2}$ & 19.26 & 21.1 .0 \\
\hline$\alpha_{2}$ & 0.177 & 0.237 \\
\hline$\lambda_{2}$ & 0.286 & 0.270 \\
\hline C & 0.005 & 0.004 \\
\hline$\overline{\mathrm{n}}$ & 33.66 & 31.24 \\
\hline $8(0-14)$ & 8.63 & 5.59 \\
\hline$\frac{\circ}{6}(15-64)$ & 78.30 & 84.60 \\
\hline$q(65+)$ & 13.07 & 9.81 \\
\hline$\delta_{1}$ & 0.977 & 0.548 \\
\hline$\delta_{12}$ & 0.038 & 0.011 \\
\hline$\beta_{12}$ & 1.77 & 1.82 \\
\hline$c_{2}$ & 1.61 & 1.14 \\
\hline$x_{i}$ & 11.09 & 11.38 \\
\hline $\mathrm{x}_{\mathrm{h}}$ & 20.94 & 21.59 \\
\hline$x$ & 9.85 & 10.21 \\
\hline$A$ & 42.30 & 45.13 \\
\hline B & 0.045 & 0.063 \\
\hline
\end{tabular}


dad, aumentados a causa de las descripciones analíticas de los perfiles por edades (Coale y Trussell, 1974).

En virtud de que los patrones de migración por edades por lo general muestran un grado de variabilidad más elevado por regiones que los de mortalidad y fecundidad, también se espera que el desarrollo de un conjunto adecuado de patrones modelo de migración requerirá un número mayor de familias y de parámetros. Tres parámetros han sido los que han recibido mayor diseminación y han obtenido mayor popularidad, aun cuando podría trazarse un buen número de métodos alternos para resumir las regularidades en la forma de familias de patrones modelo definidas por algunos de ellos:

1. El enfoque de regresión de las tablas modelo de mortalidad de Coale-Demeny (Coale y Demeny, 1966);

2. el sistema logito de Brass (Brass, 1971), y

3. la graduación doble exponencial de Coale, McNeil y Trussell. (Coale, 1977; Coale y McNeil, 1972; y Coale y Trussell, 1974).

El enfoque de regresión incorpora una perspectiva correlacional que asocia las tasas por edades distintas a un índice de nivel, en donde las asociaciones particulares pueden diferir de una "familia" de patrones a otra. Por ejemplo, en el modelo de las tablas de mortalidad de Coale-Demeny, el indice de nivel es la esperanza de vida restante a los 10 años de edad, y se establece un conjunto de ecuaciones de regresión para cada una de las cuatro "regiones" de mundo.

El sistema logito de Brass refleja la perspectiva relacional en el que las tasas en edades distintas son dadas por un patrón estándar cuya forma y nivel es susceptible de modificación para adecuarse a una población en particular.

Los patrones modelo de fecundidad de Coale-Trussell son relacionales en perspectiva (utilizan un patrón estándar sueco de primeros matrimonios), pero también introducen una descripción analítica del perfil por edad al adoptar una curva doble exponencial que define la forma de la función de primeros matrimonios por edad específica.

En este estudio se mezclan los tres enfoques anteriores con el objeto de definir dos perspectivas alternas para calcular los patrones modelo de migración en situaciones donde se dispone exclusivamente de información defectuosa o inadecuada en los flujos de migración interna (origen-destino). Ambas perspectivas dependen de la graduación analítica (exponenciales dobles más sencillas) definidas por el patrón modelo básico, de migración presentado en Rogers, Raquillet y Castro (1978). En última instancia, ambas dependen de la disponibilidad de información limitada para obtener un patrón modelo apropiado, por ejemplo, al menos dos tasas específicas por edades, tales como $M(0-4)$ y M(20-24), y supuestos formados en relación a los valores de algunas variables clave, tales como los puntos bajo y elevado del patrón. Difieren exclusivamente en el método por el cual se identifica un patrón como apropiado para una población en particular.

La primera perspectiva -el enfoque de regresión- asocia las variaciones en los parámetros y yariables derivadas del patrón modelo a cualquier otro y, después, a

8 Cada una de las cuatro regiones (norte, sur, este y oeste), define una colección de patrones similares de mortalidad, que son más uniformes en los patrones que en la totalidad de las tablas de mortalidad observadas. 
las tasas de migración especificas por edades. El segundo -el enfoque de logitoabarca distintas relaciones entre los parámetros del patrón modelo en algunos patrones estándares $y$, después, asocia los logitos de las tasas de migración en el estándar o los de la población en cuestión.

\subsection{La perspectiva correlacional: el sistema de migración de regresión}

Una manera directa de obtener un patrón modelo sintético de migración que provenga de una información limitada, consiste en asociar tal información con los parámetros del patrón modelo básico por medio de ecuaciones de regresión. Por ejemplo, en algunas cifras dadas de tasas de migración de niños pequeños y adultos jóvenes, $M(0-4)$ y $M(20-24)$, podemos utilizar, por ejemplo, ecuaciones de la forma

$$
Q_{i}=b_{0}[M(0-4)]^{b_{1}}[M(20-24)]^{b_{2}}
$$

para calcular el conjunto de parámetros $\mathrm{Q}_{\mathbf{i}}$ que define el patrón modelo. Los parámetros del patrón modelo ajustado no son, sin embargo, independientes uno del otro. Por ejemplo, si los valores promedio de $\lambda_{2}$ son más elevados, éstos tienden a asociarse con el valor promedio más bajo de $\mathrm{a}_{1}$. Si se incorporan tales dependencias al enfoque de regresión seguramente aumentaría la veracidad y consistencia del procedimiento de cálculo. Como primer paso, es necesario un examen de las asociaciones empíricas entre los parámetros y variables del patrón modelo.

Las regularidades en las covariaciones de los parámetros del patrón modelo sugieren una estrategia para constituir un patrón modelo que abarque las ecuaciones de regresión que incluya estas covariaciones. Por ejemplo, después de contar con valores dados para $\delta_{12}, \mathrm{x}_{\ell}$ y $\mathrm{x}_{\mathrm{h}}$, se puede proceder a derivar $\mu_{2}, \lambda_{2}, \sigma_{2} \mathrm{y}$ $\beta_{12}$. Puesto que $\sigma_{2}=\lambda_{2} / \alpha_{2}$ obtenemos, al mismo tiempo, un cálculo estimado para $\alpha_{2}$, que puede utilizarse para encontrar $a_{2}$. Cuando ya se estableció $a_{2}$, puede obtenerse $a_{1}$ al diseñar en la ecuación definicional $\delta_{12}=a_{1} / a_{2}$ y $\alpha_{1}$ puede encontrarse con la ecuación similar $\beta_{12}=\alpha_{1} / \alpha_{2}$. Se obtiene un valor inicial para c cuando se coloca $\mathrm{c}=\mathrm{a}_{1} / \delta_{1 \mathrm{c}}$, donde $\delta_{1 \mathrm{c}}$ se calculó por la regresión a $\delta_{12}$ y $\mathrm{a}_{1}$ $\mathrm{y}_{2}, \mathrm{y}$ se ha graduado c con el objeto de que arroje una TBM igual a la unidad.

De manera conceptual, este enfoque para construir patrones modelo comienza con el componente de la actividad económica y después se le agrega la proporción de la curva de la edad prelaboral. El valor otorgado para $\delta_{12}$ refleja los pesos relativos de estos dos componentes, con valores bajos que definen una curva dominante de edades de actividad económica y valores elevados que apuntan hacia una familia de curvas dominantes (se ha supuesto que el comportamiento de la curva de edades poslaborales se trata de manera exógena).

Comenzamos los cálculos con $\mu_{2}$ con el objeto de establecer la ubicación de la curva en los ejes de edades, queremos saber si se trata de una curva de máximo, temprano o tardío. Continuamos determinando las dos curvas de parámetros $\lambda_{2}$ y $\alpha_{2}$ por medio de la definición de una curva simétrica de trabajo. Los valores de $\sigma_{2}$ entre 1 y 2 , por lo general caracterizan una curva simétrica de trabajo; los valores más elevados describen un perfil asimétrico por edad. La regresión de $\mathrm{a}_{2}$ 
sobre $\alpha_{2}$ produce el cuarto parámetro necesario para definir el componente de la actividad económica. Con valores para $\mu_{2}, \lambda_{2}$ y $\mathrm{a}_{2}$ el procedimiento de construcción se dirige hacia el cálculo de la curva de edades prelaborales, misma que es definida por los dos parámetros, $\alpha_{1}$ y $a_{1}$. La participación relativa del área total unitaria bajo el patrón modelo de migración queda definida por el valor dado a $\delta_{12} \cdot{ }^{9}$

La recopilación de las ecuaciones de regresión mostrada en el cuadro 4.1 , ejemplifica el sistema de regresión que puede definirse para representar el conjunto de "dependencia infantil", por cuanto la variable independiente central $\delta_{12}$ es el índice de la dependencia infantil. Desde luego, existe también la posibilidad de remplazar esta variable independiente con otras, tales como las de $\sigma_{12}$ o $\beta_{12}$ para crear una "simetría laboral", o un conjunto de "regularidad de parentesco", respectivamente. Los coeficientes de regresión se obtuvieron al utilizar patrones de migración interregional por edades (graduados en unidades de Tвм ) en Suecia, Reino Unido y Japón. De estas tres variantes, el conjunto de dependencia infantil fue el que proporcionó los mejores ajustes en casi la mitad de los patrones femeninos probados, mientras que el conjunto de regularidad de parentesco resultó ser, sorprendentemente, la mejor variante de ajuste para los patrones masculinos (véase Rogers y Castro, 1981).

9 El máximo de retiro y la curva ascendente se introducen de manera exógena colocando los parámetros en igualdad de condiciones con los del patrón modelo de migración "observado".

Cuadro 4.1

CONJUNTO BÁSICO DE ECUACIONES DE REGRESIÓN

\begin{tabular}{|c|c|c|c|c|c|c|}
\hline \multirow{2}{*}{\multicolumn{2}{|c|}{$\begin{array}{l}\text { Variables } \\
\text { dependientes }\end{array}$}} & \multicolumn{5}{|c|}{ Coeficientes de regresión de variables independientes } \\
\hline & & \multirow{2}{*}{$\begin{array}{c}\text { Intersección } \\
-3.26 \\
-7.69\end{array}$} & \multirow{2}{*}{ 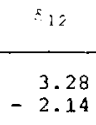 } & \multirow{2}{*}{$\begin{array}{c}\mathrm{x}_{1} \\
-0.67 \\
-0.53\end{array}$} & \multirow{2}{*}{$\begin{array}{l}\mathrm{x}_{\mathrm{h}} \\
1.39 \\
1.63\end{array}$} & \multirow[t]{2}{*}{$a_{2}$} \\
\hline$\mu_{2}$ & $\begin{array}{l}\text { (H) * } \\
(\mathrm{M}) \text { * }\end{array}$ & & & & & \\
\hline$\lambda_{2}$ & $\begin{array}{l}(\mathrm{H}) \\
(\mathrm{M})\end{array}$ & $\begin{array}{l}1.31 \\
1.19\end{array}$ & $\begin{array}{l}0.15 \\
0.13\end{array}$ & $\begin{array}{l}0.08 \\
0.08\end{array}$ & $\begin{array}{l}-0.09 \\
-0.09\end{array}$ & \\
\hline$\sigma_{2}$ & $\begin{array}{l}(\mathrm{H}) \\
(\mathrm{M})\end{array}$ & $\begin{array}{l}16.43 \\
10.97\end{array}$ & $\begin{array}{l}5.59 \\
6.05\end{array}$ & $\begin{array}{l}0.89 \\
0.63\end{array}$ & $\begin{array}{l}-1.17 \\
-0.85\end{array}$ & \\
\hline$\beta_{12}$ & $\begin{array}{l}\text { (H) } \\
\text { (M) }\end{array}$ & $\begin{array}{l}1.90 \\
1.82\end{array}$ & $\begin{array}{l}1.33 \\
1.42\end{array}$ & $\begin{array}{l}-0.03 \\
-0.04\end{array}$ & $\begin{array}{l}-0.04 \\
-0.04\end{array}$ & \\
\hline $\mathbf{a}_{2}$ & $\begin{array}{l}\text { (H) } \\
\text { (M) }\end{array}$ & $\begin{array}{l}0.03 \\
0.04\end{array}$ & & & & $\begin{array}{l}0.30 \\
0.25\end{array}$ \\
\hline$\delta_{1 \mathrm{C}}$ & $\begin{array}{l}(\mathrm{H}) \\
(\mathrm{M})\end{array}$ & $\begin{array}{l}9.41 \\
0.19\end{array}$ & $\begin{array}{l}13.83 \\
26.43\end{array}$ & & & \\
\hline
\end{tabular}

* Hombres

Mujeres 
Si se quieren utilizar las ecuaciones básicas de regresión presentadas en el cuadro 4.1, en primer lugar es necesario obtener estimaciones de $\delta_{12}, \mathrm{x}_{\ell} \mathrm{y} \mathrm{x}_{\mathrm{h}}$. Los valores para estas tres variables pueden seleccionarse para que reflejen supuestos formados, información histórica o regularidades empíricas entre las variables de los patrones modelo y la información observada sobre migración. Por ejemplo, hágase el supuesto de que la encuesta de fecundidad produjo un cálculo bruto del cociente de tasas de migración de niños pequeños a padres, a saber, $M=$ $M(0-4) / M(20-24)$. Una expresión lineal de $\delta_{12}$ de este cociente con la ecuación de regresión forzada al pasar por el origen, arroja

para mujeres, y

$$
\mathrm{F}^{\hat{\delta}_{12}}=0.6 \mathrm{M}
$$

para hombres.

$$
\mathrm{M}^{\hat{\delta}_{12}}=0.7 \mathrm{M}
$$

La gráfica 4.1 ilustra los ejemplos de calidad de ajuste proporcionada por los patrones estimados a la información observada de los modelos de migración. Se muestran dos conjuntos de patrones estimados: los que se obtuvieron con el índice observado de dependencia infantil $\left(\delta_{12}\right)$ y los que se encontraron con el índice estimado $\left(\hat{\delta}_{12}\right)$; ambos cálculos se efectuaron utilizando las regresiones anteriores. En cada caso, $\mathrm{x}_{\ell} \mathrm{y} \mathrm{x}_{\mathrm{h}}$ se presentaron similares a los valores dados por los patrones modelos de migración observados.

\subsection{La perspectiva relacional: el sistema de logito de migración}

El "sistema logito", desarrollado por William Brass hace aproximadamente veinte años, es uno de los métodos más populares para calcular la mortalidad partiendo de información poco efectiva o inadecuada; en la actualidad los demógrafos de todo el mundo han aceptado este sistema. ${ }^{10} \mathrm{El}$ enfoque logito para diseñar patrones se basa en el supuesto de que distintos patrones de mortalidad pueden relacionarse entre sí por medio de una transformación lineal de los logitos de sus respectivas probabilidades de sobrevivencia. Esto es, una serie dada de probabilidades de sobrevivencia observadas $\ell(x)$ para edades $x=1,2, \ldots, w$, puede asociarse con series "estándares" $\ell_{\mathrm{s}}(\mathrm{x})$ por medio de una relación lineal

$$
\operatorname{logit}[1-\ell(x)]=\gamma+\rho \operatorname{logit}[1-\ell s(x)]
$$

donde

$$
\operatorname{logit}[\mathrm{Y}(\mathrm{x})]=\frac{1}{2} \ln \left[\frac{\mathrm{Y}(\mathrm{x})}{1-\mathrm{Y}(\mathrm{x})}\right]=\mathrm{Y}(\mathrm{x}) \text {, siendo, } 0<\mathrm{Y}(\mathrm{x})<1,
$$

$$
\mathrm{Y}(\mathrm{x})=\gamma+\rho \mathrm{Y}_{\mathrm{s}}(\mathrm{x})
$$

10 Brass (1971), Brass y Coale (1968), Corrier y Hobcraft (1971), Hill y Trussell (1977) y Zaba (1979). 
Lo inverso de esta función es

$$
\ell(x)=\frac{1}{1+e^{2} Y(x)}
$$

El resultado más importante de esta transformación matemática de la función $\ell(x)$ no lineal es una función lineal más cercana en $x$, con un rango de menos $y$ más infinito en lugar de entre uno y cero.

Dado un patrón estándar, así como el conjunto de logitos estándar $\mathrm{Y}_{\mathrm{s}}(\mathrm{x})$, propuesto por Brass, puede elaborarse una tabla de vida seleccionando valores apropiados para $\gamma$ y $\rho$. En el sistema de Brass, $\gamma$ refleja el nivel de la mortalidad y $\rho$ define la relación entre mortalidad infantil y la de adultos. Cuanto más cercano esté $\gamma$ a cero y $\rho$ a la unidad, más se asemejará la tabla de mortalidad sintéticamente elaborada a la estándar.

La perspectiva logito puede aplicarse sin dificultad a los patrones de migración. Permítase que $\mathrm{u}(\mathrm{x})$ denote las tasas de migración por edades de un patrón tal que su tasa bruta de migraproducción (TBM) sea la unidad, y permítase que ${ }_{\mathrm{u}} \mathrm{M}_{\mathrm{s}}(\mathrm{x})$ denote el patrón estándar correspondiente. Si se toman logitos de ambos conjuntos de tasas se obtiene el sistema logito de migración

$$
u(x)=\gamma+\rho_{u} Y_{s}(x)
$$

$\mathrm{y}$

$$
{ }_{u} M(x)=\frac{1}{1+e^{-2}\left[\gamma+\rho_{u} Y_{s}(x)\right]}
$$

donde, por ejemplo,

$\operatorname{logit}\left[{ }_{u} M_{s}(x)\right]={ }_{u} Y_{s}(x)=\frac{1}{2} \ln \frac{{ }_{u} M_{s}(x)}{1-{ }_{u} M_{s}(x)}, 0<{ }_{u} M_{s}(x)<1$

La selección de un patrón de migración en particular como si fuera uno estándar, refleja la creencia de que es representativo ampliamente del patrón de migraproducción por edades en el sistema multirregional de población en consideración. ${ }^{11}$ Con el fin de ilustrar los cálculos efectuados en varios conjuntos de información multirregional, adoptaremos el patrón nacional por edades como estándar en cada caso y se intentará elaborar los cálculos de los patrones de emigración regional por edades al relacionarlos con el nacional. De manera específica: dada una tabla de $\mathrm{m} \times \mathrm{m}$ de flujos de migración interregional para cualquier edad $x$, se divide con cada flujo específico origen-destino $O_{i j}(x)$ entre la población en la región de origen $\mathrm{K}_{\mathbf{i}}(\mathrm{x})$ para definir la tasa asociada de migración por edad $\mathrm{M}_{\mathrm{ij}}(\mathrm{x})$. Si se suman todos los orígenes y destinos, se obtiene la tasa nacional correspondiente, M...(x), y graduando todos los patrones a la unidad de la TBM, se obtiene ${ }_{\mathbf{u}} \mathbf{M}_{\mathbf{j}}(\mathrm{x})$ y $\mathrm{M}$...(x), respectivamente.

11 Nuestros patrones estándares siempre contarán con una TBM unitaria, de ahí que el subíndice izquierdo en ${ }_{\mathbf{u}} \mathrm{Y}_{\mathbf{s}}(\mathrm{x})$ descenderá de aquí en adelante. 


\section{Gráfica 4.1.}

AJUSTE DE LOS PATRONES MODELO ESTIMADOS DE MIGRACIÓN CORRELACIONALES A LA INFORMACION DE LA POBLACIÓN FEMENINA DE ESTOCOLMO, LONDRES, TOKIO Y AMSTERDAM

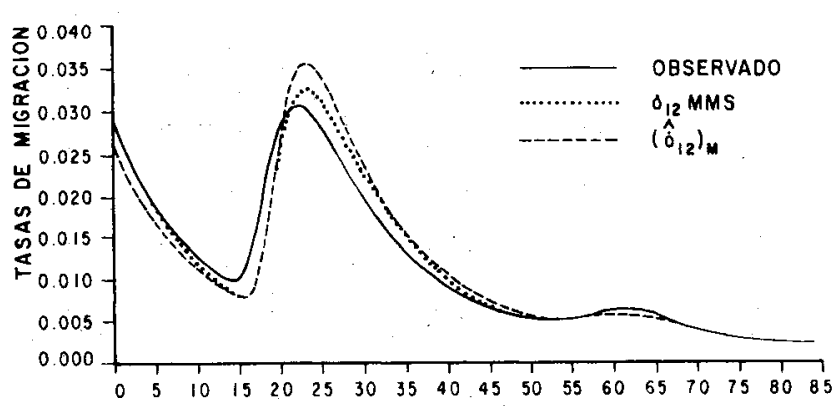

a. Region de Estocolmo

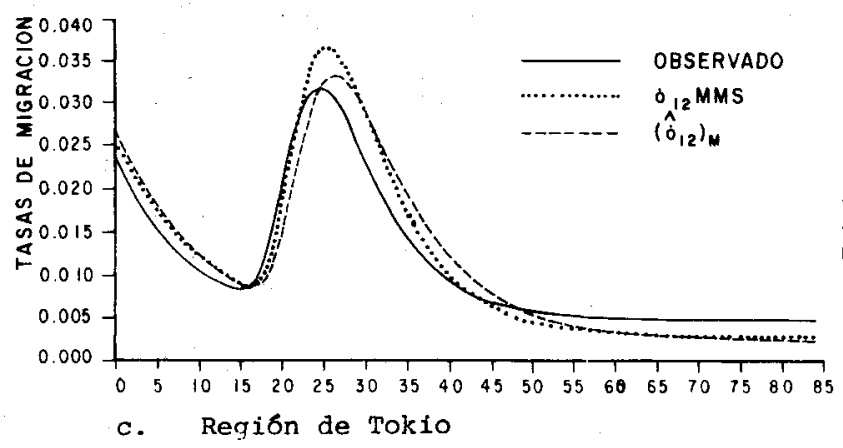

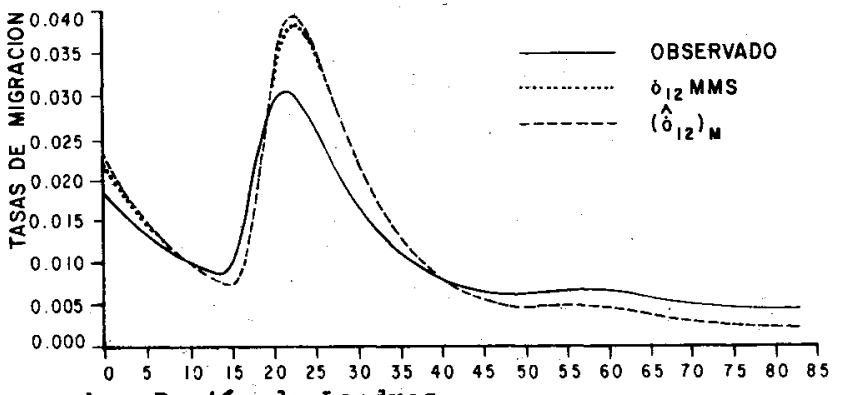

b. Reqión de Londres

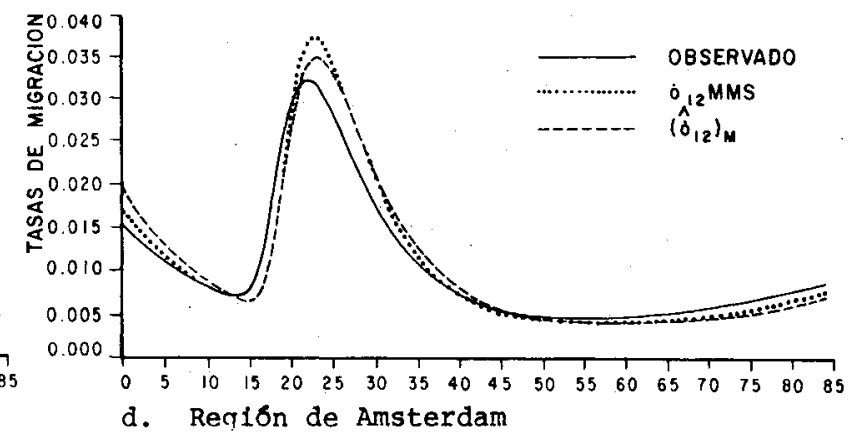

d. Req1ón de Amsterdan 
Gráfica 4.2.

Patrones estándares nacionales Para hombres: Suecia, Reino Unido, Japón, Países Bajos
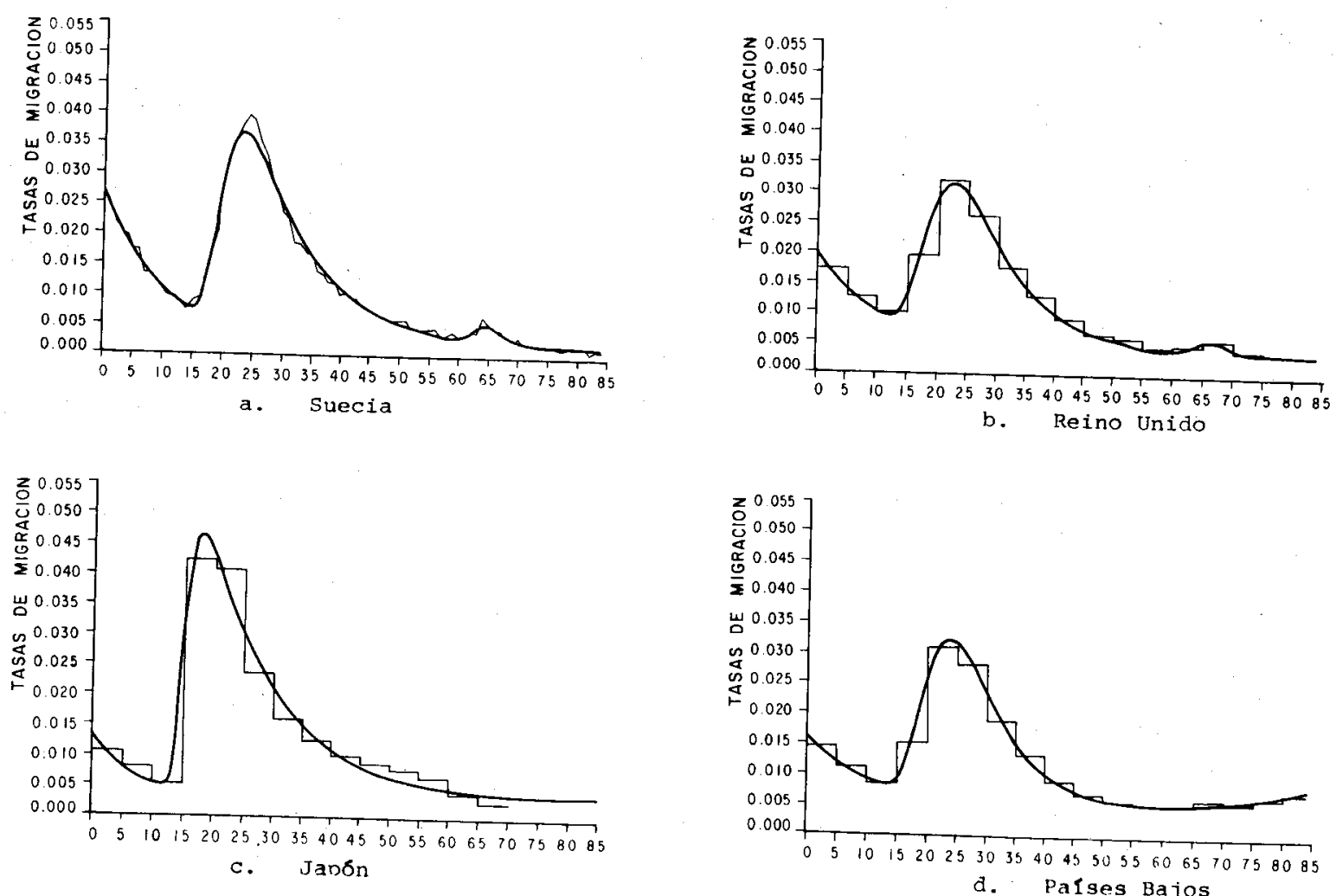
La gráfica 4.2 presenta los estándares nacionales masculinos en Suecia, el Reino Unido, Japón y los Países Bajos. Únicamente se tratará con ajustes graduados puesto que toda la información, con excepción de Suecia, consta de intervalos de cinco años $\mathrm{y}$, por lo tanto, es necesario graduarlos primero, para así proporcionar perfiles por edades individuales a través de la interpolación. Se remarcan las diferencias en los perfiles por edades. Solamente los estándares de Suecià y el Reino Unido muestran un máximo de retiro. El perfil japonés está descrito sin éste, porque la distribución por edades de los migrantes reflejada en los censos finaliza con el intervalo abierto de 65 años y más. La información para los Países Bajos, por el otro lado, muestra una marcada curva ascendente en las edades poslaborales por lo que ésta se ha graduado dentro del patrón modelo de 9 parámetros con curva ascendente.

Si se efectúa la regresión de logitos de las tasas de emigración por edades específicas de cada región sobre la de los estándares nacionales (las TBM de ambos, primero se graduaron en la unidad) arroja valores estimados para $\gamma$ y $\rho$. Si se invierte el procedimiento y se combinan valores seleccionados de $\gamma$ y con el estándar nacional de valores logito, se reconoce una regularidad importante: cuando $\gamma=2(\rho-1)$ entonces la TBM del patrón modelo estimado se aproxima a la unidad (Rogers y Castro, 1981). Regresiones de la forma

$$
\gamma=\delta_{0}+\delta_{1} \rho
$$

que se ajustaron a nuestra información para Suecia, Reino Unido, Japón y Países Bajos, producen, de manera consistente, cálculos estimados para $\delta_{0}$ y $\delta_{1}$ que casi son iguales a 2 en magnitud y que difieren exclusivamente en símbolo, i. e.,

$$
\begin{array}{lll}
\hat{\delta}_{0}=-2 & \mathrm{y} & \hat{\delta}_{1}=+2
\end{array}
$$

Por lo tanto,

$$
\gamma=-2+2 \rho=2(\rho-1)
$$

Las diferencias en los patrones estándares por naciones que se ilustraron en la gráfica 4.2, sugieren que el patrón simple estándar puede ser un supuesto más restrictivo en los análisis de migración que los de estudios sobre mortalidad. Por lo tanto, tal vez resulte necesario seguir la estrategia de Coale-Demeny (1966), en el sentido de desarrollar familias de patrones apropiados.

Los análisis comparativos de los patrones de migración interregionales y nacionales que se llevaron a cabo en la sección 3 , identificaron por lo menos tres familias distintas de perfiles por edades. Primero, estaba el patrón modelo de migración básico de 11 parámetros con un máximo de retiro que describia, de manera adecuada, un número de flujos interregionales - por ejemplo, los perfiles por edades- de los migrantes que abandonan la capital de la región tales como Estocolmo y Londres. La eliminación del máximo de retiro dio un incremento a la forma reducida de 7 parámetros de este patrón básico, forma que se utilizó para describir un gran número de perfiles de dominancia de edades activas y los patrones por edades de los patrones de migración con el mismo intervalo termi- 
nal de edades abierto para la población en edad poslaboral - por ejemplo, los patrones de migración japoneses-. Para terminar, la existencia de una cola monótonamente creciente en los patrones de migración, como los que mostraron la información alemana, condujeron a la definición de un tercer perfil: el patrón modelo de migración con curva ascendente de 9 parámetros.

Dentro de cada familia de patrones, puede exponerse un número de parámetros o variables clave para clasificar con posterioridad las categorías diferentes de los perfiles de migración. Por ejemplo, en la sección 3 identificamos la importancia tan especial de los aspectos siguientes de forma y ubicación junto con el eje de edades:

1. Máximo: máximo temprano contra máximo tardio $\left(\mu_{2}\right)$;

2. dominancia: dominancia infantil contra dominancia de edades activas $\left(\delta_{12}\right)$;

3. simetría: simetría de edades activas contra asimetría de edades activas $\left(\sigma_{2}\right)$;

4 regularidad regularidad de parentesco contra irregularidad de parentesco $\left(\beta_{12}\right)$.

Estas familias fundamentales, además de los 4 parámetros clave, ocasionan el aumento hacia una gran variedad de patrones estándares. Por ejemplo, aun cuando se restringieran los 4 parámetros clave exclusivamente a valores de dicotomia, todavía se necesitan $2^{4}=16$ patrones estándares. Además, si deben diferenciarse los sexos, entonces los 32 patrones estándares son un mínimo. Un gran número de patrones estándares puede originar que el enfoque logito se convierta en una alternativa poco deseable. De ahí que examinaremos la viabilidad de adoptar exclusivamente un estándar simple para ambos sexos y suponer que la forma de las edades poslaborales del patrón puede determinarse de manera exógena. ${ }^{12}$

La similitud de los valores medios de los parámetros para hombres y mujeres presentada en los cuadros 3.9 y 3.10 (Suecia, Reino Unido y Japón, respectivamente), sugiere que puede utilizarse el promedio de los valores para los dos sexos para definir asi el estándar unisexual. Un redondeo aproximado de estos promedios simplificaría las cosas aún más. El cuadro 4.2 presenta los parámetros estándares básicos y simplificados que se obtuvieron por este medio. Los valores de $\mathrm{a}_{1}$ $\mathrm{y}_{2}, \mathrm{y} \mathrm{c}$ exclusivamente son valores iniciales y necesitan graduarse de manera proporcional para asegurar una unidad de TBM. La gráfica 4.3 ilustra el perfil por edades de este patrón estándar de migración básico y simplificado.

Mencionamos con anterioridad que cuando $\gamma=$ o y $\rho=1$, el patrón modelo estimado es idéntico al estándar. Más aún, puesto que la TBM del modelo estándar siempre es unitaria, los valores de $\gamma$ y $\rho$ que satisfacen la igualdad $\gamma=2(\rho-1)$, garantizan una TBM unitaria para los patrones estimados. ¿Cuáles son los efectos de otras combinaciones de valores en estos dos parámetros?

La gráfica 4.4 ilustra la forma en que el patrón estándar básico y simplificado se transforma cuando $\gamma$ y $\rho$ tienen asignados parejas de valores particulares. La gráfica 4.4 muestra que si se fija $\gamma=0$ y se aumenta $\rho$ de 0.75 a 2.5 , desciende el

12 Por lo tanto, en pruebas de nuestro sistema logito de migración el máximo de retiro de las edades poslaborales, o la curva ascendente, siempre está en el mismo nivel de los valores de los patrones modelo observados. 
Gráfica 4.3

PATRón ESTÁNDAR dE MIGRACIÓN BÁSICO Y SIMPLIFICADO

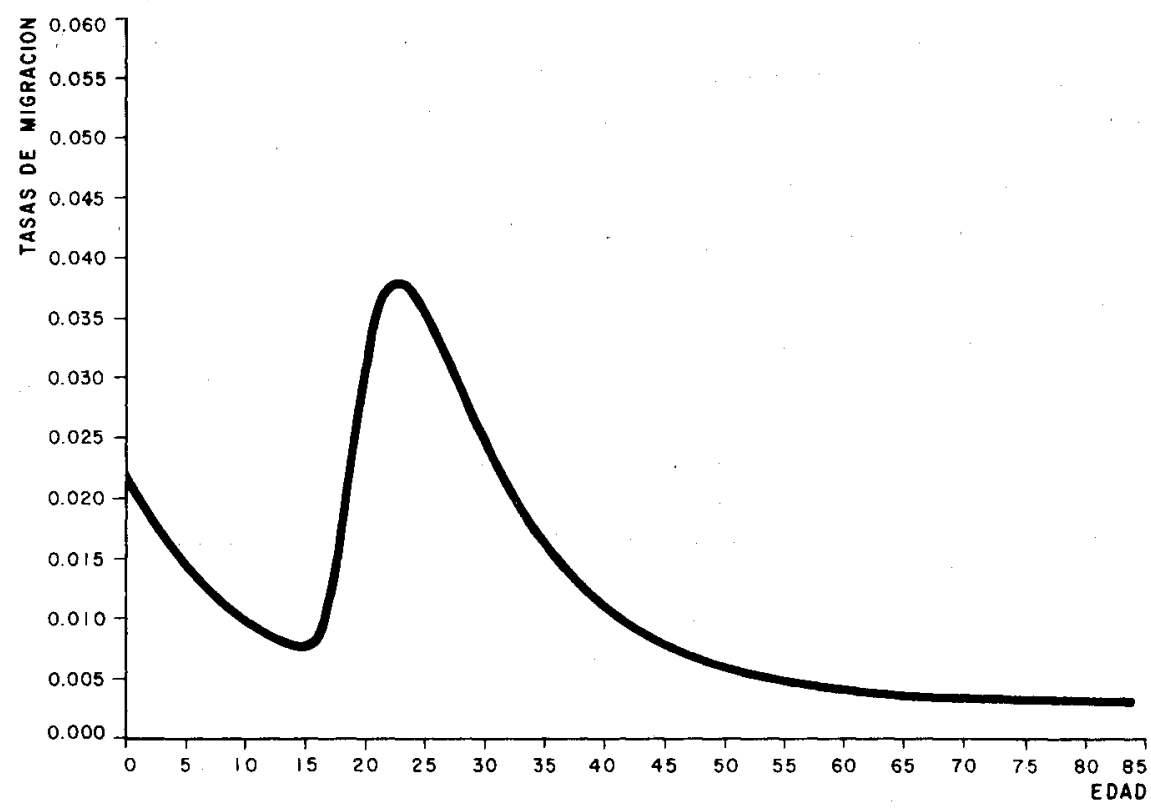

patrón, lo que origina que las tasas de migración sean más pequeñas en valor que las del patrón estándar. Por otro lado, si se fija $\rho=0.75$ y se aumenta $\gamma$ de -1 a 0 , origina el aumento del patrón, tal como se muestra en la gráfica $4.4 \mathrm{~b}$. Para terminar, si se fija la TBM $=1$ al seleccionar valores de $\gamma$ y $\rho$ que satisfagan la igualdad $\gamma=2(\rho-1)$, se muestra que mientras aumentan $\gamma$ y $\rho$, también lo hace el grado de dominancia de edades activas exhibida en el patrón estimado. Por ejemplo, si se va de un patrón estimado con $\gamma=-0.5$ y $\rho=0.75$ a uno con $\gamma=0.5$ y $\rho=1.25$, no se altera el área bajo la curva $(\mathrm{TBM}=1)$ pero sí aumenta su dominancia de edades activas (gráfica 4.4c).

Dado un patrón estándar y algunas tasas observadas, tales como $\mathrm{M}(0-4) \mathrm{y}$ $\mathrm{M}(20-24)$, por ejemplo, nos preguntamos cómo pueden encontrarse las estimaciones para $\gamma$ y $\rho$, y continuar con esas estimaciones para obtener el parrón estimado total.

Primero, si se toman logitos de las dos tasas de migración observadas, se origina $Y(0-4)$ y $Y(2-24)$, y asociando estos dos logitos con la pareja de los logitos correspondientes para el patrón estándar, se origina

$$
\begin{gathered}
\mathrm{Y}(0-4)=\gamma+\rho \mathrm{Y}_{\mathbf{s}}(0-4) \\
\mathrm{Y}(20-24)=\gamma+\rho \mathrm{Y}_{\mathbf{s}}(20-24)
\end{gathered}
$$

Resolviendo estas dos ecuaciones en dos desconocidas, arroja cálculos brutos para $\gamma$ y $\rho$, y aplicándola a los conjuntos completos de logitos de los patrones 


\section{Gráfica 4.4}

SENSITIVIDAD DEL PATRÓN MODELO LOGITO DE MIGRACIÓN A VARIACIONES EN.$\gamma$. Y $\rho .:$ PATRÓN FSTANDAR DE MIGRACION BASICO Y SIMPLIFICADO
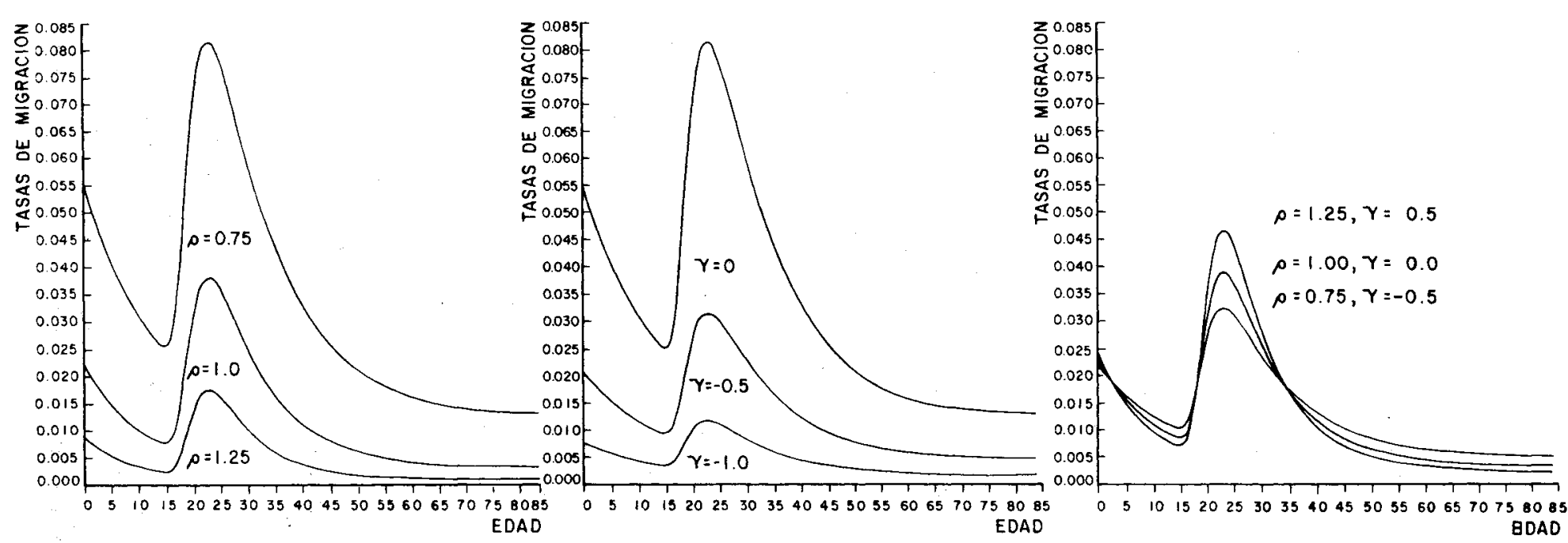
a. . $\gamma$. fijo y . $\rho$. vartante
b..$\rho$. fijo $v \cdot \gamma$. variante
c....$\gamma \quad \gamma \quad$, $\rho$. variante 
Cuadro 4.2

PATRÓN ESTÁNDAR DE MIGRACIÓN BÁSICO Y SIMPLIFICADO

\begin{tabular}{|c|c|c|}
\hline$\hat{c}_{12}=1 / 3$ & & $H_{2}=20$ \\
\hline$\sigma_{2}=4$ & $a_{1}=0.02$ & $a_{2}=0.06$ \\
\hline$B_{12}=1$ & $\alpha_{1}=0.10$ & $\alpha_{2}=0.10$ \\
\hline$\delta_{1 C}=6$ & $c=0.003$ & $\lambda_{2}=0.40$ \\
\hline
\end{tabular}

estándares, resulta un conjunto de logitos para el patrón estimado. De éstos, pueden obtenerse las tasas de migración, como se mostró con anterioridad. Sin embargo, la comprobación de tal procedimiento con la información de migración, sueca, inglesa, japonesa y holandesa, indica que el método es muy errático en la calidad de los ajustes que produce, por lo que se precisan procedimientos más refinados. Tales procedimientos (para el caso de la mortalidad) están descritos en la literatura del sistema logito de Brass (por ejemplo, en Brass, 1975 y Carrier y Goh, 1972).

Se sugiere una primera aproximación (que parece razonable) a un método de estimación mejorado para el caso de migración, por medio del enfoque de regresión que se describió en la subsección 4.2. Imagínese una regresión de $\rho$ en el cociente $\mathrm{M}, \mathrm{M}(0-4) / \mathrm{M}(20-24)$. Si se comienza con el patrón estándar de migración básico y simplificado y se efectúan variantes de $\rho$ dentro de un rango de valores observados, puede obtenerse el conjunto correspondiente de cocientes $M$. Si se asocia $\rho$ con el cociente $M$ de esta forma, puede procederse a utilizar la ecuación relacional para calcular $\gamma$ de $\rho$ :

$$
\hat{\gamma}=\alpha(\hat{\rho}-1)
$$

Puede hacerse una simplificación posterior, forzando la línea de regresión, para pasar a través del origen. Puesto que el coeficiente de regresión resultante tiene signo negativo y la intersección muestra casi el mismo valor absoluto, pero con signo positivo, las ecuaciones de regresión continúan de la forma

$$
\hat{\rho}=2.1(1-M)
$$

Dado un patrón estándar y estimaciones para $\gamma$ y $\rho$, puede procederse a efectuar el cálculo del patrón modelo de migración estimado y asociado. La gráfica 4.5 ilustra ejemplos representativos de la calidad de ajuste que se obtuvo al utilizar este procedimiento. Se ilustran dos patrones estimados con cada uno de los 
Gráfica 4.5.

AJUSTES DE LOS PATRONES MODELO DE MIGRACIÓN CON ESTIMACIONES RELACIONALES, CON LA INFORMACIÓN DE LA POBLACIÓN FEMENINA DE ESTOCOLMO, LONDRES, TOKIO Y AMSTERDAM.

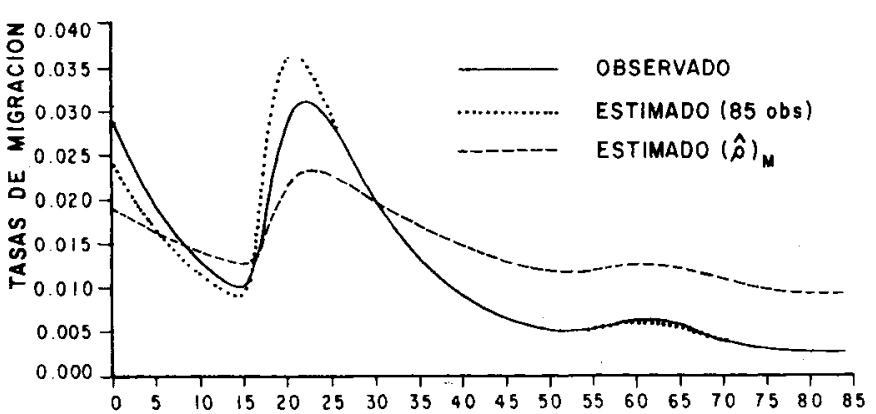

a. Reqión de Estocolmo

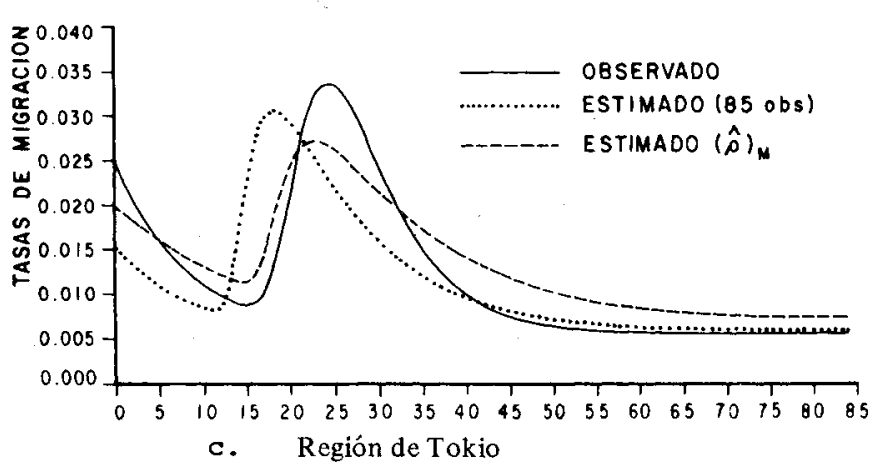

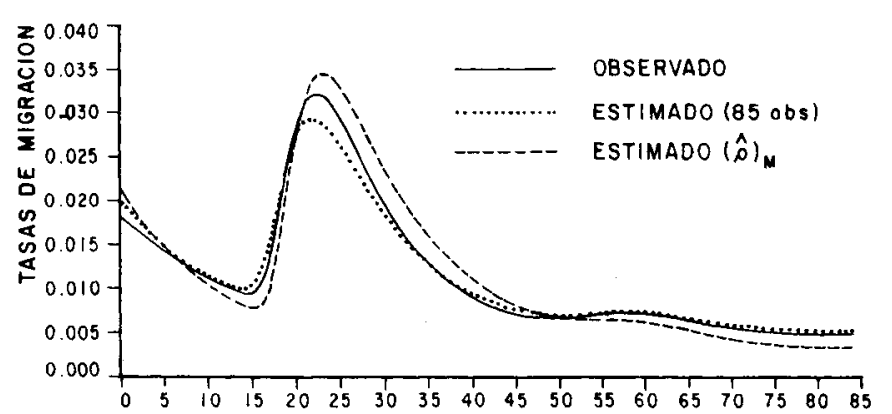

b. Rerión de Londres

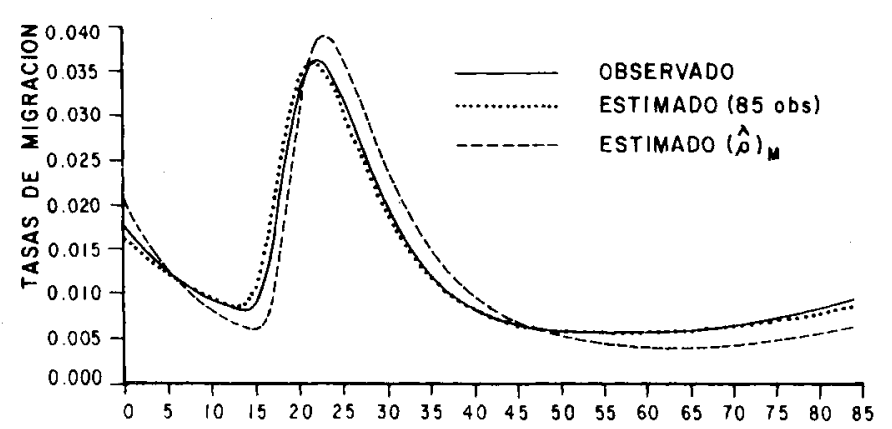

d. Región de Amsterdam 
patrones modelo de migración observados: los que se calcularon con observaciones interpoladas de edades individuales de 85 años, las estimaciones mínimas cuadráticas resultantes $\gamma$ y $\rho$, y las que se calcularon utilizando las ecuaciones de regresión $\rho$ en el cociente $\mathrm{M}$. A pesar de que los ajustes tuvieron un éxito moderado, es evidente que se precisa el estudio posterior de este problema.

\section{Conclusión}

Este trabajo se inició con la observación de que las regularidades empíricas caracterizan los patrones de migración observados a modo de que no sean menos importantes que las regularidades correspondientes - bien establecidas- en los patrones de fecundidad o mortalidad observados. La sección 2 se dedicó a definir de manera matemática tales regularidades en los patrones de migración observados, con el fin de explotar las ventajas notacionales, computacionales y analíticas que proporciona tal formulación. La sección 3 informó sobre los resultados del examen que se efectuó en aproximadamente 500 programas de migración, subrayándose la gran generalidad del patrón modelo de migración y ayudando a identificar un número de familias de tales patrones.

Las regularidades en los perfiles por edades condujo, de manera natural, al desarrollo de patrones modelo de migración hipotéticos que pueden emplearse en estudios sobre población en los que su información es defectuosa o inadecuada. La sección 4, versó sobre las técnicas utilizadas en la literatura correspondiente sobre fecundidad y mortalidad y desarrolló los procedimientos para inferir los patrones de migración en ausencia de información exacta sobre migración.

Entonces, ¿qué utilidad tiene el patrón modelo de migración definido en este trabajo? ¿Cuáles son algunas de sus aplicaciones prácticas?

El patrón modelo de migración puede utilizarse para graduar la información observada para así suavizar estas irregularidades y atribuir a la información medidas someras que puedan utilizarse para estudios comparativos. Se puede aprovechar para interpolarse a edades individuales y a patrones de migración observados que se utilizan para intervalos de edades más amplios. La disponibilidad de los patrones estándares de familias de migración aumenta la valoración de la confiabilidad de la información empírica sobre migración y las indicaciones de estrategias adecuadas para lograr su corrección. Para terminar, tales patrones también pueden aprovecharse para ayudar a resolver los problemas que causa la falta de información.

El análisis de los patrones nacionales de migración por edades que se mencionaron en este estudio, busca demostrar la utilidad de examinar las regularidades de los perfiles por edades mostrados en los patrones empíricos de migración interregional. Sin embargo, se ha logrado un comienzo modesto a pesar de que las limitaciones de la información han restringido algunos de los descubrimientos y éstos queden sólo en conjeturas. Esperamos que los resultados presentados en este trabajo lleven a otros estudiosos a dedicar más atención a este tema. 


\section{APÉNDICE}

\section{CÁlCULO dE PARÁMETROS NO LINEALES CON PATRONES MODELO DE MIGRACIÓN}

Este apéndice intenta ilustrar, brevemente, el procedimiento de la programación matemática utilizada para calcular los parámetros del patrón modelo de migración. El problema sobre la estimación no lineal puede definirse como la búsqueda de los valores de los parámetros "más idóneos" para la función

$$
\begin{aligned}
& M(x)=a_{1} e^{-\alpha_{1} x} \\
& +a_{2} e^{-\alpha_{2}\left(x-\mu_{2}\right)-e^{-\lambda_{2}\left(x-\mu_{2}\right)}} \\
& +a_{3} e^{-\alpha_{3}\left(x-\mu_{3}\right)-e^{-\lambda_{3}\left(x-\mu_{3}\right)}} \\
& +\mathrm{c}
\end{aligned}
$$

en vez del sentido de que la función objetivo predefinida se minimiza cuando los parámetros toman en cuenta estos valores.

Éste es el clásico problema de estimación de parámetros no lineales sin optimización de restricciones. Todos los métodos que están disponibles comienzan con un conjunto de condiciones iniciales dadas, o por supuestos iniciales de los valores de los parámetros, de donde parte la búsqueda para obtener estimaciones más adecuadas siguiendo criterios convergentes específicos. La secuencia iterativa finaliza después de un número finito de iteraciones; la solución se acepta cuando se proporcionan las estimaciones "más idóneas" para los parámetros.

El problema de seleccionar un "buen" método ha sido resumido, con gran utilidad, por Bard (1974, p. 84) en los términos siguientes:

...ningún método simple de los surgidos hasta la fecha ha demostrado ser el más apto para solucionar la programación de todos los problemas no lineales. Ni siquiera puede esperarse que algún dia se encontrará el método "más idóneo", puesto que las variaciones de los problemas son muchas en tamaño y naturaleza. Para lograt la estimación de los problemas relacionados con los parámetros, debemos buscar métodos que sean apropiados para la naturaleza especial de estos problemas, mismos que pueden caracterizarse de la siguiente manera:

1. Un número relativamente pequeño de desconocidos, que en raras ocasiones excedan la docena.

2. Una función objetivo, altamente no lineal (aunque continua y diferenciable), cuyo cálculo con frecuencia lleva mucho tiempo. 
3. Un número relativamente pequeño (en ocasiones cero) de restricciones sin calidad. Éstas por lo general tienen una naturaleza muy simple, i. e., límites más elevados y más bajos.

4. Restricciones sin calidad, con excepción del caso de modelos estructurales exactos (donde, incidentalmente, el número de desconocidos es amplio)...

Para conveniencia de cálculos, hemos escogido el método Marquardt (Levenberg, 1944; Marquardt, 1963). Este método busca un vector de parámetro $\mathrm{P}^{*}$ que minimice la función objetivo siguiente:

$$
\phi(\mathrm{P})=\|f \mathrm{p}\|_{2}^{2}
$$

donde $f$ p es el vector residual y $\|\cdot\|$ representa la conocida norma del vector euclidiano. Para el caso de un patrón modelo con máximo de retiro, el vector $\mathrm{P}$ cuenta con los elementos siguientes:

$$
\mathrm{P}^{\mathrm{T}}=\left[\mathrm{a}_{1}, \alpha_{1}, \mathrm{a}_{2}, \alpha_{2}, \mu_{2}, \lambda_{2}, \mathrm{a}_{3}, \alpha_{3}, \mu_{3}, \lambda_{3}, \mathrm{c}\right] .
$$

Los elementos del vector $f \mathrm{p}$ pueden calcularse con cualquiera de las dos siguientes expresiones:

$$
\begin{gathered}
f \mathrm{p}(\mathrm{x})=[\mathrm{M}(\mathrm{x})-\hat{\mathrm{M}} \mathrm{p}(\mathrm{x})] \\
f \mathrm{p}(\mathrm{x})=[\mathrm{M}(\mathrm{x})-\hat{\mathrm{M}} \mathrm{p}(\mathrm{x})] \quad \hat{\mathrm{M}}_{\mathrm{p}}^{\frac{1}{2}}(\mathrm{x})
\end{gathered}
$$

donde $\mathrm{M}(\mathrm{x})$ es el valor observado en una edad $\mathrm{x}$ y $\hat{\mathrm{M}} \mathrm{p}(\mathrm{x})$ es el valor estimado utilizando la ecuación (A1) y un vector dado $P$ de parámetros estimados.

Si se introduce la ecuación (A4) en la función objetivo mostrada en la ecuación (A2), se minimiza la suma de los cuadrados; si, por el otro lado, se introduce la ecuación (A5), se minimiza la estadística chicuadrada.

En notación matricial, el método Levenberg-Marquardt sigue la secuencia interativa que se muestra a continuación:

$$
P_{q_{+1}}=P_{q}-\left\{{ }^{{ }^{T}} J_{q}+\lambda_{q} D_{q}\right\}^{-1} J_{q}^{T} f p_{q}
$$

donde $\lambda$ es un parámetro no negativo ajustado para asegurar que en cada iteración se reduzca la función (A2), $\mathrm{J}_{\mathbf{q}}$ denota la matriz jacobina de $\phi(\mathrm{P})$ valorada en iteración $q$, y $D$ es una matriz diagonal igual a la diagonal de $J^{T} J$.

La dificultad principal en la estimación de un parámetro no lineal es la de la convergencia, y este método no es la excepción. El algoritmo parte del supuesto de algunos parámetros iniciales; el nuevo vector $P$ se calcula según el valor de $\lambda$, el que, a su vez, también se modifica siguiendo algunos criterios gradiente. En cuando se alcanzan algunos valores tope dados, el vector $\mathrm{P}^{*}$ refleja la mínima local que puede mejorarse con condiciones iniciales más adecuadas y un conjunto diferente de criterios gradiente. 
También se analizó el impacto de los criterios gradiente en el vector $\mathrm{P}^{*}$ óptimo, utilizando los métodos de Newton y de Steepest Descent. Los efectos de estas dos alternativas se reflejaron en los tiempos del cálculo, no así en los valores del vector P*. Sin embargo, Bard (1974) ha sugerido que ambos métodos pueden crear problemas en la estimación y, por tanto, deben utilizarse con precaución para evitar cálculos de parámetros que no sean realistas. Parece que pueden mejorarse los valores iniciales del parámetro por medio de un enfoque interactivo sugerido por Benson (1979). 